\title{
On the heating of the outer radiation belt to produce high fluxes of relativistic electrons: Measured heating rates at geosynchronous orbit for high-speed stream-driven storms
}

\author{
Joseph E. Borovsky ${ }^{1}$ and Michael H. Denton ${ }^{2}$ \\ Received 5 February 2010; revised 2 July 2010; accepted 10 August 2010; published 4 December 2010.
}

[1] The heating rate of the outer electron radiation belt at geosynchronous orbit is determined for the interval from 36 to $72 \mathrm{~h}$ after the onset of high-speed stream-driven storms. Multisatellite measurements of the radiation belt temperature are used for 93 high-speed stream-driven storms. During the storms, the outer electron radiation belt temperature changes from $\sim 120 \mathrm{keV}$ to $\sim 190 \mathrm{keV}$. The average heating rate of $32 \mathrm{keV} \mathrm{d}^{-1}$ is obtained. The heating rate during the storms is found to be positively correlated with the solar wind velocity and with the Kp index of geomagnetic activity and to be negatively correlated with the solar wind number density. When the solar wind velocity is held fixed, the correlation of the heating rate with $\mathrm{Kp}$ vanishes. Expressions for the change in the heating rate as function of the solar wind speed, the solar wind density, and the Kp index are fit to the data. The heating rate is uncorrelated with the amplitude of magnetic field fluctuations in the magnetosphere. Correlations between the heating rate and the level of velocity, density, and magnetic field fluctuations in the magnetosphere and in the solar wind are weaker than the correlations of the heating rate with the solar wind velocity and density. The heating rates correspond to a kinetic energy density change of $3.6 \times 10^{-11} \mathrm{erg} \mathrm{cm}^{-3} \mathrm{~d}^{-1}$ at geosynchronous orbit, to a specific entropy change of $4.1 \times 10^{6} \mathrm{eV} \mathrm{cm}^{2} \mathrm{~d}^{-1}$ at geosynchronous orbit, and to a total heating rate of the geosynchronous orbit region of $5.3 \times 10^{6}$ Watts.

Citation: Borovsky, J. E., and M. H. Denton (2010), On the heating of the outer radiation belt to produce high fluxes of relativistic electrons: Measured heating rates at geosynchronous orbit for high-speed stream-driven storms, J. Geophys. Res., 115, A12206, doi:10.1029/2010JA015342.

\section{Introduction}

[2] During geomagnetic storms the fluxes of relativistic electrons in the middle magnetosphere can reach dangerous levels, bringing on the designation "killer electrons" [Graham, 1994]. Determining the critical conditions and physical mechanisms producing these energetic electrons are among the most important problems being studied in radiation belt physics [Friedel et al., 2002; Hudson et al., 2008]. Geomagnetic storms can be divided into two types [Borovsky and Denton, 2006]: CME-driven (coronal mass ejection driven) storms and CIR-driven (corotating interaction region driven) storms. These two types are also known as cloud-driven storms and high-speed stream-driven storms, respectively. Of the two types, high-speed stream-driven storms are more important for the production of high fluxes of relativistic electrons in the magnetosphere [Paulikas and Blake, 1976; Love et al., 2000; Lam, 2004; Borovsky and Denton, 2006].

\footnotetext{
${ }^{1}$ Space Science and Applications, Los Alamos National Laboratory, Los Alamos, New Mexico, USA.

${ }^{2}$ Physics Department, Lancaster University, Lancaster, UK.

Copyright 2010 by the American Geophysical Union. 0148-0227/10/2010JA015342
}

High-speed stream-driven storms have long durations (several days) and tend to recur with the 27 day rotation period of the Sun.

\subsection{Density-Temperature Description}

[3] The solar wind that drives the high-speed streamdriven storms tends to have a repeatable signature leading to a calm/storm cycle, with a few days long calm before the storm and a storm lasting for several days. During the calm before the storm the relativistic electron flux of the outer electron radiation belt decays slowly. Early in the storm the relativistic electron flux often drops rapidly to a level at or below instrument backgrounds and then partially recovers. During the several days of the storm the relativistic electron flux steadily increases. The electron flux reaches a peak value several days into the storm, with the flux peaking later in time for higher energies [Nagai, 1988; Baker et al., 1990; Borovsky et al., 1998a]. It is possibly the long durations of high-speed stream-driven storms that make them so efficient at producing high fluxes of relativistic electrons.

[4] Discussion of the evolution of the outer electron radiation belt often focuses on the flux of the relativistic electrons. A flux description makes sense, particularly because the particle fluxes relate directly to measures of spacecraft damage 


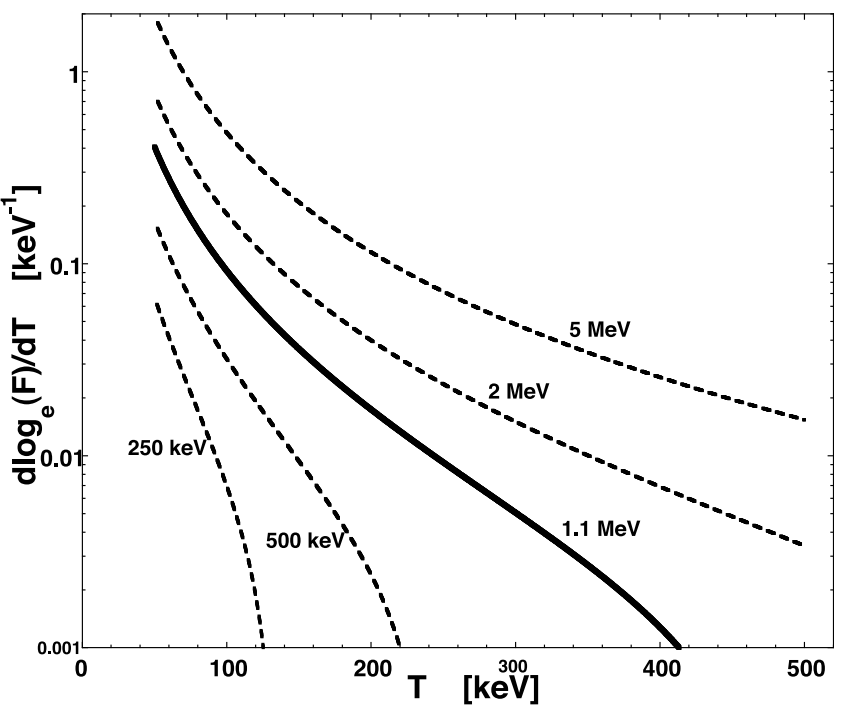

Figure 1. For a relativistic Maxwellian distribution, the logarithmic derivative of the differential flux $F$ with respect to temperature $\mathrm{T}$ is plotted. The solid curve is for the flux at an electron energy of $1.1 \mathrm{MeV}$, and the dashed curves are for the flux at lower and higher energies as indicated.

[Wrenn et al., 2002; Romanova et al., 2005] and penetrating radiation instrument backgrounds [Borovsky et al., 1998a]. During high-speed stream-driven storms the measured fluxes of relativistic electrons can increase by orders of magnitude [Varotsou et al., 2008].

[5] Another useful description of the evolution of the outer electron radiation belt comes from a density-temperature point of view wherein the entire population of radiation belt electrons is considered [Cayton et al., 1989; Borovsky et al., 1998a; Denton et al., 2010]. Measurements of the number density and the temperature of the outer electron radiation belt can be obtained from the same instruments that provide electron flux measurements [Cayton et al., 1989; Pierrard and Lemaire, 1996; Cayton and Belian, 2007]. At geosynchronous orbit $\left(6.6 \mathrm{R}_{\mathrm{E}}\right)$, typical number densities of the outer electron radiation belt are $1 \times 10^{-4}-8 \times 10^{-4} \mathrm{~cm}^{-3}$ and typical temperatures are 100-200 keV [Denton et al., 2010]. The density-temperature description clarifies processes such as heating, particle gain, or particle loss that can be ambiguous when observed only in single-energy flux measurement. During the latter phases of high-speed stream-driven storms the relativistic electron flux increases by orders of magnitude: in the flux description this looks like a need for a powerful acceleration mechanism whereas in the density-temperature description this is viewed as a modest heating of the outer electron radiation belt.

\subsection{Sensitivity of the Flux to Changes in Density and Temperature}

[6] The outer electron radiation belt at geosynchronous orbit is well fit by a relativistic Maxwellian distribution function [Cayton et al., 1989; Pierrard and Lemaire, 1996]. In the present study, relativistic Maxwellian fits to the electron count rates in energetic electron detectors are used to obtain measurements of the density and temperature of the radiation belt electrons, and with the same detectors fits to electron count rates are used to obtain differential electron fluxes at fixed energies. The relativistic Maxwellian distribution function $\mathrm{f}(\mathrm{E})$ used for the fit is of the form [Cayton and Belian, 2007]

$$
\mathrm{f}(\mathrm{E})=\mathrm{n}\left(\mathrm{c} / 4 \pi \mathrm{m}_{\mathrm{e}} \mathrm{T}^{2}\right)\left[\alpha \mathrm{e}^{\alpha} \mathrm{K}_{2}(\alpha)\right]^{-1} \mathrm{e}^{-\mathrm{E} / \mathrm{T}}
$$

where $E$ is the electron kinetic energy, $\mathrm{m}_{\mathrm{e}}$ is the electron rest mass, $\mathrm{c}$ is the velocity of light, $\alpha=\mathrm{m}_{\mathrm{e}} \mathrm{c}^{2} / \mathrm{T}, \mathrm{K}_{2}$ is a modified Bessell function, $\mathrm{n}$ is the number density, and $\mathrm{T}$ is the temperature in energy units (i.e., with Boltzmann's constant absorbed). From the distribution function $\mathrm{f}(\mathrm{E})$, the differential energy flux $F(E)$ at energy $E$ of a relativistic Maxwellian distribution is given by [Cayton and Belian, 2007; T. Cayton, private communication, 2009] $\mathrm{F}(\mathrm{E})=2 \mathrm{~m}_{\mathrm{e}} \mathrm{E}\left(1+\mathrm{E} / 2 \mathrm{~m}_{\mathrm{e}} \mathrm{c}^{2}\right)$ $\mathrm{f}(\mathrm{E})$. Using this and expression (1) the differential flux at energy $E$ is written

$$
\mathrm{F}(\mathrm{E})=\mathrm{n}\left[\mathrm{h}(\mathrm{E}) / \mathrm{T}^{2} \mathrm{~g}(\mathrm{~T})\right] \mathrm{e}^{-\mathrm{E} / \mathrm{T}}
$$

where the functions $\mathrm{h}$ and $\mathrm{g}$ are defined as

$$
\mathrm{h}(\mathrm{E})=(2 \mathrm{cE} / 4 \pi)\left(1+\mathrm{E} / 2 \mathrm{~m}_{\mathrm{e}} \mathrm{c}^{2}\right)
$$

$$
\mathrm{g}(\mathrm{T})=\alpha \mathrm{e}^{\alpha} \mathrm{K}_{2}(\alpha)
$$

with $\alpha=\mathrm{m}_{\mathrm{e}} \mathrm{c}^{2} / \mathrm{T}$. At energies $\mathrm{E}$ that are greater than the temperature $\mathrm{T}$, the differential flux (expression (2)) is a very sensitive function of $\mathrm{T}$; that is, a small change in $\mathrm{T}$ yields a large change in $\mathrm{F}$. An expression of interest is $\partial \mathrm{F} / \partial \mathrm{T}$, which will describe the connection between these changes $\Delta \mathrm{F}$ and $\Delta \mathrm{T}$. In the temperature range of interest $50 \mathrm{keV}<$ $\mathrm{T}<500 \mathrm{keV}$ (which is approximately $1<\alpha<10$ ) the function $\mathrm{g}(\mathrm{T})$ (expression (3b)) can be well approximated by

$$
\mathrm{g}(\mathrm{T}) \approx 3.2 \alpha^{-0.61}+1.15 \alpha^{0.539}
$$

making differentiation of expression (2) possible, yielding

$$
\partial \mathrm{F} / \partial \mathrm{T} \approx \mathrm{n}\left[\mathrm{h}(\mathrm{E}) / \mathrm{T}^{2} \mathrm{~g}(\mathrm{~T})\right] \mathrm{b}_{\mathrm{keV}}(\mathrm{T}, \mathrm{E}) \mathrm{e}^{-\mathrm{E} / \mathrm{T}}=\mathrm{b}_{\mathrm{keV}}(\mathrm{T}, \mathrm{E}) \mathrm{F}
$$

where the function $b_{\mathrm{kev}}(\mathrm{T}, \mathrm{E})$ is defined as

$$
\begin{aligned}
b_{k e v}(T, E)= & {\left[\left(E / T^{2}\right)-\left(\left(0.186 \mathrm{~T}^{1.61}+48.5 \mathrm{~T}^{0.46}\right) /\right.\right.} \\
& \left.\left(0.0713 \mathrm{~T}^{2.61}+33.2 \mathrm{~T}^{1.46}\right)\right]
\end{aligned}
$$

where in expression (6) $\mathrm{E}$ and $\mathrm{T}$ are in units of $\mathrm{keV}$. Using $(1 / \mathrm{F}) \partial \mathrm{F} / \partial \mathrm{T}=\partial \log _{\mathrm{e}}(\mathrm{F}) / \partial \mathrm{T}$, expression (5) simplifies to

$$
\partial \log _{\mathrm{e}}(\mathrm{F}) / \partial \mathrm{T} \approx \mathrm{b}_{\mathrm{kev}}(\mathrm{T}, \mathrm{E}) .
$$

[7] Figure 1 plots $\partial \log _{\mathrm{e}}(\mathrm{F}) / \partial \mathrm{T}$ as a function of $\mathrm{T}$ for $\mathrm{E}=$ 1.1 MeV (solid curve) and for other values of $\mathrm{E}$ (dashed curves) using expression (6). As can be seen by the solid curve, in the vicinity of $\mathrm{T}=150 \mathrm{keV}$ the value of the derivative is $\partial \log _{\mathrm{e}}(\mathrm{F}) / \partial \mathrm{T} \approx 0.036 \mathrm{keV}^{-1}$. Using this value, for a change in temperature $\Delta \mathrm{T}$ of $60 \mathrm{keV}$ going from $\mathrm{T}=$ $120 \mathrm{keV}$ to $\mathrm{T}=180 \mathrm{keV}$ the logarithm of the differential flux $\log _{\mathrm{e}}(\mathrm{F})$ at $\mathrm{E}=1.1 \mathrm{MeV}$ changes by an amount $\Delta \log _{\mathrm{e}}(\mathrm{F})=$ $\left[\partial \log _{e}(\mathrm{~F}) / \partial \mathrm{T}\right] \Delta \mathrm{T}=(0.036)(50)=2.16$. Thus, for a $\sim 40 \%$ increase in the temperature, the logarithm of the relativistic 
Table 1. A Collection of Measurements of the $24 \mathrm{~h}$ Changes in the Temperature of the Outer Electron Radiation Belt at Geosynchonous Orbit 36 h to 72 h After Storm Onset for 93 High-Speed Stream-Driven Storms ${ }^{\text {a }}$

\begin{tabular}{|c|c|c|c|c|}
\hline Quantity & Explanation & All Local Times & Noon Sector & Midnight Sector \\
\hline $\mathrm{dT} / \mathrm{dt}$ & $\begin{array}{l}\text { Daily heating rate (fitting superposed } \\
\left.\text { averages of } \log _{10}(T)\right)\end{array}$ & $24 \mathrm{keV} \mathrm{d}^{-1}$ & $25 \mathrm{keV} \mathrm{d}^{-1}$ & $24 \mathrm{keV} \mathrm{d}^{-1}$ \\
\hline $\mathrm{dT} / \mathrm{dt}$ & $\begin{array}{l}\text { Daily heating rate (fitting superposed } \\
\text { averages of } T \text { ) }\end{array}$ & $24 \mathrm{keV} \mathrm{d}^{-1}$ & $25 \mathrm{keV} \mathrm{d}^{-1}$ & $23 \mathrm{keV} \mathrm{d}^{-1}$ \\
\hline $\mathrm{dT} / \mathrm{dt}$ & $\begin{array}{l}\text { Daily heating rate (averaging individual } \\
\text { measurements of } \Delta T_{24} \text { ) }\end{array}$ & $32 \mathrm{keV} \mathrm{d}^{-1}$ & $35 \mathrm{keV} \mathrm{d}^{-1}$ & $29 \mathrm{keV} \mathrm{d}^{-1}$ \\
\hline$\partial \Delta \mathrm{T}_{24} / \partial \mathrm{Kp}$ & Change in heating rate associated with $\mathrm{Kp}$ & $7.8 \mathrm{keV} \mathrm{d}^{-1} \mathrm{Kp}^{-1}$ & $9.0 \mathrm{keV} \mathrm{d}^{-1} \mathrm{Kp}^{-1}$ & $6.4 \mathrm{keV} \mathrm{d}^{-1} \mathrm{Kp}^{-1}$ \\
\hline$\partial \Delta \mathrm{T}_{24} / \partial \mathrm{v}_{\mathrm{sw}}$ & Change in heating rate associated with $\mathrm{v}_{\mathrm{sw}}$ & $0.11 \mathrm{keV} \mathrm{d}^{-1}\left(\mathrm{~km} \mathrm{~s}^{-1}\right)^{-1}$ & $0.10 \mathrm{keV} \mathrm{d}^{-1}\left(\mathrm{~km} \mathrm{~s}^{-1}\right)^{-}$ & $0.11 \mathrm{keV} \mathrm{d}^{-1}\left(\mathrm{~km} \mathrm{~s}^{-1}\right)^{-1}$ \\
\hline$\partial \Delta \mathrm{T}_{24} / \partial \mathrm{n}_{\mathrm{sw}}$ & Change in heating rate associated with $\mathrm{n}_{\mathrm{sw}}$ & $-4.4 \mathrm{keV} \mathrm{d}^{-1}\left(\mathrm{~cm}^{-3}\right)^{-1}$ & $-4.1 \mathrm{keV} \mathrm{d}^{-1}\left(\mathrm{~cm}^{-3}\right)^{-1}$ & $-4.6 \mathrm{keV} \mathrm{d}^{-1}\left(\mathrm{~cm}^{-3}\right)^{-1}$ \\
\hline $\mathrm{d} \varepsilon / \mathrm{dt}$ & $\begin{array}{l}\text { Rate of change of the radiation belt } \\
\text { energy density }\end{array}$ & $3.6 \times 10^{-11} \mathrm{erg} \mathrm{cm}^{-3} \mathrm{~d}^{-1}$ & $3.9 \times 10^{-11} \mathrm{erg} \mathrm{cm}^{-3} \mathrm{~d}^{-1}$ & $3.3 \times 10^{-11} \mathrm{erg} \mathrm{cm}^{-3} \mathrm{~d}^{-1}$ \\
\hline $\mathrm{dP} / \mathrm{dt}$ & Rate of change of the radiation belt pressure & $3.6 \times 10^{-3} \mathrm{nPa} \mathrm{d}^{-1}$ & $3.9 \times 10^{-3} \mathrm{nPa} \mathrm{d}^{-1}$ & $3.3 \times 10^{-3} \mathrm{nPa} \mathrm{d}^{-1}$ \\
\hline $\mathrm{d} \varepsilon / \mathrm{dt}$ & Total heating rate near geosynchronous orbit & $5.3 \times 10^{6}$ Watt & & \\
\hline $\mathrm{dS} / \mathrm{dt}$ & $\begin{array}{l}\text { Rate of change of the radiation belt } \\
\text { specific entropy }\end{array}$ & $4.1 \times 10^{6} \mathrm{eV} \mathrm{cm}^{2} \mathrm{~d}^{-1}$ & $4.4 \times 10^{6} \mathrm{eV} \mathrm{cm}^{2} \mathrm{~d}^{-1}$ & $4.7 \times 10^{6} \mathrm{eV} \mathrm{cm}^{2} \mathrm{~d}^{-1}$ \\
\hline
\end{tabular}

${ }^{\text {a }}$ The values entered in rows $3-6$ are acknowledged to be lower limits.

electron flux changes by 2.16 and the relativistic electron flux $\mathrm{F}$ changes by a factor of $\mathrm{e}^{2.16}=8.7$, which is $870 \%$. A modest change in the temperature of the outer electron radiation belt leads to a large change in the flux [cf. Borovsky et al., 1998a].

[8] Note from expression (2) that the differential energy flux varies linearly with number density $n$. Hence a doubling of the number density of the outer electron radiation belt would result in a doubling of the flux $\mathrm{F}$ at all energies.

\subsection{This Study}

[9] In this study the heating rates of the outer electron radiation belt during high-speed stream-driven storms will be measured. Multispacecraft measurements of energetic electrons at geosynchronous orbit will be used during 93 high-speed stream-driven storms. Superposed epoch analysis will be used, both superposed averaging and statistical analysis of collections of data from similar epochs. Correlations between measured heating rates and (1) the level of geomagnetic activity, (2) the solar wind velocity, (3) the solar wind number density, (4) the level of geomagnetic fluctuations at geosynchronous orbit, (5) the level of solar wind velocity fluctuations, (6) the level of solar wind density fluctuations, and (7) the level of solar wind magnetic field fluctuations will be examined to determine the effect of these physical quantities on the heating rates. Examination of the correlations will provide indications of parameters linked to heating rates for the outer electron radiation belt, but will not provide definitive information. Owing to multiple interconnected correlations between variables interpretation of individual correlations will be difficult.

[10] This manuscript is organized as follows. In section 2 the methodology of the study is discussed, including event selection and data sets. In section 3 an overview of the 93 high-speed stream-driven storms is presented, including a look at the solar wind that drives the storms, the geomagnetic activity reaction of the magnetosphere, and the evolution of the outer electron radiation belt. In section 4 the heating rates (in units of $\mathrm{keV}$ per day) of the outer electron radiation belt at geosynchronous orbit are measured and the values obtained are collected into Table 1 . In section 5 the correlations between measured heating rates and the $\mathrm{Kp}$ index of geomagnetic activity are explored and in section 6 the correlations between measured heating rates and the solar wind velocity and number density are explored. Section 7 contains an analysis of the four-way correlations between the heating rate, the $\mathrm{Kp}$ index, the solar wind speed, and the solar wind density to determine which correlations are more causal. In section 8 the correlations between the measured heating rates and the levels of magnetic field fluctuations in the magnetosphere are explored. In section 9 the correlations between the measured heating rates and the amplitudes of velocity fluctuations, density fluctuations, and magnetic field fluctuations in the solar wind are explored. Section 10 contains a discussion of the measured heating rates and a discussion of energization mechanisms. The study is summarized in section 11. Estimates of the statistical significance of correlation coefficient are discussed in Appendix A.

\section{Methods}

\subsection{Event Selection}

[11] The 93 high-speed stream-driven storms used in the present study are a subset of the 124 recurring high-speed stream-driven storms utilized in several previous studies [Denton and Borovsky, 2008, 2009; Borovsky and Denton, 2008, 2009a, 2009b; Denton et al., 2010]. Those 124 highspeed stream-driven storms were chosen according to the strength and duration of magnetospheric convection. The 124 storms were found by using the McPherron list of solar wind stream interfaces [McPherron and Weygand, 2006; R. McPherron, private communication, 2007] and then examining temporal plots of the $\mathrm{Kp}$ index to identify storms following the stream interfaces. Only storms that are preceded by and/or followed by another storm 27 days earlier or later were accepted into the collection. From the original 124 storms, 21 were eliminated as being weak or short lived [Borovsky and Denton, 2010a], leaving 93 robust high-speed streamdriven storms. These storms are from the years 1993-2005. A search for more recent storms was made by examining solar wind and geomagnetic data for the years 2006-2008, where 27 day repeating high-speed streams are prevalent. However, the geomagnetic activity driven by those streams in 2006- 
2008 is weak in terms of magnetospheric convection and so no additional storms were selected.

\subsection{Data Sets}

[12] The magnetospheric population of energetic electrons is measured by the Synchronous Orbit Particle Analyzer (SOPA) [Belian et al., 1992; Cayton and Belian, 2007] onboard 7 satellites in geosynchronous orbit $\left(6.6 \mathrm{R}_{\mathrm{E}}\right)$. The SOPA detectors measure count rates of electrons in the energy range $\sim 30 \mathrm{keV}$ to $>2 \mathrm{MeV}$ every $10 \mathrm{~s}$. Spin-averaged count rates are used to produce differential flux measurements [Belian, 1999]. Additionally in the current study, the spin-averaged counting rates for each electron energy channel are modeled as linear combinations of two Maxwellian components plus a nonelectron "background" contribution; minimizing the squared deviations between the observed and model counting rates summed over 10 electron channels yields the best fit two Maxwellian spectra (see Cayton and Belian [2007] for full details). Spin-averaged count rates (obtained by averaging over the spacecraft spin) are fit rather than omnidirectional count rates (obtained by integrating over the pitch angle distribution); analysis has shown that spinaveraged and omnidirectional quantities are almost identical for the energetic electrons measured by SOPA at geosynchronous orbit (R. Friedel, private communication, 2009). Cayton et al. [1989] found that relativistic bi-Maxwellians are excellent fits to the omnidirectional electron fluxes at geosynchronous orbit; Pierrard and Lemaire [1996] drew similar conclusions for the outer electron radiation belt away from geosynchronous orbit. The bi-Maxwellian fitting describes two independent populations of electrons: a "soft" population of electrons with a temperature of $\sim 30 \mathrm{keV}$ and a "hard" population of electrons with a temperature of $\sim 150 \mathrm{keV}$. The "soft" population is the suprathermal tail of the electron plasma sheet whose appearance at geosynchronous orbit is associated with substorm injections [Lezniak et al., 1968; Cayton et al., 1989; Birn et al., 1998]. The "hard" population is the outer electron radiation belt [Cayton et al., 1989; Belian et al., 1996]. The temperature and density are determined every $10 \mathrm{~s}$ by SOPA from each satellite. To reduce the influence of outliers when the measurements are noisy, and to produce a more manageably sized data set, median values of the density and temperature are calculated for every $30 \mathrm{~min}$ of data [cf. Denton et al., 2010].

[13] To measure magnetic field fluctuations in the magnetosphere, vector magnetic field measurements from the GOES spacecraft [Singer et al., 1996] in geosynchronous orbit are used. The GOES spacecraft measures the magnetic field vector using a fluxgate magnetometer [Dunham et al., 1996]. Data from the years 1995-2005 are utilized, involving 5 GOES satellites (GOES-8 - GOES-12). Typically, two GOES spacecraft are in operation at any one time. For the spacecraft GOES-8 only, the magnetic field measurements are corrected by subtracting $7.22 \mathrm{nT}$ from the $\mathrm{z}$ component magnetic field following the recommendations of Tsyganenko et al. [2003]. Before use, all of the GOES magnetic field data is cleaned to eliminate magnetosheath intervals using the methodology of Borovsky and Denton [2010a]. The magnetic field measured by the GOES satellites was not as reliable prior to 1995 as it is after 1995: using magnetic field measurements only from 1995 onward provides measurements for 63 of the 93 high- speed stream-driven storms [see also Borovsky and Denton, 2010a].

[14] The $1 \mathrm{~h}$ resolution values of the solar wind velocity and the level of fluctuations in the direction and speed of the solar wind and of the vector magnetic field of the solar wind are obtained from the OMNI2 solar wind data set [King and Papitashvili, 2005]. Values of the Kp index of geomagnetic activity are also obtained from the OMNI2 data set.

\subsection{Specific Entropy}

[15] This report will introduce the use of measurements of the specific entropy (entropy density) of the outer electron radiation belt. The specific entropy $\mathrm{S}=\mathrm{T} / \mathrm{n}^{2 / 3}$ of the outer electron radiation belt at geosynchronous orbit will be calculated from the half hour median temperature $\mathrm{T}$ and density $n$ measurements. Examination of the measured specific entropy is useful (1) for monitoring nonadiabatic processes such as heating acting on a population of particles and (2) for discerning whether two populations of particles can have the same origin. Examining the value of the specific entropy $\mathrm{S}=\mathrm{T} / \mathrm{n}^{2 / 3}$ in time series data is a powerful method of discerning different plasmas [e.g., Burlaga et al., 1990; Crooker et al., 1996; Borovsky et al., 1998c; Burton et al., 1999; Osherovich et al., 1999; Lazarus et al., 2003; Neugebauer et al., 2004; Pagel et al., 2004; Borovsky, 2008].

[16] The outer radiation belt electrons are usually considered to be a nonfluid population of electrons governed by single-particle motion [Roederer, 1970] whereas the specific entropy as a conserved quantity is a fluid/thermodynamic concept. The specific entropy $\mathrm{S}=\mathrm{T} / \mathrm{n}^{2 / 3}$ as a conserved quantity holds for an adiabatic gas which collisionally remains isotropic [cf. Jeans, 1954] or for an adiabatic magnetized plasma that remains isotropic [cf. Birn et al., 2009]. The isotropy assumption is built into the selection of the adiabatic index $\Gamma$ being $\Gamma=5 / 3$ for the expression $S=P / n^{\Gamma}=T / n^{2 / 3}$. When a population of energetic particles trapped in a dipole magnetic field is constantly isotropized (by pitch angle scattering), the behavior of the population is adiabatic (as shown in Appendix 2 of Borovsky et al. [1981]); if the isotropization is not constantly enforced, the population can undergo nonadiabatic evolution [cf. Goertz, 1978]. For the outer electron radiation belt isotropy may or may not be a good assumption: surveys of the pitch angle isotropy of the outer electron radiation belt are rare [cf. West et al., 1973; Kaye et al., 1978; Selesnick and Blake, 2002]. The assumption of isotropy will be implicit in the present data analysis and the specific entropy expression $\mathrm{S}=\mathrm{T} / \mathrm{n}^{2 / 3}$ will be used; future analysis by the authors will produce densities and temperatures of the electron Maxwellians as functions of pitch angle and will utilize a "double adiabatic" expression for the specific entropy [cf. Birn et al., 1995].

\subsection{Superposed Epoch Analysis}

[17] Because of the repeating nature of high-speed streamdriven storms and their solar wind drivers, high-speed streamdriven storms are particularly amenable to superposed epoch analysis. For the superposed epoch analysis, the choice of a trigger to set the zero epoch is crucial [cf. Ilie et al., 2008; Denton et al., 2010]. For the present study the zero epoch is chosen to be the onset of storm levels of magnetospheric convection. For each storm, the onset time of convection (storm onset) is determined from a temporal drop in the MBI 
(midnight boundary index) index. MBI is an index created from measurements of the location of the low-latitude edge of the diffuse auroral precipitation as determined by DMSP satellite overflights, mathematically shifted to local midnight [Gussenhoven et al., 1983]. MBI is a proxy for the position of the inner edge of the electron plasma sheet [Elphic et al., 1999], which makes it an excellent indicator of magnetospheric convection, as is Kp [Thomsen, 2004], but with MBI having higher time resolution than the $3 \mathrm{~h} \mathrm{Kp}$ index. For each of the 93 storms, storm onset is taken to be the time at which MBI crosses the value $60.7^{\circ}$, which is approximately equivalent to the Kp index reaching 4.3. The storm onset times were determined to about $30 \mathrm{~min}$ accuracy. Note that this convection onset trigger differs from the minimum Dst triggers used in older superposed epoch investigations of high-speed stream-driven storms [Miyoshi and Kataoka, 2005; Denton et al., 2006; Zhang et al., 2006; Yermolaev et al., 2007; Longden et al., 2008].

\subsection{Data Fitting}

[18] Thoughout the analysis, linear regression fits to the data (least squares linear fits) are used, with the value of Pearson's linear correlation coefficient R quoted [Bevington and Robinson, 1992, equation (11.17)]. Statistical uncertainties in the values of the linear regression slopes are calculated from Bevington and Robinson [1992, equation (6.23)]; these uncertainties depend on (1) the variance of the independent variable, (2) the variance of the dependent variable about the fit, and (3) the number of data points.

[19] Linear regression fits to $(x, y)$ data points yield different formulae for fits of $y$ as a function of $x$ than they do for fits of $\mathrm{x}$ as a function of $\mathrm{y}$, yielding lines with slopes that are "too shallow." This is particularly problematic when the linear correlation coefficient between $\mathrm{x}$ and $\mathrm{y}$ is weak [cf. Borovsky et al., 1998b]. To produce symmetric fits with the same formulas for $\mathrm{x}$ versus $\mathrm{y}$ fits as for $\mathrm{y}$ versus $\mathrm{x}$ fits, Gaussian linear fits are used. In performing Gaussian fits, the two variables are normalized so that they have the same standard deviations during the fitting.

\section{Event Overview}

[20] In Figure 2 an overview of the solar wind and geomagnetic activity is presented for the 93 high-speed streamdriven storms. In Figure 2 superposed averages of several quantities are plotted. The plots extend from 3 days prior to storm onset to 4 days after onset. A vertical dashed line denotes the time of storm onset. In Figure $2 \mathrm{a}$ the superposed average of the solar wind velocity at Earth is plotted. Prior to storm onset slow solar wind passes over the Earth. The solar wind makes a transition from slow wind to fast wind across a corotating interaction region (CIR) [Belcher and Davis, 1971; Gosling and Pizzo, 1999; Richardson, 2006] where slow and fast solar wind compress against each other. The onset of storm levels of magnetospheric convection (dashed vertical line) occurs within the CIR. The transition in solar wind velocity is followed by an extended interval during which the magnetosphere is bathed in fast solar wind. In Figure $2 b$ the superposed average of $B_{z}(G S M)$ of the solar wind is plotted. Before storm onset $B_{z}$ tends to be northward (positive) and after storm onset $B_{z}$ tends to be southward (negative). This $\mathrm{B}_{\mathrm{z}}$ reversal is owed to a toward-away magnetic field sector reversal within the CIR and to the RussellMcPherron effect [Russell and McPherron, 1973], leading to a calm before the storm and a subsequent storm [Borovsky and Steinberg, 2006]. Owing to plasma compression in the CIR, B is stronger within the CIR and so the magnitude of $\mathrm{B}_{\mathrm{z}}$ tends to be greater within the CIR [Borovsky, 2010]. In Figure $2 \mathrm{c}$ the superposed average of the Kp index is plotted. $\mathrm{Kp}$ is an indicator of the strength of magnetospheric convection. A dashed horizontal line at $\mathrm{Kp}=2.3$ demarks the average value of $\mathrm{Kp}$. As can be seen, before storm onset the superposed average of $\mathrm{Kp}$ decreases below the average $\mathrm{Kp}$ value: this is owed to the occurrence of "calms before the storms"; about $66 \%$ of high-speed stream-driven storms are preceded by calms [Borovsky and Steinberg, 2006]. As can be seen in the plot, the Kp index rises quickly at storm onset and remains elevated above average for several days. The extended period of elevated magnetospheric convection demarks the high-speed stream-driven storm. In Figure $2 \mathrm{~d}$ the superposed average of the Dst index and the pressurecorrected Dst* index are plotted. The correction for Dst* taken is Dst* $=\mathrm{Dst}-20.7 \mathrm{P}_{\mathrm{ram}}^{1 / 2}+27.7$ [Borovsky and Denton, 2010a], where Dst and Dst* are in units of nT and the ram pressure of the solar wind $\mathrm{P}_{\text {ram }}$ is in units of $\mathrm{nPa}$. The Dst indices are indicators of current systems that distort the magnetic field of the inner magnetosphere. As can be seen in Figure 2d, Dst* shows two phases: a strong negative perturbation lasting about 1 day and a weaker perturbation decaying slowly over several days. The strong negative perturbation of Dst* coincides in time with a strong stretching phase of the nightside geomagnetic field [Borovsky and Denton, 2010a], indicating that this strong negative perturbation phase is owed to cross-tail current.

[21] In Figure 3 the superposed averages of several outer electron radiation belt quantities are plotted for the 93 highspeed stream-driven storms as functions of the time from storm onset. In Figure $3 \mathrm{a}$ the $\mathrm{Kp}$ index is plotted to show the storm activity. In Figure $3 b$ the superposed average of the 1.1-1.5 MeV electron omnidirectional flux at geosynchronous orbit is plotted, averaged over all local time. As can be seen, before the storm the flux decays steadily with time and then near the time of storm onset the flux drops out. This is the "relativistic electron dropout" seen at the onset of highspeed stream-driven storms [cf. Freeman, 1964; Nagai, 1988; Blake et al., 2001; Onsager et al., 2002, 2007; Green et al., 2004; Borovsky and Denton, 2009b]. About 1 day after dropout the flux partially recovers, and then the flux increases steadily in the several days of the high-speed stream-driven storm. This several day long increase in the relativistic electron flux is the interval that will be of interest for the present study.

[22] In Figure 3c the superposed average of the number density $\mathrm{n}$ of the outer electron radiation belt at geosynchronous orbit is plotted. The density plotted is an average of $n$ over all local times. Prior to the onset of the storm, the number density of the outer electron radiation belt decays steadily with time: this decay is owed to the build up of plasmaspheric plasma in the magnetosphere during calms before the storms [Borovsky and Denton, 2009a], which is thought to lead to the scattering of outer electron radiation belt electrons into the atmospheric loss cone by plasma waves in the dense plas- 


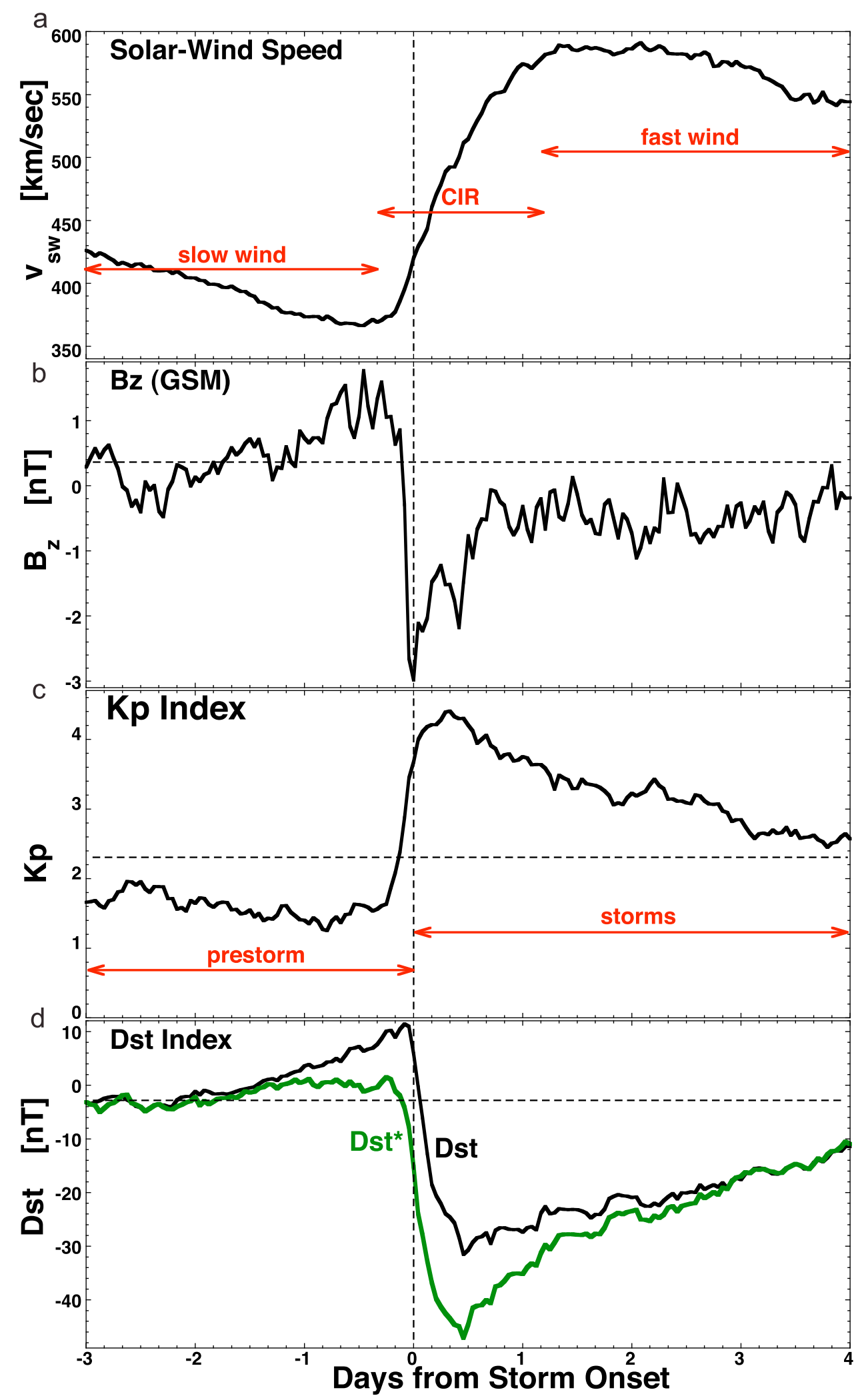

Figure 2. The morphology of the 93 high-speed stream-driven storms is explored. The zero epoch (vertical dashed line) is the onset of storm levels of magnetospheric convection. Each curve is a superposed average of the 93 events. (a) The solar wind speed from OMMI2 is plotted. (b) The GSM-z component of the solar wind magnetic field from OMNI2 is plotted. (c) The Kp index of geomagnetic activity is plotted. (d) The Dst index (black) and pressure-corrected Dst* index (green) are plotted. 


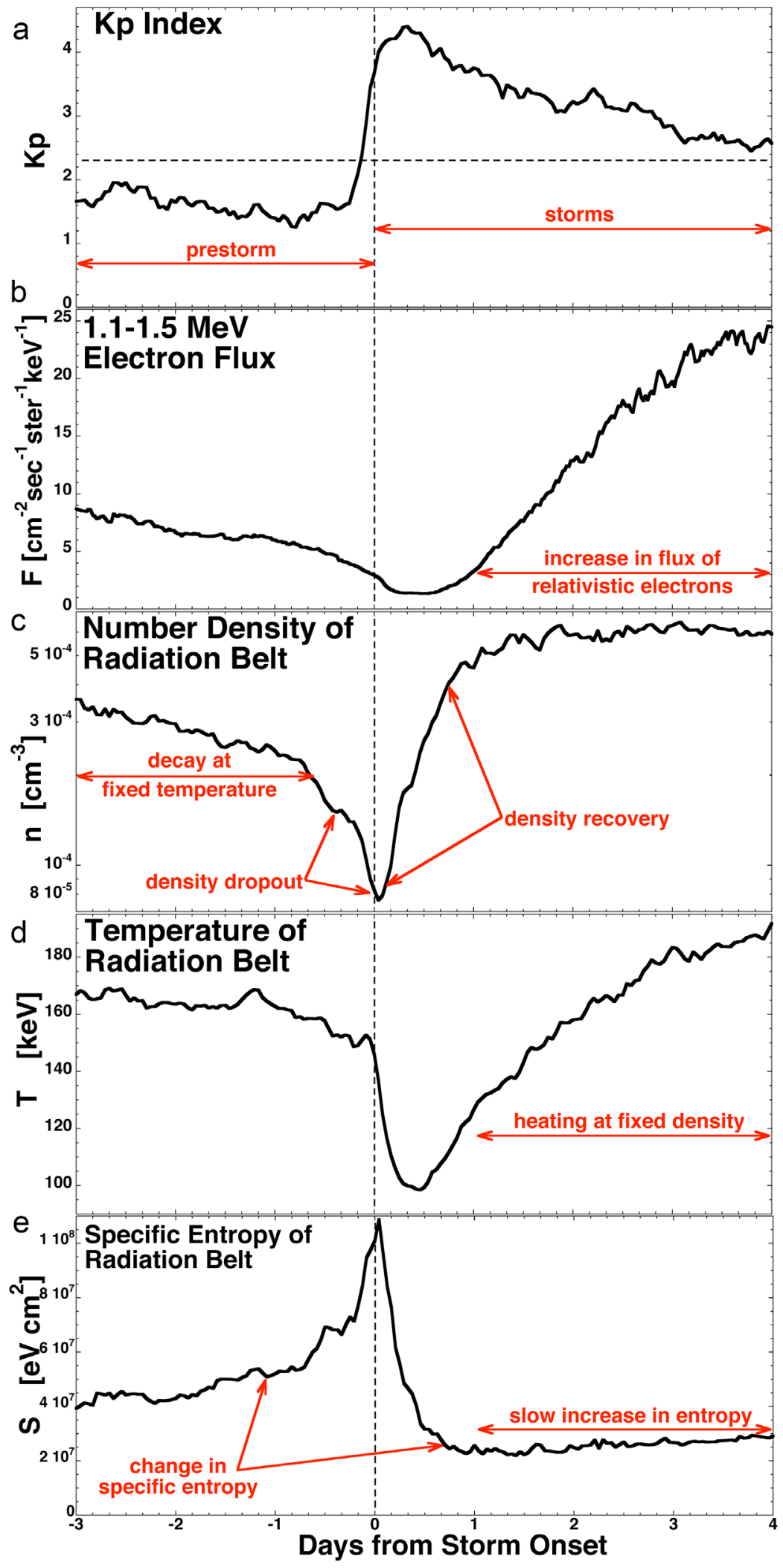

Figure 3. For the 93 high-speed stream-driven storms, superposed averages of several properties of the outer electron radiation belt at geosynchronous orbit are plotted. (a) The Kp index is plotted, (b) the flux of 1.1-1.5 MeV electrons, (c) the number density, (d) the temperature, and (e) the specific entropy. The vertical dashed line indicates the time of storm onset. The curves in the Figures $3 \mathrm{~b}-3 \mathrm{e}$ are local time averages around geosynchronous orbit. 


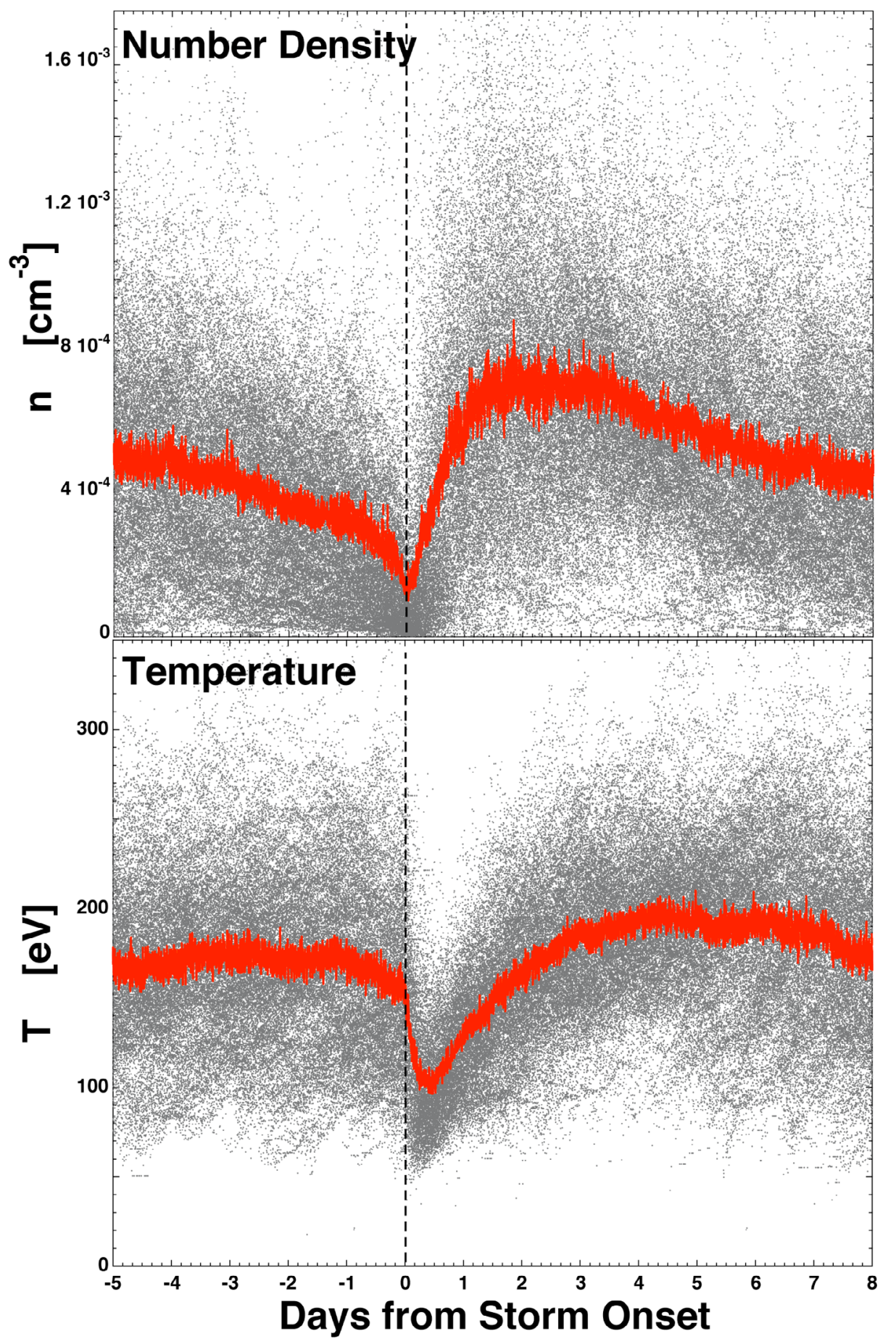

Figure 4. For the 93 high-speed stream-driven storms, the individual $1 \mathrm{~h}$ resolution measurements of the (top) number density and (bottom) temperature of the outer electron radiation belt are plotted in gray. The 100-point running averages are plotted in red. Storm onset is indicated by the vertical dashed line.

masphere [Smith et al., 1974; Kelley et al., 1975; Albert, 2004; Summers et al., 2004; Shprits and Thorne, 2004]. Near the time of storm onset the number density of the outer electron radiation belt rapidly decreases: this is the dropout of the outer electron radiation belt. A fraction of a day after the dropout, the number density rapidly increases: this is the recovery from dropout. Note that after recovery, the number density of the outer electron radiation belt at geosynchronous orbit is approximately constant for the several day duration of the storm. This temporal constancy of the number density during high-speed stream-driven storms has been noted before [Borovsky et al., 1998a; Borovsky and Steinberg, 2006].

[23] In Figure $3 d$ the superposed average of the temperature $\mathrm{T}$ of the outer electron radiation belt at geosynchro- 


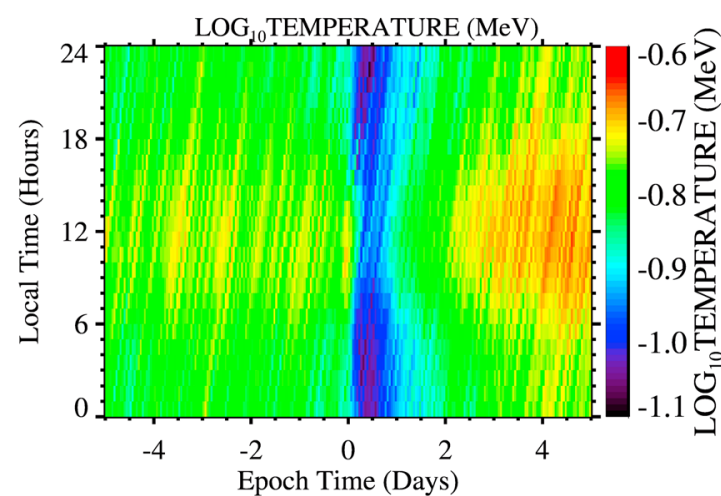

Figure 5. For 93 high-speed stream-driven storms, the superposed average of the logarithm of the temperature of the outer electron radiation belt at geosynchronous orbit is plotted as a function of time from storm onset (horizontal axis) and local time around geosynchronous orbit (vertical axis).

nous orbit is plotted, averaged over all local times. In the days prior to the storm onset, the temperature of the outer electron radiation belt is approximately constant. This is the density decay at fixed temperature during the calms before the storms [Borovsky and Denton, 2009a]. During the density dropout near storm onset the temperature decreases to below $100 \mathrm{keV}$. This value may be erroneous, the temperature being difficult to discern when the number density is low. As the number density recovers (Figure $3 \mathrm{c}$ ) the temperature is at first low $(\sim 100 \mathrm{keV})$ and soon higher $(120 \mathrm{keV})$ This indicates that as the electrons recover the first electrons that arrive at geosynchronous orbit have a temperature of $\sim 100 \mathrm{keV}$ and the subsequent electrons that arrive are warmer. After density recovery the temperature of the outer electron radiation belt steadily increases (at constant number density) for the several days of the storm. This increase in the temperature of the outer electron radiation belt during the days of the storms will be the subject of this study.

[24] In Figure 3e the superposed average of the specific entropy $\mathrm{S}=\mathrm{T} / \mathrm{n}^{2 / 3}$ of the outer electron radiation belt at geosynchronous orbit is plotted, averaged over local time. As can be seen, as the number density of the outer electron radiation belt decays during the calms before the storms, the specific entropy $S$ of the outer electron radiation belt slowly increases. At the time of density dropout $\mathrm{S}$ rapidly increases. At the time of recovery from dropout the specific entropy $S$ decreases strongly as the number density strongly increases. It is important to note that the specific entropy $\mathrm{S}$ of the outer electron radiation belt is different after recovery from dropout than it was before dropout: this indicates that the electron population after recovery is not the same electron population as before dropout. Finally, during the heating of the outer electron radiation belt at fixed density in the several days of the storm, the specific entropy of the outer electron radiation belt steadily increases. This increase is an indication of nonadiabatic processes ongoing, i.e., heating that is not due to adiabatic compression.

[25] To be able to gauge the spread in the measurements of the number density and the temperature, in Figure 4 the individual $1 \mathrm{~h}$ resolution measurements of the density and temperature for the 93 storms are plotted in gray, with a 100-point running averages plotted in red. As can be seen, there is considerable spread to the data, but the trend highlighted by the average is robust.

\section{Measured Heating Rates}

[26] In Figure 5 the superposed average of the logarithm of the temperature $\mathrm{T}$ of the outer electron radiation belt at geosynchronous orbit is plotted in color as functions of the time from storm onset (horizontal axis) and the local time at geosynchronous orbit (vertical axis). (The temperature curve Figure $3 \mathrm{~d}$ was a local time average of this data.) Note in Figure 5 that the temperature of the outer electron radiation belt tends to be higher at local noon than it is at local midnight. This is because equatorially mirroring energetic particles in the magnetosphere drift on orbits with constant magnetic field strength [Hones, 1963] and the magnetic field strength at geosynchronous orbit is on average higher at noon than it is at midnight [Tsyganenko, 1989; Borovsky and Denton, 2010a]; this means that the radiation belt sampled at noon geosynchronous orbit is from a population closer to the Earth than the radiation belt sampled at midnight, resulting in hotter (and denser) values at noon than at midnight. The reader will be cautioned of this noon-midnight population difference throughout this report.

[27] Note in Figure 5 that the temperature of the outer electron radiation belt is constant in the days prior to storm onset, the temperature drops near storm onset and then increases slowly in the days following storm onset. This mild and slow increase in the electron radiation belt temperature at fixed number density produces the steady strong increase in the relativistic electron flux during the several day long high-speed stream-driven storms [cf. Borovsky et al., 1998a].

[28] In Figure 6 (top) the superposed average of the logarithm of the temperature $T$ of the outer electron radiation belt at geosynchronous orbit is plotted. The black curve is the local time average of the superposed average of $\log _{10}(\mathrm{~T})$, the upper curve (red) is the superposed average of $\log _{10}(\mathrm{~T})$ in the noon sector (10-14 LT) and the bottom curve (blue) is the superposed average of $\log _{10}(\mathrm{~T})$ in the midnight sector (22-2 LT). In Figure 6 (bottom) the temperature is similarly plotted, where the temperature is the exponential of the superposed average of the logarithm of the temperature. Hence, Figure 6 (bottom) plots the superposed logarithmic average of the temperature. Again, the black curve is the local time average of the temperature, the upper curve (red) is the temperature in the noon sector (10-14 LT) and the bottom curve (blue) is the temperature in the midnight sector (22-2 LT).

[29] In the $36 \mathrm{~h}$ to $72 \mathrm{~h}$ range of times after storm onset, the superposed averages of $\log _{10}(\mathrm{~T})$ in Figure 6 (top) are well fit (thee green curves) by the formulas

$$
\begin{gathered}
\log _{10}\left(\mathrm{~T}_{\text {allLT }}\right)=2.10+0.33 \log _{10}(\mathrm{t}) \\
\log _{10}\left(\mathrm{~T}_{\text {noon }}\right)=2.15+0.30 \log _{10}(\mathrm{t}) \\
\log _{10}\left(\mathrm{~T}_{\text {midnight }}\right)=2.06+0.35 \log _{10}(\mathrm{t})
\end{gathered}
$$




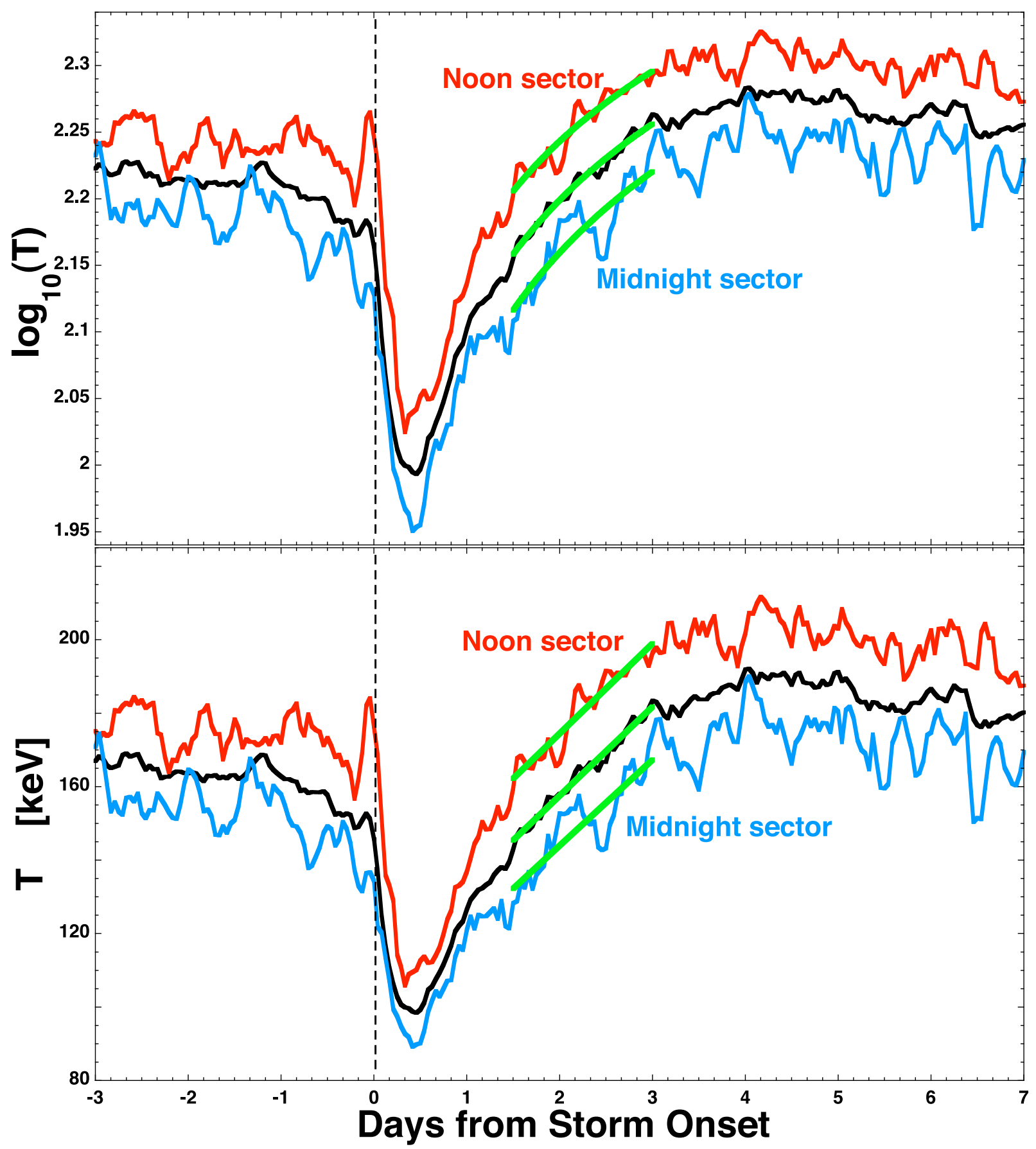

Figure 6. For the 93 high-speed stream-driven storms, superposed averages of the (top) logarithm of the temperature of the outer electron radiation belt and (bottom) temperature are plotted. The black curves are averages over all local times, the red curves pertain to the noon sector of local time, and the blue curves pertain to the midnight sectors. Storm onset is indicated by the vertical dashed line.

where $\mathrm{T}$ is in $\mathrm{keV}$ and $\mathrm{t}$ is the time after storm onset in days. Algebraically, expressions (8) yield time derivatives of the temperature of

$$
\begin{gathered}
\mathrm{dT} / \mathrm{dt}=41 \mathrm{keV} \mathrm{d}^{-1} \mathrm{t}^{-0.67} \text { (all local times) } \\
\mathrm{dT} / \mathrm{dt}=42 \mathrm{keV} \mathrm{d}^{-1} \mathrm{t}^{-0.70} \text { (noon) } \\
\mathrm{dT} / \mathrm{dt}=39 \mathrm{keV} \mathrm{d}^{-1} \mathrm{t}^{-0.65} \text { (midnight) }
\end{gathered}
$$

where $t$ is in units of days. Averaging expressions (9) over the time range from $36 \mathrm{~h}$ to $72 \mathrm{~h}$ after storm onset, the thee expressions yield mean values of the $24 \mathrm{~h}$ change in the temperature $\mathrm{T}$ of the outer electron radiation belt at geosynchronous in the time range 36-72 $\mathrm{h}$ after storm onset of $\Delta \mathrm{T}_{24}=24 \mathrm{keV}$ for all local times, $\Delta \mathrm{T}_{24}=25 \mathrm{keV}$ for the noon sector, and $\Delta \mathrm{T}_{24}=24 \mathrm{keV}$ for the midnight sector. 


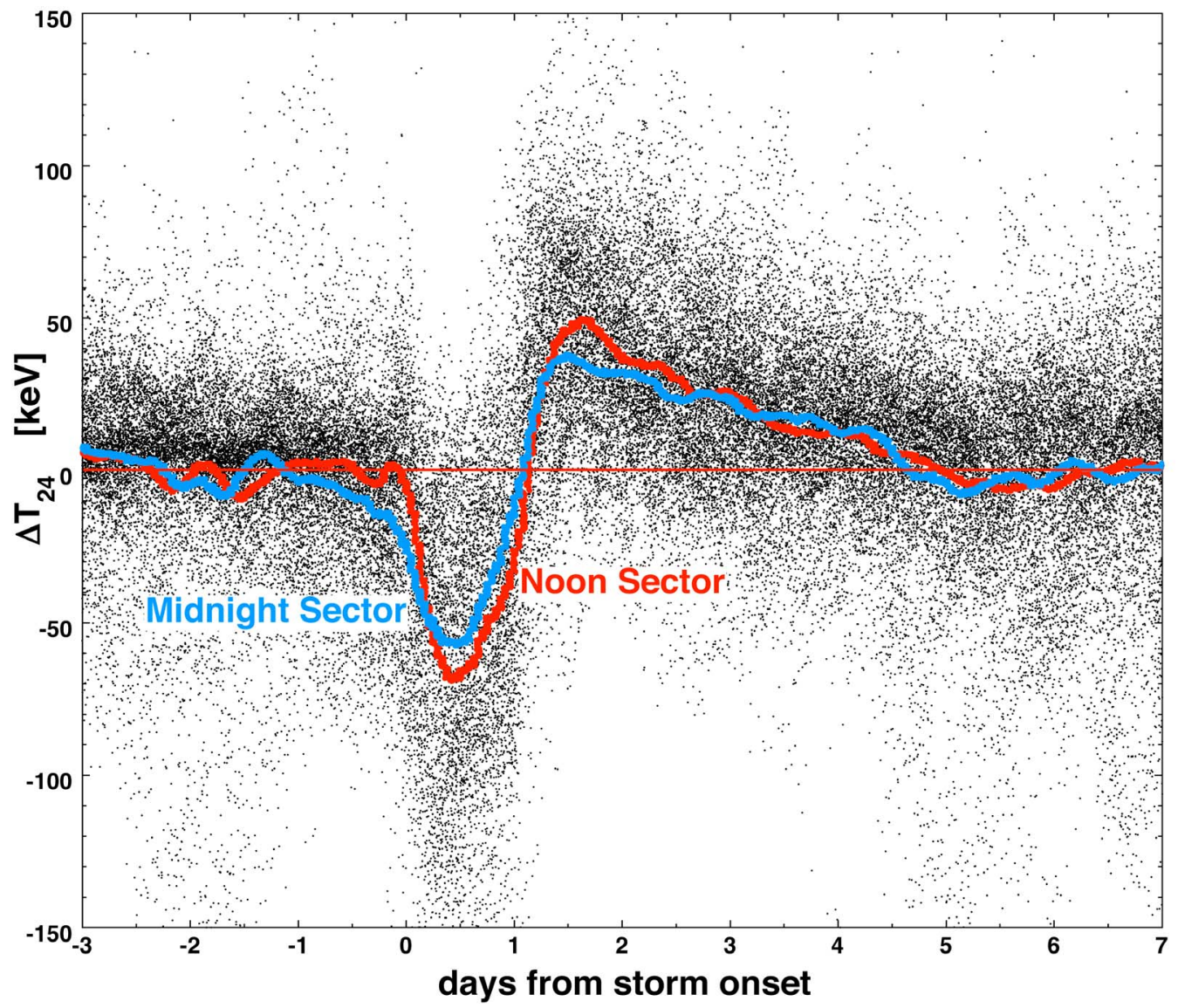

Figure 7. For 93 high-speed stream-driven storms, measured $24 \mathrm{~h}$ changes $\Delta \mathrm{T}_{24}$ in the temperature $\mathrm{T}$ of the outer electron radiation belt are plotted (black points) as a function of the time from storm onset. A 300-point running average of the points pertaining to the noon sector of local time is plotted in red, and a 300-point running average for the midnight sector is plotted in blue.

[30] In the $36 \mathrm{~h}$ to $72 \mathrm{~h}$ range of times after storm onset, the superposed averages of $\mathrm{T}$ in Figure 6 (bottom) are well fit (thee green curves) by the formulas

$$
\begin{aligned}
& \mathrm{T}_{\text {allLT }}=109+24.2 \mathrm{t} \\
& \mathrm{T}_{\text {noon }}=125+24.5 \mathrm{t} \\
& \mathrm{T}_{\text {midnight }}=97+23.4 \mathrm{t}
\end{aligned}
$$

where $\mathrm{T}$ is in units of $\mathrm{keV}$ and $\mathrm{t}$ is in units of days. Expressions (10) yield time derivatives of the temperature of

$$
\begin{gathered}
\mathrm{dT} / \mathrm{dt}=24.2 \mathrm{keV} \mathrm{d}^{-1} \text { (all local times) } \\
\mathrm{dT} / \mathrm{dt}=24.5 \mathrm{keV} \mathrm{d}^{-1} \text { (noon) } \\
\mathrm{dT} / \mathrm{dt}=23.4 \mathrm{keV} \mathrm{d}^{-1} \text { (midnight). }
\end{gathered}
$$

[31] Expressions (11) yield values of the $24 \mathrm{~h}$ change in the temperature $\mathrm{T}$ of the outer electron radiation belt at geosynchronous in the time range 36-72 $\mathrm{h}$ after storm onset of $\Delta \mathrm{T}_{24}=24 \mathrm{keV}$ for all local times, $\Delta \mathrm{T}_{24}=25 \mathrm{keV}$ for the noon sector, and $\Delta \mathrm{T}_{24}=23 \mathrm{keV}$ for the midnight sector. These values, which are almost identical to the values obtained by fitting the superposed average of the logarithm of the temperature (previous paragraph), are entered into Table 1 .

[32] In Figure 7 the $24 \mathrm{~h}$ change $\Delta \mathrm{T}_{24}=\mathrm{T}(\mathrm{t})-\mathrm{T}(\mathrm{t}-24 \mathrm{~h})$ of the temperature $\mathrm{T}$ of the outer electron radiation belt at geosynchronous orbit is plotted as a function of the time $t$ since storm onset for the 93 high-speed stream-driven storms. Each point represents $1 \mathrm{~h}$ of satellite data at time $\mathrm{t}$ and $1 \mathrm{~h}$ of satellite data at time $\mathrm{t}-24 \mathrm{~h}$. As can be seen from the black points the $24 \mathrm{~h}$ change in the temperature is negative early in the storm and then is positive for several days. For data pertaining to the noon sector of local time (10-14 LT) and to the midnight sector of local time (22-2 LT), 300-point running averages of $\Delta T_{24}$ are plotted in red and blue, respectively, in Figure 7. As can be seen from those two curves, the $24 \mathrm{~h}$ change in the temperature of the outer electron radiation belt is near zero before storm onset and it is near zero many days after storm onset; during the first day of the storm (the time of dropout and recovery) $\Delta \mathrm{T}_{24}$ is negative and during days 2-4 of the storm $\Delta \mathrm{T}_{24}$ is positive. The 300-point 


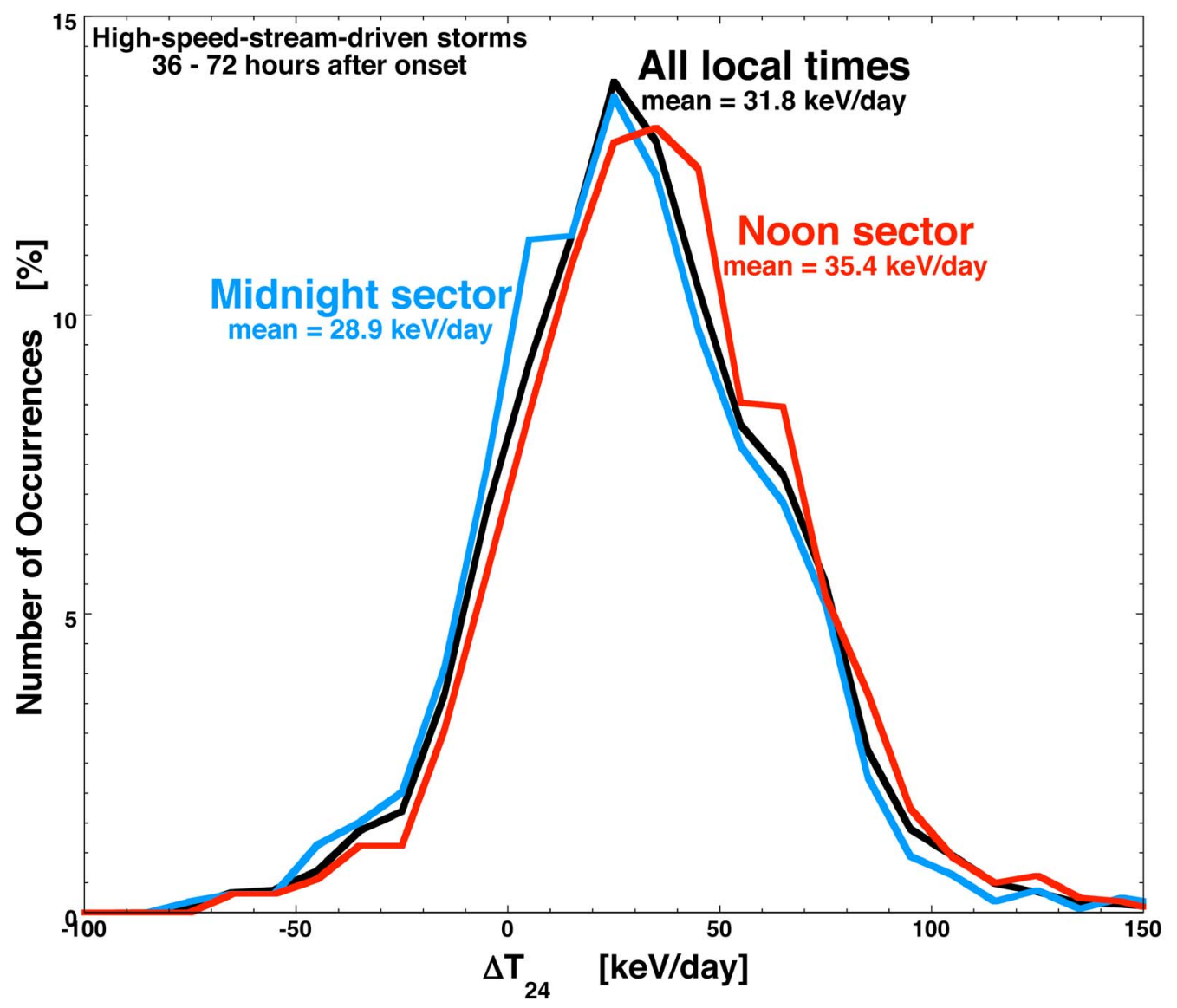

Figure 8. The measured $24 \mathrm{~h}$ changes in the temperature $\Delta \mathrm{T}_{24}$ of the outer electron radiation belt at geosynchronous orbit for the 36-72 h interval after storm onset for the 93 high-speed stream-driven storms are binned. The black curve is the occurrence distribution for all local times, the red curve the occurrence distribution for local noon, and the blue curve the occurrence distribution for local midnight. Mean values of $\Delta T_{24}$ are indicated.

running averages of $\Delta T_{24}$ at local noon and at local midnight in the $\mathrm{t}=36 \mathrm{~h}$ to $\mathrm{t}=72 \mathrm{~h}$ time after onset are well fit by

$$
\begin{array}{r}
\Delta \mathrm{T}_{24 \text { noon }}=36.0 \mathrm{keV}-9.35(\mathrm{t}-1.5 \text { day }) \\
\Delta \mathrm{T}_{24 \text { midnight }}=48.9 \mathrm{keV}-18.2(\mathrm{t}-1.5 \text { day })
\end{array}
$$

where $\Delta \mathrm{T}_{24}$ is in units of $\mathrm{keV}$ and $\mathrm{t}$ is in units of days. As can be seen by the black points in Figure 7, there is a large spread in the measured values of the $24 \mathrm{~h}$ change in the temperature of the outer electron radiation belt at geosynchronous orbit. For the 36-72 $\mathrm{h}$ range of times after storm onset, the $\Delta \mathrm{T}_{24}$ values in Figure 7 are binned and the occurrence distributions are plotted in Figure 8. The distribution plotted in black is of $\Delta T_{24}$ measurements at all local times, the distribution in red is for measurements in the local noon sector (10-14 LT), and the distribution in blue is for measurements in the local midnight sector (22-2 LT). As can be seen the thee distributions in Figure 8 are similar, with the mean value of $\Delta \mathrm{T}_{24}$ being slightly higher at local noon than it is at midnight.

[33] Averaging the data in Figure 7, the mean values of the $24 \mathrm{~h}$ change in the temperature in the $36 \mathrm{~h}$ to $72 \mathrm{~h}$ time after storm onset for high-speed stream-driven storms are

$$
\begin{gathered}
\left\langle\Delta \mathrm{T}_{24}\right\rangle_{\text {noon }}=35.4 \mathrm{keV} \mathrm{d}^{-1} \\
\left\langle\Delta \mathrm{T}_{24}\right\rangle_{\text {midnight }}=28.9 \mathrm{keV} \mathrm{d}^{-1} \\
\left\langle\Delta \mathrm{T}_{24}\right\rangle_{\text {all }}=31.8 \mathrm{keV} \mathrm{d}^{-1}
\end{gathered}
$$

for local noon (10-14 LT), local midnight (22-2 LT), and all local times (0-24 LT). The reader is reminded that the populations sampled at local midnight and local noon are different. These values are entered into Table 1.

[34] Note that there is a substantial difference between the heating rate obtained from temporal fits to the superposed epoch average of the temperature (e.g., expression (11a)) and the direct average of the $24 \mathrm{~h}$ differences of the measured temperatures (e.g., expression (13a)). The direct method is a cleaner measurement and should be the preferred. The weighting of the points that goes into the two methods differs considerably, and even the data that goes into the two methods differs. On the weighting: the superposed epoch method 


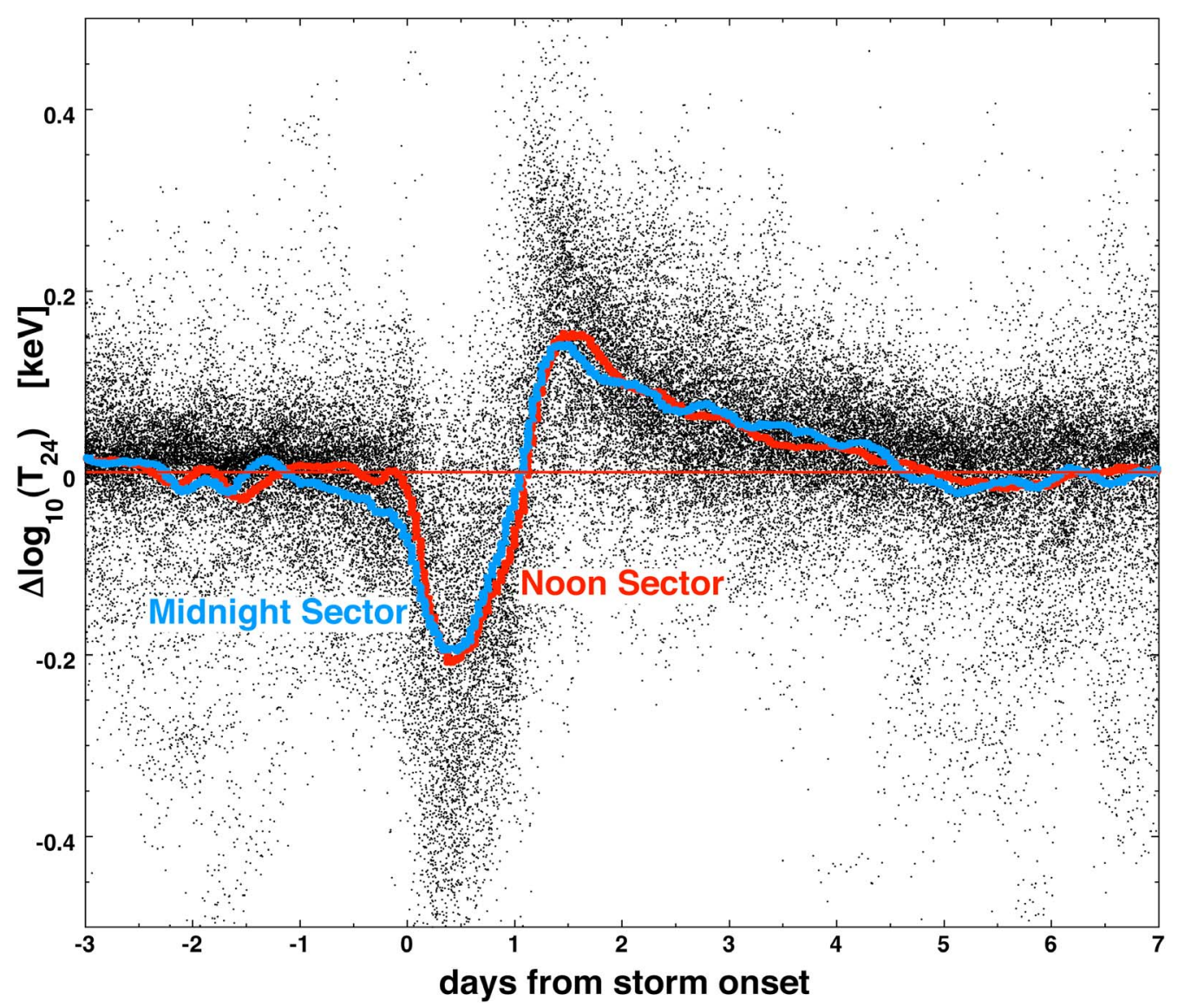

Figure 9. For 93 high-speed stream-driven storms, measured $24 \mathrm{~h}$ changes in the logarithm of the temperature of the outer electron radiation belt are plotted (black points) as a function of the time from storm onset. A 300-point running average of the points pertaining to the noon sector of local time is plotted in red, and a 300-point running average for the midnight sector is plotted in blue.

counts all data points going into a $1 \mathrm{~h}$ time versus $1 \mathrm{~h}$ local time bin as one point, with a logarithmic average of the points in the bin. (This logarithmic average weighs low values higher than a nonlogarithmic binning.) Then these bin values are averaged over local time. A curve is fit (which is another average) to the slope in time of that double average. In contrast the direct method averages once (rather than thee times) with all points getting the same weight. On the inclusion of data: the direct method averages $24 \mathrm{~h}$ differences and for a measurement to be included in the average that measurement must have a mate $24 \mathrm{~h}$ earlier. If there was no mate (for telemetry reasons), the point is not included. Additionally, in the direct method, a data point at a given time carries information from $24 \mathrm{~h}$ earlier since a $24 \mathrm{~h}$ difference is used: this brings in information from outside the $36-72 \mathrm{~h}$ window into the averaging.

[35] In Figure 9 the $24 \mathrm{~h}$ change $\Delta \log _{10}(\mathrm{~T})_{24}=\log _{10}(\mathrm{~T}(\mathrm{t}))-$ $\log _{10}(\mathrm{~T}(\mathrm{t}-24 \mathrm{~h}))$ in the logarithm of the temperature $\mathrm{T}$ of the outer electron radiation belt at geosynchronous orbit is plotted as a function of the time $t$ since storm onset for the 93 high-speed stream-driven storms. Each black point represents $1 \mathrm{~h}$ of satellite data at time $\mathrm{t}$ and $1 \mathrm{~h}$ of satellite data at time $\mathrm{t}-24 \mathrm{~h}$. As can be seen from the points in Figure 9 the $24 \mathrm{~h}$ change in the logarithm of the temperature is negative early in the storm and then it is positive for several days during the storm. For data pertaining to the noon sector of local time (10-14 LT) and the midnight sector of local time (22-2 LT), 300-point running averages of $\Delta \log _{10}(\mathrm{~T})_{24}$ are plotted in red and blue, respectively, in Figure 9. As can be seen from the red and blue curves, the $24 \mathrm{~h}$ change in the logarithm of the temperature of the outer electron radiation belt is near zero before storm onset and it is near zero many days after storm onset; during the first day of the storm (the time of dropout and recovery) $\Delta \log _{10}(\mathrm{~T})_{24}$ is negative and during days $2-4$ of the storm $\Delta \log _{10}(\mathrm{~T})_{24}$ is positive. The 300 -point running averages of $\Delta \mathrm{T}_{24}$ at noon and at midnight in the $\mathrm{t}=36 \mathrm{~h}$ to $\mathrm{t}=72 \mathrm{~h}$ time after onset are well fit by

$$
\begin{gathered}
\Delta \log _{10}(\mathrm{~T})_{24 \text { noon }}=0.147-0.068(\mathrm{t}-1.5 \text { day }) \\
\Delta \log _{10}(\mathrm{~T})_{24 \text { midnight }}=0.123-0.043(\mathrm{t}-1.5 \text { day })
\end{gathered}
$$

where $t$ is in units of days. Averaging the data in Figure 9, the mean values of the $24 \mathrm{~h}$ change in the logarithm of the 
temperature in the $36 \mathrm{~h}$ to $72 \mathrm{~h}$ time after storm onset for high-speed stream-driven storms are

$$
\begin{gathered}
\left\langle\Delta \log _{10}(\mathrm{~T})_{24}\right\rangle_{\text {noon }}=0.0961 \\
\left\langle\Delta \log _{10}(\mathrm{~T})_{24}\right\rangle_{\text {midnight }}=0.0896 \\
\left\langle\Delta \log _{10}(\mathrm{~T})_{24}\right\rangle_{\text {allLT }}=0.0930
\end{gathered}
$$

for local noon (10-14 LT), local midnight (22-2 LT), and all local times (0-24 LT). Converting from base 10 logarithms to natural logarithms, expressions (14) yield e-folding times for the increase in the temperature of the outer electron radiation belt at geosynchronous orbit during high-speed stream-driven storms of 4.5 days at local noon, 4.8 days at local midnight, and 4.7 days for all local times. The reader is reminded that the populations at noon and midnight differ.

\section{Heating Rates and the Kp Index}

[36] The $3 \mathrm{~h} \mathrm{Kp}$ index is a measure of magnetospheric convection [Thomsen, 2004] and is a general measure of geomagnetic activity [Bartels et al., 1939; Bartels and Veldkamp, 1949; Rostoker, 1972].

[37] Note in Figure 7 that there is a wide range in measured values of the $24 \mathrm{~h}$ change in the temperature of the outer electron radiation belt at geosynchronous orbit during high-speed stream-driven storms. This spread is depicted in the occurrence distributions of $\Delta \mathrm{T}_{24}$ plotted in Figure 8. Some of this spread in the heating values of the outer electron radiation belt could be caused by the intermittency of the high-speed stream-driven storms, i.e., the fact that the storms are not constantly on but that geomagnetic activity increases and decreased during the several days of the storms [Tsurutani et al., 1999, 2006a, 2006b]. (This on-off nature of the solar wind-driven storms and the on-off nature of the solar wind driving has been identified as one of the key research topics for high-speed stream-driven storms [Denton et al., 2008].) During intervals when geomagnetic activity is high, the heating could be active, and during intervals when geomagnetic activity is low, the heating could be inactive.

[38] In Figure 10 (top) the measured value $\Delta \mathrm{T}_{24}$ of the $24 \mathrm{~h}$ change in the temperature $\mathrm{T}$ of the outer electron radiation belt at geosynchronous orbit is plotted as a function of the $24 \mathrm{~h}$ average $\langle\mathrm{Kp}\rangle_{24}$ of the Kp index. The $\Delta \mathrm{T}_{24}$ values were obtained from time intervals $36-72 \mathrm{~h}$ after the onset of the 93 high-speed stream-driven storms. In this $36 \mathrm{~h}$ long time interval, the multiple satellites in geosynchronous orbit yielded 9563 independent values of $\Delta T_{24}$. For each value of $\Delta \mathrm{T}_{24}=\mathrm{T}(\mathrm{t})-\mathrm{T}(\mathrm{t}-24 \mathrm{~h})$, the average value $\langle\mathrm{Kp}\rangle_{24}$ was calculated by averaging the $\mathrm{Kp}$ index from time $\mathrm{t}-24 \mathrm{~h}$ to time $\mathrm{t}$. As denoted in Figure 10 (top), the linear correlation coefficient between $\Delta T_{24}$ and $\langle K p\rangle_{24}$ is $\mathrm{R}_{\text {corr }}=+0.23$.

[39] A rule of thumb for the significance of a correlation coefficient $\mathrm{R}_{\text {corr }}$ comes from comparing $\mathrm{R}_{\text {corr }}$ to $1 / \mathrm{N}_{\text {ind }}^{1 / 2}$ [cf. Hald, 1952], where $\mathrm{N}_{\text {ind }}$ is the number of independent measurements going into $\mathrm{R}_{\text {corr }}$. This rule of thumb expresses the 2 sigma level of correlation relative to random correlations. The number of total measurements going into Figure 10 is $\mathrm{N}_{\text {meas }}=9563$. If $\mathrm{N}_{\text {meas }} / 11$ is taken as the number of independent measurements $\mathrm{N}_{\text {ind }}$ owing to persistence in the $\Delta T_{24}$ measurements (see Appendix A), then $1 / \mathrm{N}_{\text {ind }}^{1 / 2}=0.0678$. Accordingly, the coefficient $\mathrm{R}_{\text {corr }}=0.23$ between $\Delta \mathrm{T}_{24}$ and $\langle\mathrm{Kp}\rangle_{24}$ is at the 6.8 sigma level, which is definite correlation. (Note that even if $\mathrm{N}_{\text {meas }} / 36$ is taken (see Appendix A) for $\mathrm{N}_{\text {ind }}$, the coefficient $\mathrm{R}_{\text {corr }}=0.23$ is at the 3.7 sigma level of correlation.) Hence, there is a definite statistical correlation between $\langle\mathrm{Kp}\rangle_{24}$ and $\Delta \mathrm{T}_{24}$, but there is also a lot of variance in $\Delta \mathrm{T}_{24}$ that is not described solely by the value of $\langle K p\rangle_{24}$.

[40] In Figure 10 a 300-point running average of $\Delta T_{24}$ for all of the data is plotted as the yellow points; this running average reveals the underlying trend between $\Delta T_{24}$ and $\langle\mathrm{Kp}\rangle_{24}$. Also, 100-point running averages for noon-only data points (red) and midnight-only data points (blue) are plotted; note that there is not much statistical difference between the values at noon and at midnight. A least squares linear regression fit to all of the data in Figure 10 (top) yields

$$
\Delta \mathrm{T}_{24}=7.84\langle\mathrm{Kp}\rangle_{24}+4.16
$$

where $\Delta \mathrm{T}_{24}$ is in units of $\mathrm{keV}$ and $\mathrm{Kp}$ is dimensionless. This fit is plotted as the green line in Figure 10 (top). The statistical error on this slope of 7.84 is \pm 5.83 . A Gaussian linear fit to the $\Delta \mathrm{T}_{24}$ versus $\langle\mathrm{Kp}\rangle_{24}$ points is plotted as the purple dashed line Figure 10 (top), yielding the formula

$$
\Delta \mathrm{T}_{24}=34.1\langle\mathrm{Kp}\rangle_{24}-88
$$

which has a slope much steeper than the fit of expression (16). In expression (17) $\Delta \mathrm{T}_{24}$ is in units of keV. Expressing $\Delta \mathrm{T}_{24}$ as dT/dt in expressions (16) and (17) and then taking the Kp derivatives of expressions (16) and (17), rates of change $\partial(\mathrm{dT} / \mathrm{dt}) / \partial \mathrm{Kp}$ of the time rate of change in temperature $\mathrm{T}$ associated with the value of $\mathrm{Kp}$ of

$$
\begin{array}{r}
\partial(\mathrm{dT} / \mathrm{dt}) / \partial \mathrm{Kp}=7.8 \mathrm{keV} \mathrm{d}^{-1} \mathrm{Kp}^{-1} \text { (linear) } \\
\partial(\mathrm{dT} / \mathrm{dt}) / \partial \mathrm{Kp}=34 \mathrm{keV} \mathrm{d}^{-1} \mathrm{Kp}^{-1} \text { (Gaussian) }
\end{array}
$$

are obtained, where the units are $\mathrm{keV}$ of temperature change per day per unit of Kp index. Expressions (18) are interpreted as 7.8 and $34 \mathrm{keV} \mathrm{d}^{-1}$ of increased heating for each unit of $\mathrm{Kp}$ increase during the heating interval. The linear regression value of $7.8 \mathrm{keV} \mathrm{d}^{-1}$ is lower than the true value owing to the linear correlation coefficient $\mathrm{R}_{\text {corr }}$ being substantially less than unity. The Gaussian value of $34 \mathrm{keV} \mathrm{d}^{-1}$ is an upper limit, attributing all of the variation in $\Delta \mathrm{T}_{24}$ to all of the variation in $\langle\mathrm{Kp}\rangle_{24}$. The linear regression value $\left(7.8 \mathrm{keV} \mathrm{d}^{-1} \mathrm{Kp}^{-1}\right)$, which is deemed to be too low, is entered into Table 1. Linear regression fits are also made for the noon-only and midnight-only data yielding $9.0 \mathrm{keV} \mathrm{d}^{-1} \mathrm{Kp}^{-1}$ for noon and $6.4 \mathrm{keV} \mathrm{d}^{-1} \mathrm{Kp}^{-1}$ for midnight (with statistical errors of \pm 8.9 for noon and \pm 9.2 for midnight): these values are entered into Table 1.

[41] In Figure 10 (bottom) the $24 \mathrm{~h}$ change $\Delta \log _{10}(\mathrm{~T})_{24}$ in the logarithm of the temperature $\mathrm{T}$ of the outer electron radiation belt at geosynchronous orbit is plotted as a function of the mean value of $\mathrm{Kp}$ during that $24 \mathrm{~h}$. The $24 \mathrm{~h}$ change in the logarithm $\Delta \log _{10}(\mathrm{~T})_{24}$ is $\log _{10}(\mathrm{~T}(\mathrm{t}))-\log _{10}(\mathrm{~T}(\mathrm{t}-24 \mathrm{~h}))$. The data pertain to times $\mathrm{t}$ from $36 \mathrm{~h}$ to $72 \mathrm{~h}$ after storm onset 

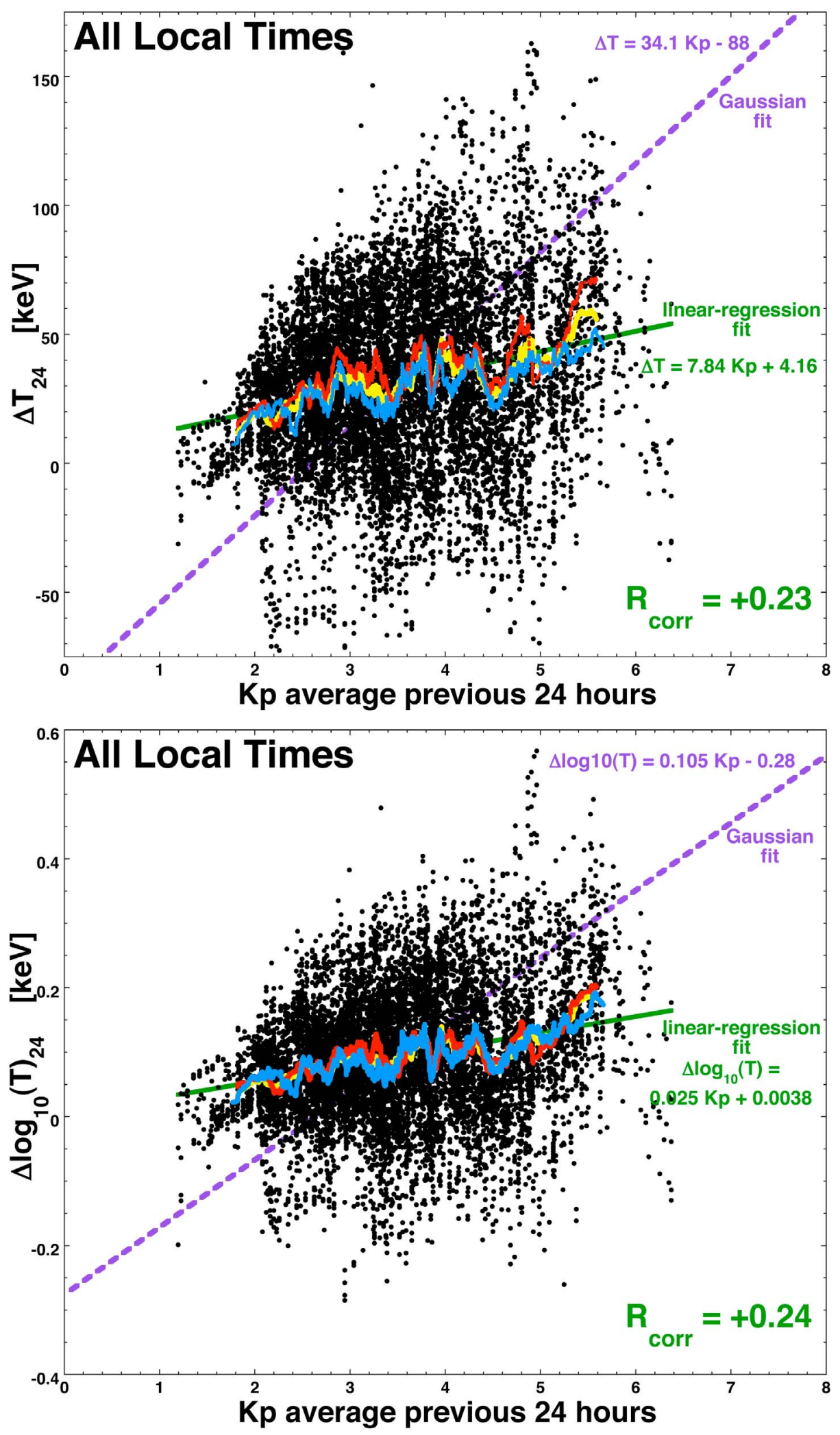

Figure 10. (top) For the 36-72 h intervals of the 93 high-speed stream-driven storms, the $24 \mathrm{~h}$ changes $\Delta \mathrm{T}_{24}$ in the temperature $\mathrm{T}$ of the outer electron radiation belt are plotted as functions of the $24 \mathrm{~h}$ average of the $\mathrm{Kp}$ index for the same $24 \mathrm{~h}$. (bottom) The logarithm of the change is so plotted. Linear regression fits are plotted in green, Gaussian fits are plotted in purple, and 300-point running averages are plotted in yellow. Also plotted are 100-point running averages of the noon-only data (red) and the midnight only data (blue). 
for the 93 high-speed stream-driven storms. Each data point represents $1 \mathrm{~h}$ of data plus $1 \mathrm{~h}$ of data $24 \mathrm{~h}$ earlier from one geosynchronous spacecraft. As denoted in Figure 10 (bottom), the linear correlation coefficient between $\Delta \log (\mathrm{T})_{24}$ and $\langle\mathrm{Kp}\rangle_{24}$ is $\mathrm{R}_{\text {corr }}=+0.24$, which is at the 7 sigma level of correlation as compared with random for $\mathrm{N}_{\text {ind }}=\mathrm{N}_{\text {meas }} / 11=$ 9563/11 independent measurements. A 300-point running average of $\Delta \log (\mathrm{T})_{24}$ is plotted as the yellow point and 100 -point running averages for noon-only data (red) and for midnight-only data (blue) are plotted; note again that there is not much statistical difference between the values at noon and at midnight. A least squares linear regression fit to all of the 36-72 $\mathrm{h}$ data in Figure 10 (bottom) yields

$$
\Delta \log _{10}(\mathrm{~T})_{24}=0.025\langle\mathrm{Kp}\rangle_{24}+0.0038
$$

where $\mathrm{T}$ is in units of $\mathrm{keV}$ and $\mathrm{Kp}$ is dimensionless. This linear regression fit is plotted as the green line in Figure 10 (bottom). A Gaussian linear fit to the $\Delta \log (\mathrm{T})_{24}$ versus $\langle\mathrm{Kp}\rangle_{24}$ points yields the formula

$$
\Delta \log _{10}(\mathrm{~T})_{24}=0.105\langle\mathrm{Kp}\rangle_{24}-0.28
$$

where $\mathrm{T}$ is in units of keV. The Gaussian linear fit is plotted as the purple dashed line in Figure 10 (bottom). Noting that the $24 \mathrm{~h}$ change in the logarithm is also equal to the logarithm of the ratio of the values separated by $24 \mathrm{~h} \Delta \log (\mathrm{T})_{24}=$ $\log (\mathrm{T}(\mathrm{t}))-\log (\mathrm{T}(\mathrm{t}-24 \mathrm{~h}))=\log [\mathrm{T}(\mathrm{t}) / \mathrm{T}(\mathrm{t}-24 \mathrm{~h})]$, expressions (19) and (20) can be rewritten as

$$
\begin{array}{r}
\mathrm{T}(\mathrm{t}) / \mathrm{T}(\mathrm{t}-24 \mathrm{~h})=1.01 \mathrm{e}^{\mathrm{Kp} / 17.4} \text { (linear) } \\
\mathrm{T}(\mathrm{t}) / \mathrm{T}(\mathrm{t}-24 \mathrm{~h})=0.525 \mathrm{e}^{\mathrm{Kp} / 4.14} \text { (Gaussian) }
\end{array}
$$

for the linear regression fit and the Gaussian linear fit, respectively.

\section{Heating Rates and Solar Wind Speed and Density}

[42] There is long-standing knowledge about a connection between high fluxes of relativistic electrons in the outer electron radiation belt and high solar wind velocities [Paulikas and Blake, 1979; Fung and Tan, 1998; Desorgher et al., 1998; Vassiliadis et al., 2002] and a newer report about a connection between high fluxes and low solar wind densities [Lyatsky and Khazanov, 2008; Burin des Rozier et al., 2009].

[43] In Figure 11 (top) the measured value $\Delta T_{24}$ of the $24 \mathrm{~h}$ change in the temperature $\mathrm{T}$ of the outer electron radiation belt at geosynchronous orbit is plotted as a function of the $24 \mathrm{~h}$ average $\left\langle\mathrm{v}_{\mathrm{sw}}\right\rangle_{24}$ of the solar wind speed $\mathrm{v}_{\mathrm{sw}}$. The $\Delta \mathrm{T}_{24}$ values were obtained from time interval 36-72 $\mathrm{h}$ after the onset of the 93 high-speed stream-driven storms. In this time interval, the multiple satellites in geosynchronous orbit yielded 9220 independent values of $\Delta T_{24}$ that had solar wind speed available, wherein $\mathrm{v}_{\mathrm{sw}}$ was averaged over the $24 \mathrm{~h}$ to produce a $\left\langle v_{\text {sw }}\right\rangle_{24}$ value. As denoted Figure 11 (top), the linear correlation coefficient between $\Delta T_{24}$ and $\left\langle v_{s w}\right\rangle_{24}$ is $\mathrm{R}_{\text {corr }}=+0.29$, which is at the 8 sigma level of correlation as compared with random for $\mathrm{N}_{\text {ind }}=9220 / 11$ independent measurements: a definite statistical correlation. A 300-point running average of $\Delta \mathrm{T}_{24}$ is plotted in Figure 11 (top) as the yellow points. 100-point running averages for noon-only data (red) and for midnight-only data (blue) are also plotted; note that there is not much statistical difference between the values at noon and at midnight. A least squares linear regression fit to all of the data (black points) in Figure 11 (top) in the 36-72 $\mathrm{h}$ interval yields

$$
\Delta \mathrm{T}_{24}=0.109\left\langle\mathrm{v}_{\mathrm{sw}}\right\rangle_{24}-32
$$

where $\Delta \mathrm{T}_{24}$ is in units of $\mathrm{keV}$ and $\mathrm{v}_{\mathrm{sw}}$ is in units of $\mathrm{km} \mathrm{s}^{-1}$. The statistical error for the slope of this fit is \pm 0.057 . This fit is plotted as the green line. A Gaussian linear fit to the $\Delta \mathrm{T}_{24}$ versus $\left\langle\mathrm{v}_{\mathrm{sw}}\right\rangle_{24}$ points in the $36-72 \mathrm{~h}$ interval is plotted as the purple dashed line in Figure 11 (top), yielding the formula

$$
\Delta \mathrm{T}_{24}=0.374\left\langle\mathrm{v}_{\mathrm{sw}}\right\rangle_{24}-188
$$

which has a slope much steeper than the fit of expression (22). Again, in expression (23) $\Delta \mathrm{T}_{24}$ is in units of $\mathrm{keV}$ and $\mathrm{v}_{\mathrm{sw}}$ is in units of $\mathrm{km} \mathrm{s}^{-1}$. Expressing $\Delta \mathrm{T}_{24}$ as $\mathrm{dT} / \mathrm{dt}$ in expressions (22) and (23) and then taking the $\mathrm{v}_{\mathrm{sw}}$ derivatives of expressions (22) and (23), rates of change $\partial(\mathrm{dT} / \mathrm{dt}) / \partial \mathrm{v}_{\mathrm{sw}}$ of the time rate of change in temperature $\mathrm{T}$ associated with the value of $v_{\text {sw }}$ of

$$
\begin{gathered}
\partial(\mathrm{dT} / \mathrm{dt}) / \partial \mathrm{v}_{\mathrm{sw}}=0.11 \mathrm{keV} \mathrm{d}^{-1}\left(\mathrm{~km} \mathrm{~s}^{-1}\right)^{-1} \text { (linear) } \\
\partial(\mathrm{dT} / \mathrm{dt}) / \partial \mathrm{v}_{\mathrm{sw}}=0.37 \mathrm{keV} \mathrm{d}^{-1}\left(\mathrm{~km} \mathrm{~s}^{-1}\right)^{-1}(\text { Gaussian})
\end{gathered}
$$

are obtained. Expressions (24) are interpreted as 0.11 and $0.37 \mathrm{keV} \mathrm{d}^{-1}$ of increased heating for each $\mathrm{km} \mathrm{s}^{-1}$ of $\mathrm{v}_{\mathrm{sw}}$ increase during the heating interval. The Gaussian value of 0.37 is an upper limit, attributing all of the variation in $\Delta T_{24}$ to all of the variation in $\left\langle v_{\mathrm{sw}}\right\rangle_{24}$. The linear regression value $0.11 \mathrm{keV} \mathrm{d}^{-1}\left(\mathrm{~km} \mathrm{~s}^{-1}\right)^{-1}$, which is acknowledged to be low, is entered into Table 1. Linear regression fits are also made for the noon-only $0.10 \mathrm{keV} \mathrm{d}^{-1}\left(\mathrm{~km} \mathrm{~s}^{-1}\right)^{-1}$ and midnightonly $0.11 \mathrm{keV} \mathrm{d}^{-1}\left(\mathrm{~km} \mathrm{~s}^{-1}\right)^{-1}$ data and those values are also entered into Table 1. The statistical errors of these slopes are \pm 0.069 and \pm 0.091 , respectively. And the reader is again cautioned that the populations measured at noon and at midnight are different.

[44] In Figure 11 (bottom) the $24 \mathrm{~h}$ change $\Delta \log _{10}(\mathrm{~T})_{24}$ in the logarithm of the temperature $\mathrm{T}$ of the outer electron radiation belt at geosynchronous orbit is plotted as a function of the mean value of $\mathrm{v}_{\mathrm{sw}}$ during that $24 \mathrm{~h}$. The $24 \mathrm{~h}$ change in the logarithm $\Delta \log _{10}(\mathrm{~T})_{24}$ is $\log _{10}(\mathrm{~T}(\mathrm{t}))-\log _{10}(\mathrm{~T}(\mathrm{t}-24 \mathrm{~h}))$. The data pertain to times $\mathrm{t}$ from $36 \mathrm{~h}$ to $72 \mathrm{~h}$ after storm onset for the 93 high-speed stream-driven storms. Each data point represents $1 \mathrm{~h}$ of data plus $1 \mathrm{~h}$ of data $24 \mathrm{~h}$ earlier from one geosynchronous spacecraft. As denoted in Figure 11 (bottom), the linear correlation coefficient between $\Delta \log (\mathrm{T})_{24}$ and $\left\langle v_{\mathrm{sw}}\right\rangle_{24}$ is $\mathrm{R}_{\mathrm{corr}}=+0.24$, which is at the 7 sigma level of correlation as compared with random for $9220 / 11$ independent measurements. A 300-point running average of $\Delta \log (\mathrm{T})_{24}$ is plotted as the yellow points in Figure 11 (bottom) and 100-point running averages for noon-only data (red) and for midnight-only data (blue) are plotted; note again that there is not much statistical difference between the values 

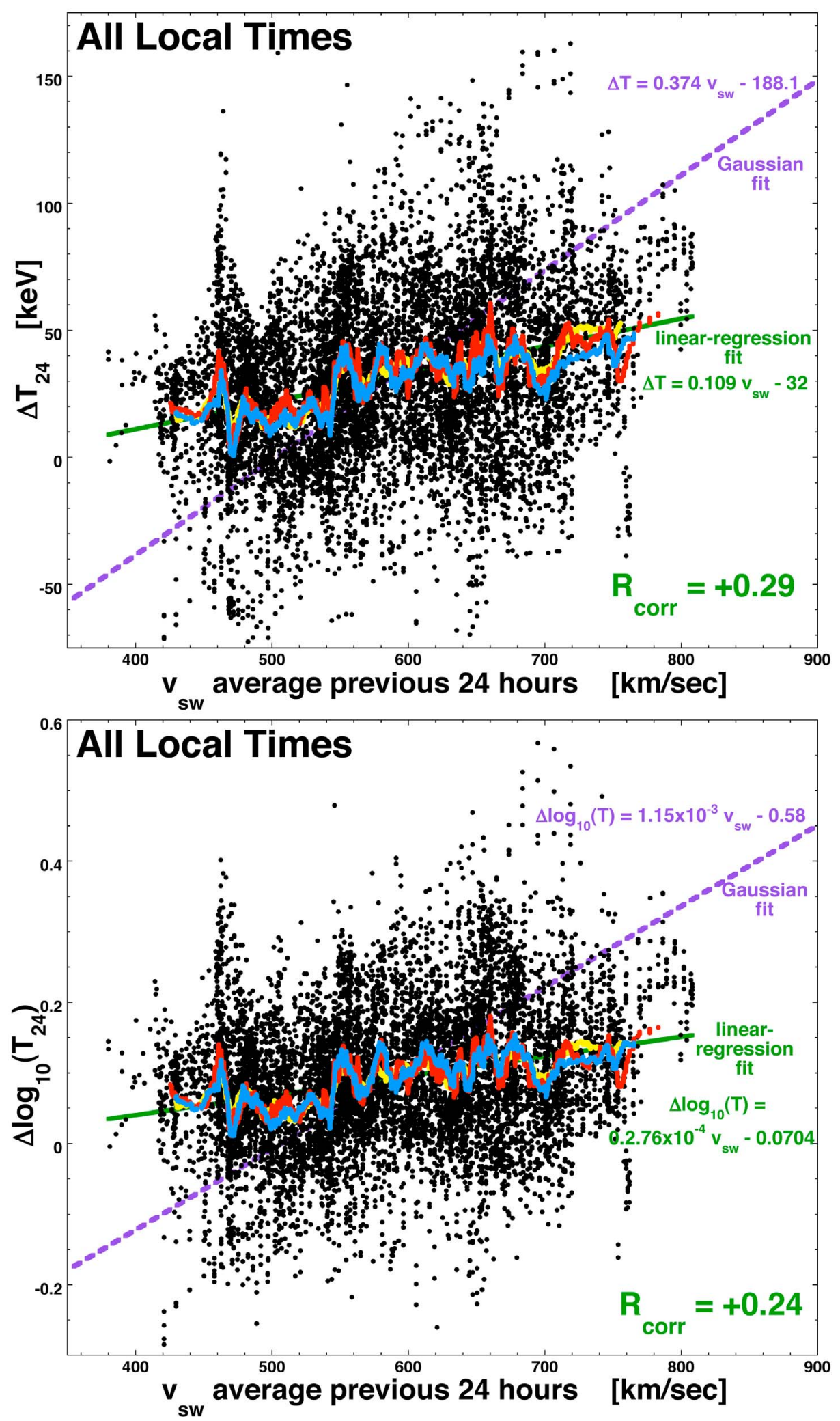

Figure 11. (top) For the 36-72 h intervals of the 93 high-speed stream-driven storms, the $24 \mathrm{~h}$ changes $\Delta \mathrm{T}_{24}$ in the temperature $\mathrm{T}$ of the outer electron radiation belt are plotted as functions of the $24 \mathrm{~h}$ average of the solar wind speed for the same $24 \mathrm{~h}$. (bottom) The logarithm of the change is so plotted. Linear regression fits are plotted in green, Gaussian fits are plotted in purple, and 300-point running averages are plotted in yellow. Also plotted are 100-point running averages of the noon-only data (red) and the midnight only data (blue). 
at noon and at midnight. A least squares linear regression fit to all of the data in Figure 11 (bottom) yields

$$
\Delta \log _{10}(\mathrm{~T})_{24}=2.76 \times 10^{-4}\left\langle\mathrm{v}_{\mathrm{sw}}\right\rangle_{24}-0.0704
$$

where $\mathrm{T}$ is in units of $\mathrm{keV}$ and $\mathrm{v}_{\mathrm{sw}}$ is in units of $\mathrm{km} \mathrm{s}^{-1}$. This linear regression fit is plotted as the green line in Figure 11 (bottom). A Gaussian linear fit to the $\Delta \log (\mathrm{T})_{24}$ versus $\left\langle v_{\mathrm{sw}}\right\rangle_{24}$ points yields the formula

$$
\Delta \log _{10}(\mathrm{~T})_{24}=1.15 \times 10^{-3}\left\langle\mathrm{v}_{\mathrm{sw}}\right\rangle_{24}-0.58
$$

where $\mathrm{T}$ is in units of $\mathrm{keV}$ and $\mathrm{v}_{\mathrm{sw}}$ is in units of $\mathrm{km} \mathrm{s}^{-1}$. This Gaussian linear fit (expression (26)) is plotted as the purple dashed line in Figure 11 (bottom). Noting that $\Delta \log (\mathrm{T})_{24}=\log$ $(\mathrm{T}(\mathrm{t}))-\log (\mathrm{T}(\mathrm{t}-24 \mathrm{~h}))=\log [\mathrm{T}(\mathrm{t}) / \mathrm{T}(\mathrm{t}-24 \mathrm{~h})]$, expressions $(25)$ and (26) can be rewritten as

$$
\begin{gathered}
\mathrm{T}(\mathrm{t}) / \mathrm{T}(\mathrm{t}-24 \mathrm{~h})=0.85 \mathrm{e}^{\text {vsw } / 1570} \text { (linear) } \\
\mathrm{T}(\mathrm{t}) / \mathrm{T}(\mathrm{t}-24 \mathrm{~h})=0.26 \mathrm{e}^{\text {vsw } / 380}(\text { Gaussian})
\end{gathered}
$$

for the linear regression fit and the Gaussian linear fit, respectively.

[45] In the fast solar wind that produces high-speed streamdriven storms there is a strong anticorrelation between the solar wind speed $\mathrm{v}_{\mathrm{sw}}$ and the solar wind number density $\mathrm{n}_{\mathrm{sw}}$ : for the 93 storm data set used here, in the time interval 36-72 $\mathrm{h}$ after storm onset the linear correlation coefficient between $\left\langle\mathrm{v}_{\mathrm{sw}}\right\rangle_{24}$ and $\left\langle\mathrm{n}_{\mathrm{sw}}\right\rangle_{24}$ is $\mathrm{R}_{\mathrm{corr}}=-0.567$. As there is a positive correlation between the radiation belt heating rate $\mathrm{dT} / \mathrm{dt}$ and $\mathrm{v}_{\mathrm{sw}}$, there is a negative correlation between $\mathrm{dT} / \mathrm{dt}$ and $\mathrm{n}_{\mathrm{sw}}$. In Figure 12 (top) the measured value $\Delta \mathrm{T}_{24}$ of the $24 \mathrm{~h}$ change in the temperature $\mathrm{T}$ of the outer electron radiation belt at geosynchronous orbit is plotted as a function of the $24 \mathrm{~h}$ average $\left\langle\mathrm{n}_{\mathrm{sw}}\right\rangle_{24}$ of the solar wind number density. The $\Delta T_{24}$ values were obtained from time interval 36-72 $\mathrm{h}$ after the onset of the 93 high-speed stream-driven storms: each data point represents $1 \mathrm{~h}$ of data plus $1 \mathrm{~h}$ of data $24 \mathrm{~h}$ earlier from one geosynchronous spacecraft. The linear correlation coefficient between $\Delta T_{24}$ and $\left\langle n_{s w}\right\rangle_{24}$ is $R_{\text {corr }}=-0.28$, which is at the 8 sigma level of correlation as compared with random for $\mathrm{N}_{\text {ind }}=\mathrm{N}_{\text {meas }} / 11=8651 / 11$ independent measurements, a definite statistical anticorrelation. A 300-point running average of $\Delta T_{24}$ is plotted in Figure 12 (top) as the yellow points and 100-point running averages for noononly data (red) and for midnight-only data (blue) are plotted; note that there is not much statistical difference between the values at noon and at midnight. A least squares linear regression fit (green line) to all of the data (black points) in Figure 12 (top) in the 36-72 $\mathrm{h}$ interval yields

$$
\Delta \mathrm{T}_{24}=-4.42\left\langle\mathrm{n}_{\mathrm{sw}}\right\rangle_{24}+49
$$

where $\Delta \mathrm{T}_{24}$ is in units of $\mathrm{keV}$ and $\mathrm{n}_{\mathrm{sw}}$ is in units of $\mathrm{cm}^{-3}$. The statistical error of this -4.42 slope is \pm 1.76 . A Gaussian linear fit (purple dashed line) in the 36-72 $\mathrm{h}$ interval yields the formula

$$
\Delta \mathrm{T}_{24}=-15.6\left\langle\mathrm{n}_{\mathrm{sw}}\right\rangle_{24}+94
$$

where again $\Delta \mathrm{T}_{24}$ is in units of $\mathrm{keV}$ and $\mathrm{n}_{\mathrm{sw}}$ is in units of $\mathrm{cm}^{-3}$. Expressing $\Delta \mathrm{T}_{24}$ as $\mathrm{dT} / \mathrm{dt}$ in expressions (28) and (29) and then taking the $\mathrm{n}_{\mathrm{sw}}$ derivatives, rates of change $\partial(\mathrm{dT} / \mathrm{dt}) / \partial \mathrm{n}_{\mathrm{sw}}$ of the time rate of change in temperature $T$ associated with the value of $n_{\mathrm{sw}}$ of

$$
\begin{gathered}
\partial(\mathrm{dT} / \mathrm{dt}) / \partial \mathrm{n}_{\mathrm{sw}}=-4.42 \mathrm{keV} \mathrm{d}^{-1} \mathrm{~cm}^{-3} \text { (linear) } \\
\partial(\mathrm{dT} / \mathrm{dt}) / \partial \mathrm{n}_{\mathrm{sw}}=-15.6 \mathrm{keV} \mathrm{d}^{-1} \mathrm{~cm}^{-3} \text { (Gaussian) }
\end{gathered}
$$

are obtained. Expressions (30) are interpreted as 4.42 and $15.6 \mathrm{keV} \mathrm{d}{ }^{-1}$ of increased heating for each $\mathrm{cm}^{-3}$ of $\mathrm{n}_{\mathrm{sw}}$ decrease during the heating interval. The linear regression value $-4.42 \mathrm{keV} \mathrm{d}^{-1} \mathrm{~cm}^{-3}$, which is acknowledged to be too low, is entered into Table 1. Linear regression fits are also made for the noon-only $\left(-4.1 \mathrm{keV} \mathrm{d}^{-1} \mathrm{~cm}^{-3}\right)$ and midnightonly $\left(-4.6 \mathrm{keV} \mathrm{d}^{-1} \mathrm{~cm}^{-3}\right)$ data and those values are also entered into Table 1; the statistical errors for these heating rates are both $\pm 4.2 \mathrm{keV} \mathrm{d}^{-1} \mathrm{~cm}^{-3}$.

[46] In Figure 12 (bottom) the $24 \mathrm{~h}$ change $\Delta \log _{10}(\mathrm{~T})_{24}$ in the logarithm of the temperature $\mathrm{T}$ of the outer electron radiation belt at geosynchronous orbit is plotted as a function of the mean value of $n_{s w}$ during that $24 \mathrm{~h}$. For data from $36 \mathrm{~h}$ to $72 \mathrm{~h}$ after storm onset, the linear correlation coefficient between $\Delta \log (\mathrm{T})_{24}$ and $\left\langle\mathrm{n}_{\mathrm{sw}}\right\rangle_{24}$ is $\mathrm{R}_{\text {corr }}=-0.18$, which is at the 5 sigma level of correlation for $8651 / 11$ independent measurements. A 300-point running average of $\Delta \log (\mathrm{T})_{24}$ is plotted as the yellow points in Figure 12 (bottom) and 100-point running averages for noon-only data (red) and midnight-only data (blue) are plotted; note again that there is not much statistical difference between the values at noon and at midnight. A least squares linear regression fit (green line) to all the data in Figure 12 (bottom) yields

$$
\Delta \log _{10}(\mathrm{~T})_{24}=-8.66 \times 10^{-3}\left\langle\mathrm{n}_{\mathrm{sw}}\right\rangle_{24}+0.13
$$

and a Gaussian linear fit (purple dashed line) yields

$$
\Delta \log _{10}(\mathrm{~T})_{24}=-4.77 \times 10^{-2}\left\langle\mathrm{n}_{\mathrm{sw}}\right\rangle_{24}+0.28
$$

where in expressions (31) and (32) $\mathrm{T}$ is in units of $\mathrm{keV}$ and $\mathrm{n}_{\mathrm{sw}}$ is in units of $\mathrm{cm}^{-3}$.

\section{Heating Rates and the Thee-Way Correlations of $\mathbf{v}_{\mathbf{s w}}, \mathbf{n}_{\mathrm{sw}}$, and $\mathrm{Kp}$}

[47] In section 5 it was seen that the rate of heating $\mathrm{dT} / \mathrm{dt}$ of the outer electron radiation belt at geosynchronous orbit is increased when the $\mathrm{Kp}$ index is higher. And in section 6 it was seen that the rate of heating is increased when the solar wind velocity $\mathrm{v}_{\mathrm{sw}}$ is higher and increased when the solar wind number density $\mathrm{n}_{\mathrm{sw}}$ is lower. Between the four quantities $\mathrm{dT} / \mathrm{dt}, \mathrm{Kp}, \mathrm{v}_{\mathrm{sw}}$, and $\mathrm{n}_{\mathrm{sw}}$ there are multiple correlations. For example, higher solar wind velocities $\mathrm{v}_{\mathrm{sw}}$ tend to drive higher levels of geomagnetic activity [Snyder et al., 1963; Crooker et al., 1977; Maezawa and Murayama, 1986], and in fast solar wind, there is a well-known anticorrelation between the density and velocity [Neugebauer and Snyder, 1966; Hundhausen et al., 1970; Richardson et al., 1996]. For the 36-72 h interval after storm onset, 

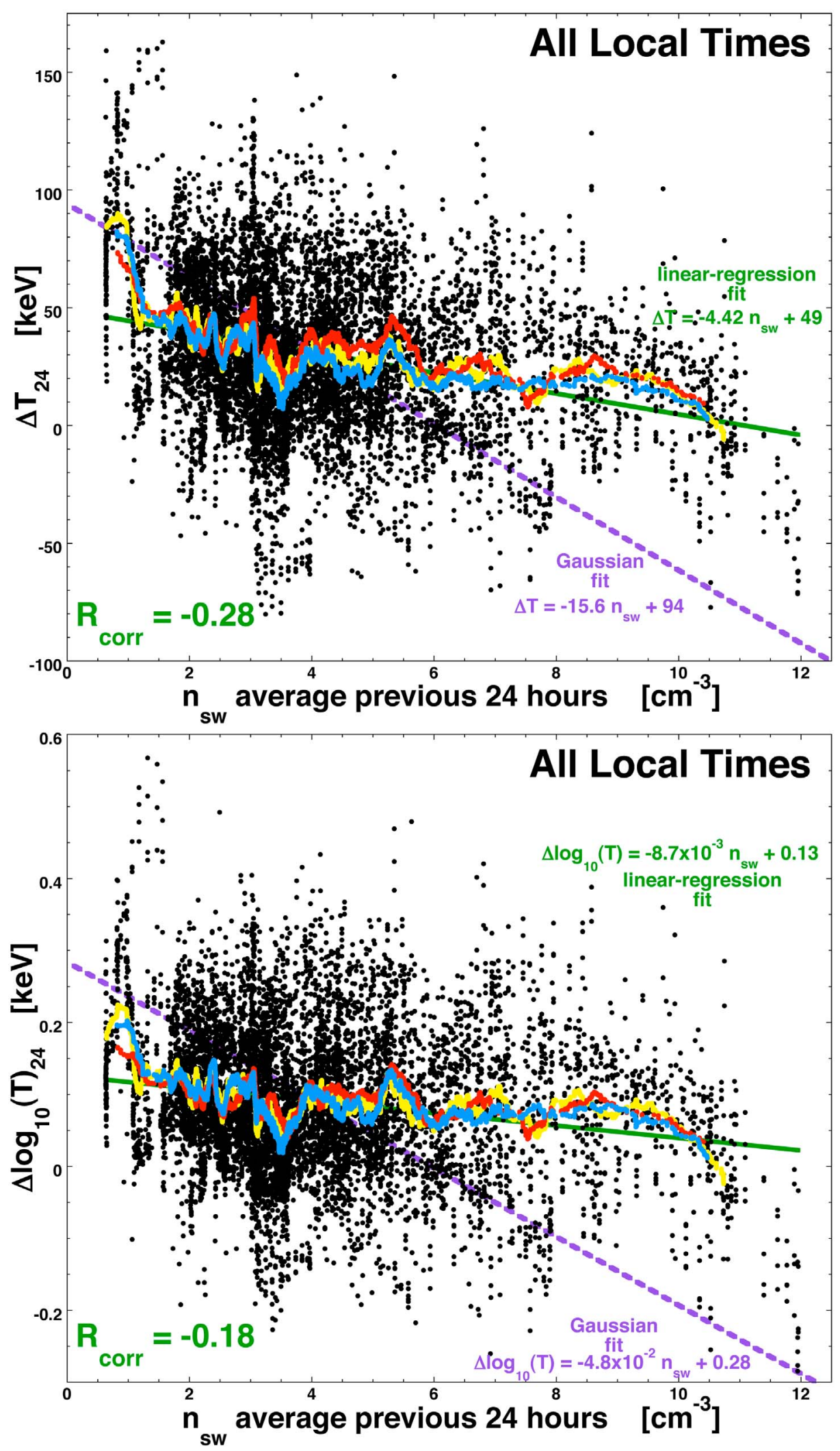

Figure 12. (top) For the 36-72 h intervals of the 93 high-speed stream-driven storms, the $24 \mathrm{~h}$ changes $\Delta \mathrm{T}_{24}$ in the temperature $\mathrm{T}$ of the outer electron radiation belt are plotted as functions of the $24 \mathrm{~h}$ average of the solar wind number density $\mathrm{n}_{\mathrm{sw}}$ for the same $24 \mathrm{~h}$. (bottom) The logarithm of the change is so plotted. Linear regression fits are plotted in green, Gaussian fits are plotted in purple, and 300-point running averages are plotted in yellow. Also plotted are 100-point running averages of the noon-only data (red) and the midnight only data (blue). 


\section{Correlations in the 36-72 Hour Interval}

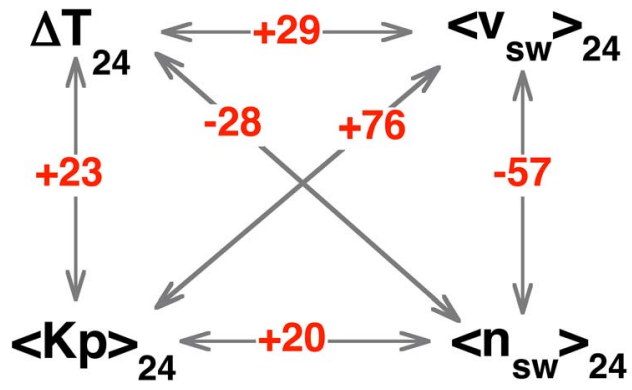

Figure 13. The four-way linear correlation coefficients $\mathrm{R}_{\text {corr }}$ (in percent) between the heating rate $\Delta \mathrm{T}_{24}$ and the $24 \mathrm{~h}$ averages of $\mathrm{Kp}, \mathrm{v}_{\mathrm{sw}}$, and $\mathrm{n}_{\mathrm{sw}}$ in the time interval from 36 to $72 \mathrm{~h}$ after storm onset for the 93 high-speed streamdriven storms.

these four-way linear correlations (in per cent) are displayed in Figure 13.

\subsection{Kp Versus $\mathbf{v}_{\text {sw }}$}

[48] In the 36-72 $\mathrm{h}$ interval after storm onset, the radiation belt daily heating rate $\Delta \mathrm{T}_{24}$ has a correlation with the level of geomagnetic activity as measured by $\mathrm{Kp}\left(\mathrm{R}_{\text {corr }}=+0.23\right)$ and the heating rate $\Delta T_{24}$ has a correlation with the solar wind velocity $\mathrm{v}_{\mathrm{sw}}\left(\mathrm{R}_{\text {corr }}=+0.29\right)$, and $\mathrm{Kp}$ and $\mathrm{v}_{\mathrm{sw}}$ are correlated with each other $\left(\mathrm{R}_{\text {corr }}=+0.76\right)$. One can ask the question of whether $\Delta T_{24}$ is correlated with $\mathrm{Kp}$ because $\mathrm{Kp}$ is acting as a proxy for $\mathrm{v}_{\mathrm{sw}}$, or the question of whether $\Delta \mathrm{T}_{24}$ is correlated with $\mathrm{v}_{\mathrm{sw}}$ because $\mathrm{v}_{\mathrm{sw}}$ is acting as a proxy for Kp; that is, we would like to find out if one of the correlations $\left(\Delta \mathrm{T}_{24}\right.$ versus $\mathrm{Kp}$ or $\Delta \mathrm{T}_{24}$ versus $\left.\mathrm{v}_{\mathrm{sw}}\right)$ is more fundamental. To provide information about the causation in the correlations of Kp and $\mathrm{v}_{\mathrm{sw}}$ with $\Delta \mathrm{T}_{24}$, the 36-72 h data set for the $93 \mathrm{high}-$ speed stream-driven storms will be used to produce correlation coefficients between $\left\langle\mathrm{v}_{\mathrm{sw}}\right\rangle_{24}$ and $\Delta \mathrm{T}_{24}$ with $\langle\mathrm{Kp}\rangle_{24}$ held fixed and to produce correlation coefficients between $\langle\mathrm{Kp}\rangle_{24}$ and $\Delta \mathrm{T}_{24}$ with $\left\langle\mathrm{v}_{\mathrm{sw}}\right\rangle_{24}$ held fixed. These correlation coefficients will appear in Table 2 .

[49] The data set that was utilized is $9220 \Delta \mathrm{T}_{24}$ values with simultaneous $\langle\mathrm{Kp}\rangle_{24}$ and $\left\langle\mathrm{v}_{\mathrm{sw}}\right\rangle_{24}$ values. To hold $\langle\mathrm{Kp}\rangle_{24}$ approximately fixed, the occurrence distribution of $9220\langle\mathrm{Kp}\rangle_{24}$ values is divided into 10 decims each containing 922 values. The mean value of $\langle\mathrm{Kp}\rangle_{24}$ in each decim is listed in the second column of Table 2 . For each decim of $\langle\mathrm{Kp}\rangle_{24}$ values, the linear correlation coefficient $\mathrm{R}_{\text {corr }}$ between $\left\langle\mathrm{v}_{\mathrm{sw}}\right\rangle_{24}$ and $\Delta \mathrm{T}_{24}$ is calculated (with $\langle\mathrm{Kp}\rangle_{24}$ fixed into a narrow range of values) and those $\mathrm{R}_{\text {corr }}$ values are listed in the third column of Table 2 . The mean value of the 10 correlation coefficients is +0.222 . There are 922 points in each decim of data; owing to mixing of the time-sequenced measurements into different bins it is difficult to estimate the number of independent measurements $\mathrm{N}_{\text {ind }}$ in the 922 measurements per bin. The reduction $\mathrm{N}_{\text {ind }}=\mathrm{N}_{\text {meas }} / 11$ owing to the 11-point persistence in the data is probably an overestimate to the persistence when the data set is broken into 10 portions. If $\mathrm{N}_{\text {ind }}=\mathrm{N}_{\text {meas }}=922$ is taken (which provides a lower limit to the magnitude of random correlations), the 2 sigma level of correlation is 0.066 . Correlation coefficients $\left|R_{\text {corr }}\right|<0.066$ are definitely consistent with no correlation (i.e., random). Except for decims 9 and 10 (which pertain to the highest values of $\langle K p\rangle_{24}$ ), the correlations between $\left\langle v_{\text {sw }}\right\rangle_{24}$ and $\Delta T_{24}$ are positive and significant. The mean value of the $10 \mathrm{decim}$ correlation coefficients is $+22.2 \%$, which is positive correlation at the 3.4 sigma level of confidence if $\mathrm{N}_{\text {ind }}=922$ is assumed.

[50] To hold $\left\langle\mathrm{v}_{\mathrm{sw}}\right\rangle_{24}$ approximately fixed, the occurrence distribution of $\Delta T_{24}\left\langle v_{\text {sw }}\right\rangle_{24}$ values is divided into 10 decims each containing 922 values. The mean value of $\left\langle v_{\text {sw }}\right\rangle_{24}$ in each decim is listed in the fourth column of Table 2 . For each decim of $\left\langle v_{\text {sw }}\right\rangle_{24}$ values, the linear correlation coefficient $\mathrm{R}_{\text {corr }}$ between $\langle\mathrm{Kp}\rangle_{24}$ and $\Delta \mathrm{T}_{24}$ is calculated (with $\left\langle\mathrm{v}_{\mathrm{sw}}\right\rangle_{24}$ fixed into a narrow range of values) and those $R_{\text {corr }}$ values are listed in the last column of Table 2. Again, there are 922 points in each decim of data, so if $\mathrm{N}_{\text {ind }}=922$ is taken the 2 sigma level of correlations is 0.066 . As can be seen in Table 2, 4 out of 10 of the decims of data show no significant correlation between $\langle\mathrm{Kp}\rangle_{24}$ and $\Delta \mathrm{T}_{24}$ and some of the definite correlations are positive and some are negative. The mean value of the 10 decim correlation coefficients is +0.075 , which is correlation at only the 2.3 sigma level of confidence assuming $\mathrm{N}_{\text {ind }}=922$, which is borderline consistent with random correlation (i.e., uncorrelated data).

[51] The correlations between $\mathrm{v}_{\mathrm{sw}}$ and $\Delta \mathrm{T}_{24}$ with $\mathrm{Kp}$ held fixed are significant, whereas the correlations between Kp and $\Delta \mathrm{T}_{24}$ with $\mathrm{v}_{\mathrm{sw}}$ held fixed are much less significant. For the correlations in the total data set (not divided into decims) the interpretation is the following: The correlation between of the heating rate $\Delta \mathrm{T}_{24}$ with $\mathrm{v}_{\mathrm{sw}}$ (Figure 11) is more fundamental, and the correlation between the heating rate $\Delta \mathrm{T}_{24}$ and $\mathrm{Kp}$ (Figure 10) is owed to Kp acting as a proxy for $\mathrm{v}_{\mathrm{sw}}$. Physically, the interpretation seems to be that the solar wind speed has some role in the amount of heating of the outer electron radiation belt during high-speed stream-driven

Table 2. Correlations Between $\Delta \mathrm{T}_{24}$ and $\left\langle\mathrm{v}_{\mathrm{sw}}\right\rangle_{24}$ With $\langle\mathrm{Kp}\rangle_{24}$ Held Approximately Fixed and Correlations Between $\Delta \mathrm{T}_{24}$ and $\langle\mathrm{Kp}\rangle_{24}$ With $\left\langle\mathrm{v}_{\mathrm{sw}}\right\rangle_{24}$ Held Approximately Fixed ${ }^{\mathrm{a}}$

\begin{tabular}{lccccc}
\hline & $\begin{array}{c}\text { Holding }\langle\mathrm{Kp}\rangle_{24} \text { "Fixed" } \\
\text { in the Data }\end{array}$ & & \multicolumn{2}{c}{$\begin{array}{c}\text { Holding }\left\langle\mathrm{v}_{\text {sw }}\right\rangle_{24} \text { "Fixed" } \\
\text { in the Data }\end{array}$} \\
\cline { 2 - 3 } \cline { 5 - 6 } $\begin{array}{c}\text { Decim } \\
\text { Number }\end{array}$ & $\begin{array}{c}\text { Mean Value } \\
\text { of }\langle\mathrm{Kp}\rangle_{24}\end{array}$ & $\begin{array}{c}\text { Correlation } \\
\text { of } \Delta \mathrm{T}_{24} \\
\text { and }\left\langle\mathrm{v}_{\mathrm{sw}}\right\rangle_{24}\end{array}$ & & $\begin{array}{c}\text { Mean Value } \\
\text { of }\left\langle\mathrm{v}_{\mathrm{sw}}\right\rangle_{24} \\
\left.(\mathrm{~km} \mathrm{~s})^{-1}\right)\end{array}$ & $\begin{array}{c}\text { Correlation } \\
\text { of } \Delta \mathrm{T}_{24} \\
\text { and }\langle\mathrm{Kp}\rangle_{24}\end{array}$ \\
\hline 1 & 2.05 & +0.168 & & 453 & +0.434 \\
2 & 2.52 & +0.147 & & 486 & +0.057 \\
3 & 2.77 & +0.191 & & 518 & +0.118 \\
4 & 3.04 & +0.439 & & 545 & -0.110 \\
5 & 3.13 & +0.522 & & 566 & -0.119 \\
6 & 3.54 & +0.171 & & 597 & -0.019 \\
7 & 3.82 & +0.336 & & 629 & +0.230 \\
8 & 4.14 & +0.186 & & 654 & +0.225 \\
9 & 4.56 & +0.020 & 684 & -0.006 \\
10 & 5.20 & +0.044 & 733 & -0.061 \\
Average & & +0.222 & & +0.075 \\
\hline
\end{tabular}

${ }^{\mathrm{a}}$ In the second and third columns correlations between $\Delta \mathrm{T}_{24}$ and $\left\langle\mathrm{v}_{\mathrm{sw}}\right\rangle_{24}$ with $\langle\mathrm{Kp}\rangle_{24}$ held approximately fixed; in the fourth and fifth columns correlations between $\Delta \mathrm{T}_{24}$ and $\langle\mathrm{Kp}\rangle_{24}$ with $\left\langle\mathrm{v}_{\mathrm{sw}}\right\rangle_{24}$ held approximately fixed. The data pertains to $36-72 \mathrm{~h}$ after onset for the 93 high-speed stream-driven storms. Each decim contains 922 points. 
Table 3. Correlations Between $\Delta \mathrm{T}_{24}$ and $\left\langle\mathrm{n}_{\mathrm{sw}}\right\rangle_{24}$ With $\langle\mathrm{Kp}\rangle_{24}$ Held Approximately Fixed and Correlations Between $\Delta \mathrm{T}_{24}$ and $\langle\mathrm{Kp}\rangle_{24}$ With $\left\langle\mathrm{n}_{\text {sw }}\right\rangle_{24}$ Held Approximately Fixed ${ }^{\mathrm{a}}$

\begin{tabular}{lccccc}
\hline & $\begin{array}{c}\text { Holding }\langle\mathrm{Kp}\rangle_{24} \text { "Fixed" } \\
\text { in the Data }\end{array}$ & & \multicolumn{2}{c}{$\begin{array}{c}\text { Holding }\left\langle\mathrm{n}_{\text {sw }}\right\rangle_{24} \text { "Fixed" } \\
\text { in the Data }\end{array}$} \\
\cline { 2 - 3 } \cline { 5 - 6 } $\begin{array}{c}\text { Decim } \\
\text { Number }\end{array}$ & $\begin{array}{c}\text { Mean Value } \\
\text { of }\langle\mathrm{Kp}\rangle_{24}\end{array}$ & $\begin{array}{c}\text { Correlation } \\
\text { of } \Delta \mathrm{T}_{24} \\
\text { and }\left\langle\mathrm{n}_{\mathrm{sw}}\right\rangle_{24}\end{array}$ & & $\begin{array}{c}\text { Mean Value } \\
\text { of }\left\langle\mathrm{n}_{\text {sw }}\right\rangle_{24} \\
\left(\mathrm{~cm}^{-3}\right)\end{array}$ & $\begin{array}{c}\text { Correlation } \\
\text { of } \Delta \mathrm{T}_{24} \\
\text { and }\langle\mathrm{Kp}\rangle_{24}\end{array}$ \\
\hline 1 & 2.04 & -0.161 & & 1.42 & +0.398 \\
2 & 2.51 & -0.117 & & 2.21 & -0.158 \\
3 & 2.76 & -0.293 & & 2.65 & +0.470 \\
4 & 3.01 & -0.495 & & 3.08 & +0.416 \\
5 & 3.29 & -0.595 & & 3.39 & +0.0999 \\
6 & 3.52 & -0.350 & & 3.76 & +0.404 \\
7 & 3.81 & -0.404 & & 4.28 & +0.431 \\
8 & 4.12 & -0.434 & & 4.92 & +0.169 \\
9 & 4.53 & -0.129 & 6.04 & +0.225 \\
10 & 5.20 & -0.227 & 8.76 & +0.325 \\
Average & & -0.321 & & +0.278 \\
\hline
\end{tabular}

${ }^{\mathrm{a}}$ In the second and third columns correlations between $\Delta \mathrm{T}_{24}$ and $\left\langle\mathrm{n}_{\mathrm{sw}}\right\rangle_{24}$ with $\langle\mathrm{Kp}\rangle_{24}$ held approximately fixed; in the fourth and fifth columns correlations between $\Delta \mathrm{T}_{24}$ and $\langle\mathrm{Kp}\rangle_{24}$ with $\left\langle\mathrm{n}_{\mathrm{sw}}\right\rangle_{24}$ held approximately fixed. The data pertains to $36-72 \mathrm{~h}$ after onset for the $93 \mathrm{high}$-speed stream-driven storms. Each decim contains 865 points.

storms, but the level of geomagnetic activity (or of convection in the magnetosphere) does not have as large a role.

\section{2. $\quad K p$ Versus $\mathbf{n}_{\text {sw }}$}

[52] The analysis of section 7. A is now repeated to examine the correlations of the heating rate with $\mathrm{Kp}$ and with $\mathrm{n}_{\mathrm{sw}}$. As seen in Figures 10, 12, and 13, in the 36-72 $\mathrm{h}$ interval after storm onset the radiation belt daily heating rate $\Delta \mathrm{T}_{24}$ has a correlation with the level of geomagnetic activity as measured by $\langle\mathrm{Kp}\rangle_{24}$ of $\mathrm{R}_{\mathrm{corr}}=+0.23$, the heating rate $\Delta \mathrm{T}_{24}$ has a correlation with the solar wind number density $\left\langle\mathrm{n}_{\mathrm{sw}}\right\rangle_{24}$ of $\mathrm{R}_{\text {corr }}$ $=-0.28$, and $\langle\mathrm{Kp}\rangle_{24}$ and $\left\langle\mathrm{n}_{\mathrm{sw}}\right\rangle_{24}$ are correlated with each other with $\mathrm{R}_{\text {corr }}=+0.20$. We would like to find out if one of the correlations $\left(\Delta \mathrm{T}_{24}\right.$ versus $\mathrm{Kp}$ or $\Delta \mathrm{T}_{24}$ versus $\left.\mathrm{n}_{\mathrm{sw}}\right)$ is more fundamental.

[53] The data set that was utilized is 8650 values of $\Delta T_{24}$ with simultaneous $\langle\mathrm{Kp}\rangle_{24}$ and $\left\langle\mathrm{n}_{\mathrm{sw}}\right\rangle_{24}$ values. To hold $\langle\mathrm{Kp}\rangle_{24}$ approximately fixed, the occurrence distribution of $\langle\mathrm{Kp}\rangle_{24}$ values is divided into 10 decims each containing 865 values. The mean value of $\langle\mathrm{Kp}\rangle_{24}$ in each decim is listed in Table 3, as is the linear correlation coefficient $R_{\text {corr }}$ between $\left\langle n_{\text {sw }}\right\rangle_{24}$ and $\Delta \mathrm{T}_{24}$ for each decim of $\mathrm{Kp}$ values. If $\mathrm{N}_{\text {ind }}=865$ then correlation coefficients $\left|\mathrm{R}_{\text {corr }}\right|<0.068$ are consistent with no correlation (i.e., random): each of the 10 correlations between $\left\langle v_{\mathrm{sw}}\right\rangle_{24}$ and $\Delta \mathrm{T}_{24}$ are negative and significant. The mean value of the 10 decim correlation coefficients is -0.321 , which is negative correlation at the 9 sigma level of confidence.

[54] To hold $\left\langle\mathrm{n}_{\mathrm{sw}}\right\rangle_{24}$ approximately fixed, the occurrence distribution of $\left\langle\mathrm{n}_{\mathrm{sw}}\right\rangle_{24}$ values is divided into 10 decims each containing 865 values. The mean value of $\left\langle n_{\mathrm{sw}}\right\rangle_{24}$ in each decim is listed in Table 3, as is the linear correlation coefficient $R_{\text {corr }}$ between $\langle K p\rangle_{24}$ and $\Delta T_{24}$. Correlation coefficients $\left|R_{\text {corr }}\right|<0.068$ are consistent with no correlation: in the last column of Table 3 all 10 of the decims show definite correlations, with 9 positive and 1 negative. The mean value of the 10 decim correlation coefficients is +0.278 , which is positive correlation at the 8 sigma level of confidence for Nind $=865$.

[55] The correlations between $\Delta T_{24}$ and both of the quantities $\left\langle\mathrm{n}_{\mathrm{sw}}\right\rangle_{24}$ and $\langle\mathrm{Kp}\rangle_{24}$ improve when the other quantity is held fixed, perhaps because of the positive correlation between nsw and $\langle\mathrm{Kp}\rangle_{24}$ and the opposite correlations of $\Delta \mathrm{T}_{24}$ with $\left\langle\mathrm{n}_{\mathrm{sw}}\right\rangle_{24}$ and $\Delta \mathrm{T}_{24}$ with $\langle\mathrm{Kp}\rangle_{24}$. When the third variable is restricted, both of the correlation pairs become slightly larger in magnitude.

\section{3. $\mathbf{n}_{\text {sw }}$ Versus $\mathbf{v}_{\text {sw }}$}

[56] The analysis of is now repeated to examine the correlations of the heating rate with $n_{s w}$ and with $\mathrm{v}_{\mathrm{sw}}$. As seen in Figures 10, 12, and 13, in the 36-72 $\mathrm{h}$ interval after storm onset the radiation belt daily heating rate $\Delta T_{24}$ has a correlation with the solar wind number density $\left\langle\mathrm{n}_{\mathrm{sw}}\right\rangle_{24}$ of $\mathrm{R}_{\text {corr }}=$ -0.28 , the heating rate $\Delta T_{24}$ has a correlation with the solar wind velocity $\left\langle\mathrm{v}_{\mathrm{sw}}\right\rangle_{24}$ of $\mathrm{R}_{\mathrm{corr}}=+0.29$, and $\left\langle\mathrm{n}_{\mathrm{sw}}\right\rangle_{24}$ and $\left\langle\mathrm{v}_{\mathrm{sw}}\right\rangle_{24}$ are correlated with each other with $\mathrm{R}_{\text {corr }}=-0.57$. We would like to find out if one of the correlations $\left(\Delta \mathrm{T}_{24}\right.$ versus $\mathrm{n}_{\mathrm{sw}}$ or $\Delta \mathrm{T}_{24}$ versus $\left.\mathrm{v}_{\mathrm{sw}}\right)$ is more fundamental.

[57] The data set that was utilized is $8650 \Delta T_{24}$ values with simultaneous $\left\langle\mathrm{n}_{\mathrm{sw}}\right\rangle_{24}$ and $\left\langle\mathrm{v}_{\mathrm{sw}}\right\rangle_{24}$ values. To hold $\left\langle\mathrm{n}_{\mathrm{sw}}\right\rangle_{24}$ approximately fixed, the occurrence distribution of $\left\langle n_{\mathrm{sw}}\right\rangle_{24}$ values is divided into 10 decims each containing 865 values. The mean value of $\left\langle\mathrm{n}_{\mathrm{sw}}\right\rangle_{24}$ in each decim is listed in Table 4, as is the linear correlation coefficient $R_{\text {corr }}$ between $\left\langle v_{\text {sw }}\right\rangle_{24}$ and $\Delta \mathrm{T}_{24}$ for each decim of $\mathrm{n}_{\mathrm{sw}}$ values. If $\mathrm{N}_{\text {ind }}=865$ then correlation coefficients $\left|R_{\text {corr }}\right|<0.068$ are consistent with no correlation: 8 of the 10 correlations between $\left\langle v_{\mathrm{sw}}\right\rangle_{24}$ and $\Delta \mathrm{T}_{24}$ are significant, with 7 positive and 1 negative. The mean value of the 10 decim correlation coefficients is +0.172 , which is positive correlation at the 5 sigma level of confidence.

[58] To hold $\left\langle v_{\mathrm{sw}}\right\rangle_{24}$ approximately fixed, the occurrence distribution of $\left\langle v_{\mathrm{sw}}\right\rangle_{24}$ values is divided into 10 decims each containing 865 values. The mean value of $\left\langle\mathrm{n}_{\mathrm{sw}}\right\rangle_{24}$ in each decim is listed in Table 4, as is the linear correlation coefficient

Table 4. Correlations Between $\Delta \mathrm{T}_{24}$ and $\left\langle\mathrm{v}_{\mathrm{sw}}\right\rangle_{24}$ With $\left\langle\mathrm{n}_{\mathrm{sw}}\right\rangle_{24}$ Held Approximately Fixed and Correlations Between $\Delta \mathrm{T}_{24}$ and $\left\langle\mathrm{n}_{\mathrm{sw}}\right\rangle_{24}$ With $\left\langle\mathrm{v}_{\mathrm{sw}}\right\rangle_{24}$ Held Approximately Fixed ${ }^{\mathrm{a}}$

\begin{tabular}{lccccc}
\hline & $\begin{array}{c}\text { Holding }\left\langle\mathrm{n}_{\text {sw }}\right\rangle_{24} \text { "Fixed" } \\
\text { in the Data }\end{array}$ & & $\begin{array}{c}\text { Holding }\left\langle\mathrm{v}_{\mathrm{sw}}\right\rangle_{24} \text { "Fixed" } \\
\text { in the Data }\end{array}$ \\
\cline { 2 - 3 } \cline { 5 - 6 } $\begin{array}{c}\text { Decim } \\
\text { Number }\end{array}$ & $\begin{array}{c}\text { Mean Value } \\
\text { of }\left\langle\mathrm{n}_{\text {sw }}\right\rangle_{24} \\
\left(\mathrm{~cm}^{-3}\right)\end{array}$ & $\begin{array}{c}\text { Correlation } \\
\text { of } \Delta \mathrm{T}_{24} \\
\text { and }\left\langle\mathrm{v}_{\mathrm{sw}}\right\rangle_{24}\end{array}$ & & $\begin{array}{c}\text { Mean Value } \\
\text { of }\left\langle\mathrm{v}_{\mathrm{sw}}\right\rangle_{24} \\
\left(\mathrm{~km} \mathrm{~s}^{-1}\right)\end{array}$ & $\begin{array}{c}\text { Correlation } \\
\text { of } \Delta \mathrm{T}_{24} \\
\text { and }\left\langle\mathrm{n}_{\text {sw }}\right\rangle_{24}\end{array}$ \\
\hline 1 & 1.42 & +0.190 & & 453 & -0.501 \\
2 & 2.21 & -0.0565 & & 485 & -0.137 \\
3 & 2.65 & +0.198 & & 518 & -0.146 \\
4 & 3.08 & +0.266 & & 544 & -0.249 \\
5 & 3.39 & +0.0671 & & 564 & -0.458 \\
6 & 3.76 & +0.318 & & 593 & -0.302 \\
7 & 4.28 & +0.377 & & 626 & -0.229 \\
8 & 4.92 & +0.352 & & 651 & -0.102 \\
9 & 6.04 & +0.173 & & 680 & -0.105 \\
10 & 8.76 & -0.164 & 732 & -0.165 \\
Average & & +0.172 & & -0.194 \\
\hline
\end{tabular}

${ }^{\mathrm{a}}$ In the second and third columns correlations between $\Delta \mathrm{T}_{24}$ and $\left\langle\mathrm{v}_{\mathrm{sw}}\right\rangle_{24}$ with $\left\langle\mathrm{n}_{\mathrm{sw}}\right\rangle_{24}$ held approximately fixed; in the fourth and fifth columns correlations between $\Delta T_{24}$ and $\left\langle n_{\text {sw }}\right\rangle_{24}$ with $\left\langle v_{\text {sw }}\right\rangle_{24}$ held approximately fixed. The data pertains to $36-72 \mathrm{~h}$ after onset for the $93 \mathrm{high}$-speed stream-driven storms. Each decim contains 865 points. 
$\mathrm{R}_{\text {corr }}$ between $\left\langle\mathrm{n}_{\mathrm{sw}}\right\rangle_{24}$ and $\Delta \mathrm{T}_{24}$. If $\mathrm{N}_{\text {ind }}=865$ then correlation coefficients $\left|R_{\text {corr }}\right|<0.068$ are consistent with no correlation: all 10 of the decims of the last column of Table 4 show definite negative correlations. The mean value of the 10 decim correlation coefficients is -0.194 , which is positive correlation at only the 6 sigma level of confidence.

[59] When one of the variables $\left\langle\mathrm{n}_{\mathrm{sw}}\right\rangle_{24}$ or $\left\langle\mathrm{v}_{\mathrm{sw}}\right\rangle_{24}$ is held fixed, the correlation of the other variable with $\Delta T_{24}$ is reduced. Since $\left\langle\mathrm{n}_{\mathrm{sw}}\right\rangle_{24}$ and $\left\langle\mathrm{v}_{\mathrm{sw}}\right\rangle_{24}$ are strongly correlated, holding one of the two variables fixed reduces the variance of the other variable, hence it reduces the correlation of that variable with $\Delta T_{24}$. As can be seen in Table 4, correlations between $\left\langle n_{\mathrm{sw}}\right\rangle_{24}$ and $\Delta T_{24}$ are slightly more robust than correlations between $\left\langle n_{\mathrm{sw}}\right\rangle_{24}$ and $\Delta \mathrm{T}_{24}$, suggesting that the solar wind number density $\mathrm{n}_{\mathrm{sw}}$ may be more important, or at least as important, as the solar wind velocity $\mathrm{v}_{\mathrm{sw}}$ is for controlling the heating rate $\mathrm{dT} / \mathrm{dt}$ of the outer electron radiation belt at geosynchronous orbit.

\section{Heating Rates and Magnetospheric Magnetic Field Fluctuations}

[60] High fluxes of relativistic electrons in the outer electron radiation belt are associated with high levels of geomagnetic fluctuations [e.g., Rostoker et al., 1998; Mathie and Mann, 2000; Elkington et al., 2003; Mann et al., 2004]. MHD frequency fluctuations in the magnetic field are of interest for their ability to drive the radial diffusion of energetic electrons in the magnetosphere [Falthammar, 1965; Perry et al., 2005; Shprits et al., 2008a], for their drift-resonance interaction with relativistic electrons [Elkington et al., 1999; Degeling and Rankin, 2008], and for their ability to magnetically pump energetic electrons [Borovsky, 1986; Liu et al., 1999]. In this section GOES magnetic field measurements are used to calculate 1 min changes in the magnetic field at geosynchronous orbit during high-speed stream-driven storms. The quantity investigated is the magnitude $\delta \mathrm{B}$ of the 1 min change in the magnetic field vector $\delta \mathrm{B}$, where $\delta \mathrm{B}(\mathrm{t})=\mathrm{B}(\mathrm{t}+1$ min $)-$ $\mathrm{B}(\mathrm{t})$ is the 1 min change in the magnetic field vector $\mathrm{B}$ and where $\delta \mathrm{B}=|\delta \mathrm{B}|=\left(\delta \mathrm{B}_{\mathrm{x}}^{2}+\delta \mathrm{B}_{\mathrm{y}}^{2}+\delta \mathrm{B}_{\mathrm{z}}^{2}\right)^{1 / 2}$ is the magnitude of the change. The normalized quantity $\delta \mathrm{B} / \mathrm{B}$ is examined, where the denominator $\mathrm{B}$ is the magnetic field strength. No attention will be paid to the polarization of the field changes, nor to whether the changes are poloidal, toroidal, or compressive [e.g., Saito, 1969; McPherron et al., 1972; Orr, 1973]. Also, no attention will be paid to the local time dependence of the fluctuations.

[61] Note that appropriate GOES measurements are only available for 63 of the 93 high-speed stream-driven storms.

[62] In Figure 14 (bottom) the superposed average of the normalized amplitude $\delta \mathrm{B} / \mathrm{B}$ of the magnetic field fluctuations at geosynchronous orbit during the 63 high-speed stream-driven storms is plotted as a function of the time from storm onset. In Figure 14 (top) the superposed average of the $\mathrm{Kp}$ index for the full 93 storms is plotted, with the storm epoch indicated. As can be seen by comparing the two panels, the normalized amplitude $\delta \mathrm{B} / \mathrm{B}$ at geosynchronous orbit is weak before the storm, increases sharply at storm onset, and decays with time slowly during the storm. The temporal profile of the superposed average of $\delta \mathrm{B} / \mathrm{B}$ resembles the profile of the superposed average of Kp.
[63] For the values of the $24 \mathrm{~h}$ change in the temperature $\Delta \mathrm{T}_{24}$ measured with the SOPA detectors during the 63 storms, $\langle\delta \mathrm{B} / \mathrm{B}\rangle_{24}$ values are created by averaging $\delta \mathrm{B} / \mathrm{B}$ over the same $24 \mathrm{~h}$. Note that during the $24 \mathrm{~h}$ interval of the averaging, each GOES spacecraft travels though $24 \mathrm{~h}$ of local time while measuring $\delta \mathrm{B} / \mathrm{B}$ : thus $\langle\delta \mathrm{B} / \mathrm{B}\rangle_{24}$ is a combined time average and local time average. During highspeed stream-driven storms, $\delta \mathrm{B} / \mathrm{B}$ at geosynchronous orbit is largest in the midnight and dusk sectors and weakest in the noon and dawn sectors [Borovsky and Denton, 2010a], with the difference between the amplitudes at midnight and the amplitudes at noon being less than a factor of 2 .

[64] In Figure 15 the measured values $\Delta \mathrm{T}_{24}$ of the $24 \mathrm{~h}$ change in the temperature $\mathrm{T}$ of the outer electron radiation belt at geosynchronous orbit are plotted (black points) as a function of the $24 \mathrm{~h}$ average $\langle\delta \mathrm{B} / \mathrm{B}\rangle_{24}$ of the geosynchronous orbit normalized magnetic field fluctuations $\delta \mathrm{B} / \mathrm{B}$. The $\Delta \mathrm{T}_{24}$ values were obtained from the time intervals $36-72 \mathrm{~h}$ after the onset of the 63 high-speed stream-driven storms. For each $\Delta \mathrm{T}_{24}$ value that had GOES-8 -12 magnetic field data, $\delta \mathrm{B} / \mathrm{B}$ was averaged over the $24 \mathrm{~h}$ to produce a $\langle\delta \mathrm{B} / \mathrm{B}\rangle_{24}$ value. Combining the 7 SOPA satellites with the 5 GOES satellites resulted in 11948 values of $\Delta T_{24}$ that had corresponding $\langle\delta \mathrm{B} / \mathrm{B}\rangle_{24}$ values. As denoted in Figure 15, the linear correlation coefficient between $\Delta \mathrm{T}_{24}$ and $\langle\delta \mathrm{B} / \mathrm{B}\rangle_{24}$ is $\mathrm{R}_{\text {corr }}=$ -0.016 , which is much less than the 1 sigma level of correlation if $\mathrm{N}_{\text {ind }}=\mathrm{N}_{\text {meas }} / 11=11948 / 11$ is taken, which is consistent with random. Hence, there is no statistical correlation between the level of magnetospheric fluctuations $\langle\delta \mathrm{B} / \mathrm{B}\rangle_{24}$ and the daily change in the radiation belt temperature $\Delta T_{24}$ in the 36-72 h interval after storm onset. (Note that the measured amplitudes of $\delta \mathrm{B} / \mathrm{B}$ do not discern compressive from shear fluctuations.) A 300-point running average of $\Delta \mathrm{T}_{24}$ is plotted as the yellow points in Figure 15. A 100-point running averages for noon-only data (red) and for midnight-only data (blue) are also plotted; note that there is not much statistical difference between the values at noon and at midnight. As can be seen, the running average shows no underlying trend between $\Delta T_{24}$ and $\langle\delta B / B\rangle_{24}$. This coefficient $R_{\text {corr }}=-0.016$ is entered into the first row Table 5.

[65] Also noted in the first row of Table 5 is the linear correlation coefficient between $\langle\delta \mathrm{B} / \mathrm{B}\rangle_{24}$ and $\left\langle\mathrm{v}_{\mathrm{sw}}\right\rangle_{24}$ in the 36-72 $\mathrm{h}$ interval after storm onset for the 63 high-speed stream-driven storms: that coefficient is $\mathrm{R}_{\text {corr }}=+0.403$. The radiation belt heating rate $\mathrm{dT} / \mathrm{dt}$ is positively correlated with $\mathrm{v}_{\mathrm{sw}}$ (e.g., Figure 11), and $\mathrm{v}_{\mathrm{sw}}$ is positively correlated with $\delta \mathrm{B} / \mathrm{B}$ (e.g., Table 5), yet the heating rate $\mathrm{dT} / \mathrm{dt}$ is uncorrelated with $\delta \mathrm{B} / \mathrm{B}$ (e.g., Figure 15). It could be that $\Delta \mathrm{T}_{24}$ has an underlying negative correlation with $\langle\delta \mathrm{B} / \mathrm{B}\rangle_{24}$ and an underlying positive correlation with $\left\langle\mathrm{v}_{\mathrm{sw}}\right\rangle_{24}$ and the positive correlation between $\langle\delta \mathrm{B} / \mathrm{B}\rangle_{24}$ and $\left\langle\mathrm{v}_{\mathrm{sw}}\right\rangle_{24}$ reduces the correlation between $\Delta \mathrm{T}_{24}$ and $\langle\delta \mathrm{B} / \mathrm{B}\rangle_{24}$. To test this idea, the correlation coefficients $\mathrm{R}_{\text {corr }}$ between $\Delta \mathrm{T}_{24}$ and $\langle\delta \mathrm{B} / \mathrm{B}\rangle_{24}$ with $\left\langle v_{\mathrm{sw}}\right\rangle_{24}$ held approximately fixed are calculated and those coefficients are collected into Table 6 . To hold $\left\langle v_{\text {sw }}\right\rangle_{24}$ approximately constant, $\left\langle\mathrm{v}_{\mathrm{sw}}\right\rangle_{24}$ is divided into 10 decims, each with 1158 points. For 1158 points, the 2 sigma level of correlation for $\mathrm{N}_{\text {ind }}=1158$ is $2 / \mathrm{N}_{\text {ind }}^{1 / 2}$ is 0.059 . As can be seen in Table 6, when $\left\langle v_{\mathrm{sw}}\right\rangle_{24}$ is held fixed there are definite underlying anticorrelations between $\Delta \mathrm{T}_{24}$ and $\langle\delta \mathrm{B} / \mathrm{B}\rangle_{24}$ with all of the linear correlation coefficients above 0.059 in magnitude, and with the average of the 10 coefficients being 


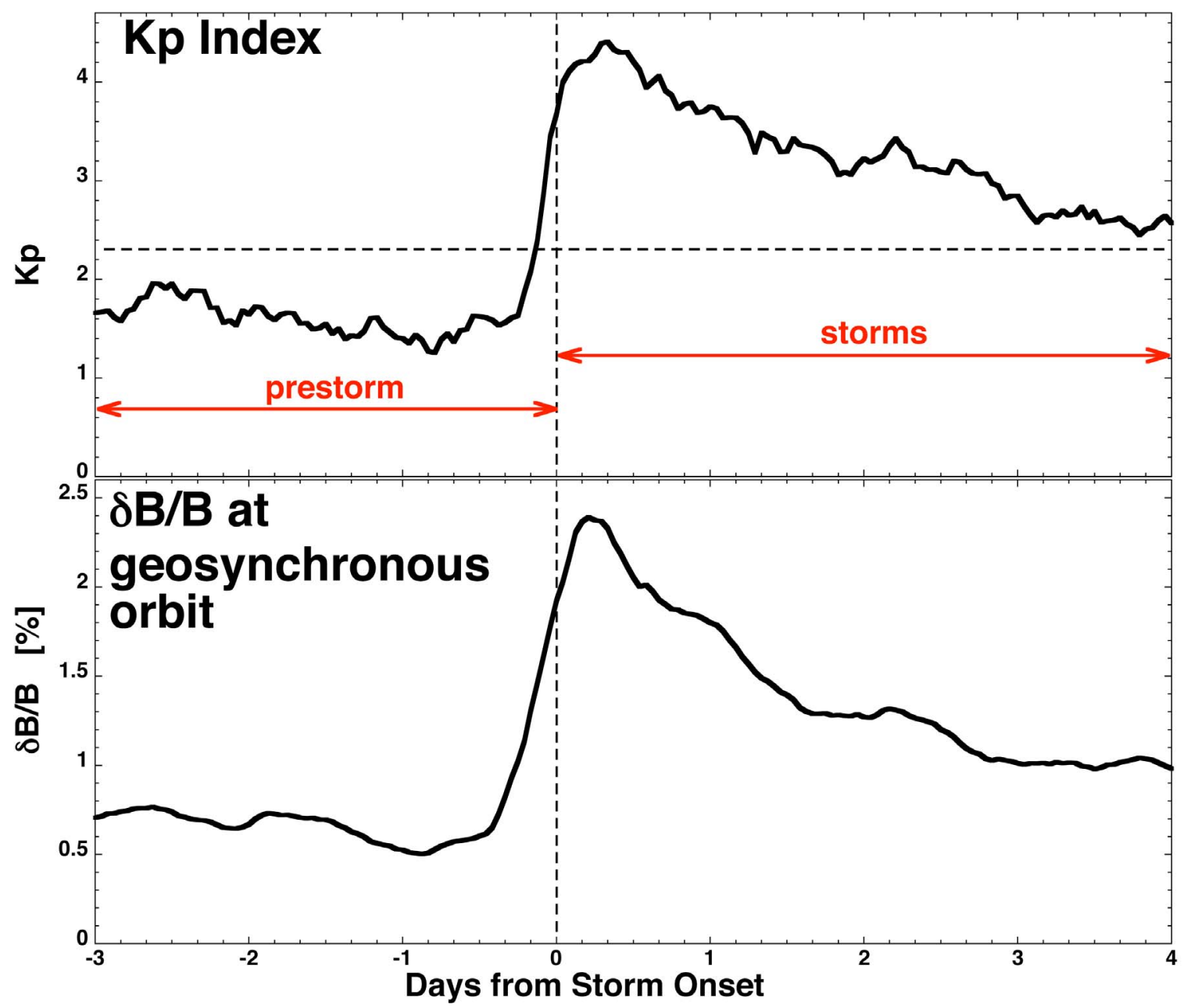

Figure 14. (top) For the 93 high-speed stream-driven storms, the superposed average of the Kp index is plotted. (bottom) For 63 of the 93 storms, the superposed average of the normalized amplitude of magnetic field fluctuations $\delta \mathrm{B} / \mathrm{B}$ at geosynchronous orbit is plotted. The plot is a $12 \mathrm{~h}$ running average.

-0.187 which is correlation at the 6 sigma level. Hence, there is a tendency for the heating rate $\mathrm{dT} / \mathrm{dt}$ of the outer electron radiation belt at geosynchronous orbit to be anticorrelated with the amplitude of magnetic field fluctuations $\delta \mathrm{B} / \mathrm{B}$ at geosynchronous orbit, but that anticorrelation is masked by the positive correlation between the heating rate $\mathrm{dT} / \mathrm{dt}$ and the solar wind speed $\mathrm{v}_{\mathrm{sw}}$.

\section{Heating Rates and Solar Wind Fluctuations}

[66] High fluxes of relativistic electrons in the outer electron radiation belt are associated with high levels of geomagnetic fluctuations in the magnetosphere [Rostoker et al., 1998; Mathie and Mann, 2000; Elkington et al., 2003; Mann et al., 2004]. The level of fluctuations in the magnetosphere is expected to be related to the level of fluctuations in the solar wind [Sibeck et al., 1989; Engebretson et al., 1994].

[67] In Figure 16 the variability of the solar wind velocity, number density, and magnetic field are overviewed for the 93 high-speed stream-driven storms. In Figure 16a the superposed average of the $\mathrm{Kp}$ index is plotted as a function of time with the era where the high-speed stream-driven storms occur indicated. In Figure 16b the superposed average of the hourly standard deviation of the measured solar wind speed is plotted. As can be seen, in the slow solar wind before storm onset the standard deviation is low $\left(\sim 4 \mathrm{~km} \mathrm{~s}^{-1}\right)$ and in the fast wind after storm onset the standard deviation is higher $\left(\sim 11 \mathrm{~km} \mathrm{~s}^{-1}\right)$ [see also Borovsky and Denton, 2010b]. In Figure 16c the hourly standard deviation of the azimuth $(\varphi)$ and elevation $(\theta)$ angle of the solar wind velocity vector are plotted. In the slow wind before storm onset the standard deviations of $\varphi$ and $\theta$ are both about $1^{\circ}$ and in the fast wind after storm onset the standard deviations of both are about $1.5^{\circ}$. In Figure $16 \mathrm{~d}$ the superposed average of the hourly standard deviation $\delta \mathrm{n}$ of the solar wind number density $\mathrm{n}$ is plotted. The standard deviation of the number density is highest near storm onset (in the CIR where the number density is highest), and the fluctuations are lower $\left(\delta \mathrm{n} \sim 0.3 \mathrm{~cm}^{-3}\right)$ after the first day of the high-speed stream-driven storms. In Figure 16e the superposed average of the hourly standard deviation $\delta \mathrm{B}$ of the magnetic field vector $B$ of the solar wind is plotted, where $\delta \mathrm{B}=\left(\delta \mathrm{B}_{\mathrm{x}}^{2}+\delta \mathrm{B}_{\mathrm{y}}^{2}+\delta \mathrm{B}_{\mathrm{z}}^{2}\right)^{1 / 2}$. Near the time of storm onset when the magnetic field is compressed in the CIR the standard deviation of the magnetic field strength is higher, and before the storm onset and well after the storm onset the standard deviation is lower. In Figure $16 \mathrm{f}$ the superposed 


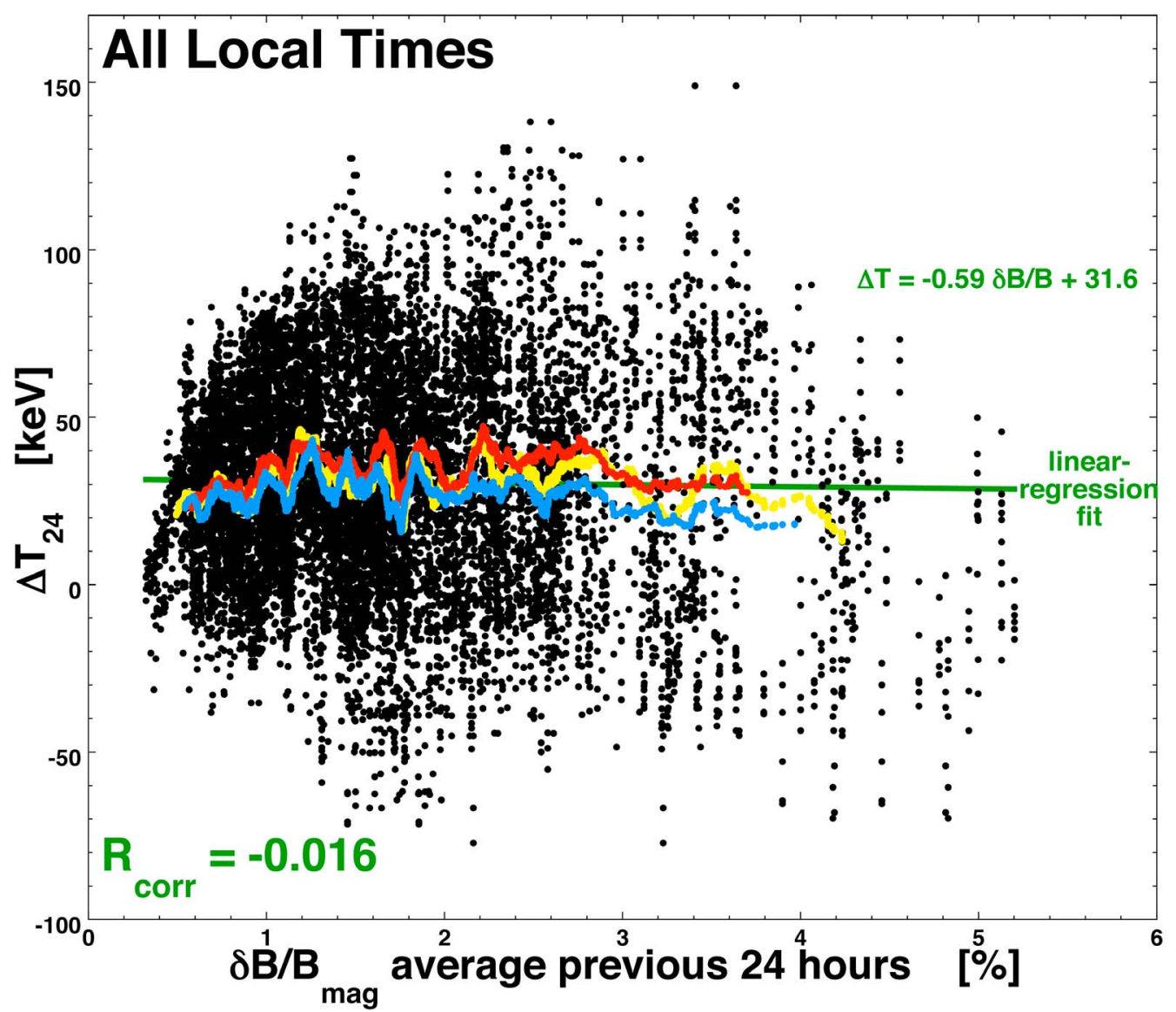

Figure 15. For the 36-72 $\mathrm{h}$ intervals of the 63 high-speed stream-driven storms with GOES measurements, the $24 \mathrm{~h}$ changes $\Delta \mathrm{T}_{24}$ in the temperature $\mathrm{T}$ of the outer electron radiation belt are plotted as functions of the $24 \mathrm{~h}$ average of the $\delta \mathrm{B} / \mathrm{B}$ at geosynchronous orbit for the same $24 \mathrm{~h}$. A linear regression fit is plotted in green, and a 300-point running average is plotted in yellow. Also plotted are 100-point running averages of the noon-only data (red) and the midnight only data (blue).

average of the normalized standard deviation of the solar wind vector magnetic field $|\delta B| / \mathrm{B}$ is plotted, where $\delta \mathrm{B}$ is the vector variation of $B$ during the hour and $\mathrm{B}$ is the hourly average of the magnitude of $\mathrm{B}$. This quantity $|\delta B| / \mathrm{B}$ is a measure of the angular fluctuations of the magnetic field vector during the hour. Note in Figure $16 \mathrm{f}$ that $|\delta B| / \mathrm{B}$ does not vary significantly from the slow wind before the storm onset, though the CIR, to the fast wind during the highspeed stream-driven storm [see also Borovsky and Denton, 2010b].

Table 5. Linear Correlation Coefficients Between Various Amplitudes of Fluctuations and the Heating Rate of the Outer Electron Radiation Belt at Geosynchonous Orbit ${ }^{\mathrm{a}}$

\begin{tabular}{|c|c|c|c|c|c|}
\hline Quantity & Location Measured & $\mathrm{R}_{\text {corr }}$ With $\Delta \mathrm{T}_{24}$ & Number of Points & $\mathrm{R}_{\text {corr }}$ With $\left\langle\mathrm{v}_{\mathrm{sw}}\right\rangle_{24}$ & $\mathrm{R}_{\text {corr }}$ With $\left\langle\mathrm{n}_{\mathrm{sw}}\right\rangle_{24}$ \\
\hline$\langle\delta \mathrm{B} / \mathrm{B}\rangle_{24}$ & Geosynchonous & -0.0158 & 11948 & +0.503 & +0.102 \\
\hline$\langle\delta \mathrm{B}\rangle_{24}$ & Solar wind & -0.159 & 8792 & +0.100 & +0.593 \\
\hline$\langle\delta \mathrm{B} / \mathrm{B}\rangle_{24}$ & Solar wind & -0.108 & 8792 & +0.245 & +0.0099 \\
\hline$\langle\delta \mathrm{v}\rangle_{24}$ & Solar wind & +0.152 & 8716 & +0.659 & -0.233 \\
\hline$\langle\delta \varphi\rangle_{24}$ & Solar wind & +0.117 & 8716 & +0.356 & -0.0522 \\
\hline$\langle\delta \mathrm{n}\rangle_{24}$ & Solar wind & -0.196 & 8588 & -0.417 & +0.856 \\
\hline$\langle\delta \mathrm{n} / \mathrm{n}\rangle_{24}$ & Solar wind & +0.176 & 8588 & +0.0302 & +0.0673 \\
\hline$\left\langle\delta n v^{2}\right\rangle_{24}$ & Solar wind & -0.094 & 8588 & +0.0405 & +0.626 \\
\hline$\langle 2 \mathrm{nv} \delta \mathrm{v}\rangle_{24}$ & Solar wind & -0.168 & 8651 & +0.123 & +0.622 \\
\hline$\left\langle\delta v^{2}+2 n v \delta v\right\rangle_{24}$ & Solar wind & -0.122 & 8588 & +0.0634 & +0.656 \\
\hline$\left\langle\mathrm{B}_{\mathrm{sw}}\right\rangle_{24}$ & Solar wind & -0.0375 & 8792 & -0.0774 & +0.570 \\
\hline$\left\langle\mathrm{v}_{\mathrm{sw}}\right\rangle_{24}$ & Solar wind & +0.285 & 8716 & +1.00 & -0.567 \\
\hline$\left\langle\mathrm{n}_{\mathrm{sw}}\right\rangle_{24}$ & Solar wind & -0.284 & 8651 & -0.567 & +1.00 \\
\hline$\left\langle\mathrm{n}_{\mathrm{sw}} \mathrm{v}_{\mathrm{sw}}^{2}\right\rangle_{24}$ & Solar wind & -0.183 & 8651 & +0.0327 & +0.759 \\
\hline
\end{tabular}

${ }^{a}$ The heating rate $\mathrm{dT} / \mathrm{dt}$ is measured with a $24 \mathrm{~h}$ difference in the temperature $\Delta \mathrm{T}_{24}$ and the various fluctuation quantities are $24 \mathrm{~h}$ averages during the $24 \mathrm{~h}$ temperature change. The last column is the number of point pairs used to calculate the correlation coefficient. The last four rows contain nonfluctuating solar wind quantities. 
Table 6. Correlations Between $\Delta \mathrm{T}_{24}$ and $\langle\delta \mathrm{B} / \mathrm{B}\rangle_{24}$ at Geosynchonous Orbit With $\left\langle v_{\text {sw }}\right\rangle_{24}$ Held Approximately Fixed ${ }^{\mathrm{a}}$

\begin{tabular}{lcc}
\hline $\begin{array}{c}\text { Decim } \\
\text { Number }\end{array}$ & $\begin{array}{c}\text { Mean Value of } \\
\left\langle\mathrm{v}_{\mathrm{sw}}\right\rangle_{24}\left(\mathrm{~km} \mathrm{~s}^{-1}\right)\end{array}$ & $\begin{array}{c}\text { Correlation of } \\
\Delta \mathrm{T}_{24} \text { and }\langle\delta \mathrm{B} / \mathrm{B}\rangle_{24}\end{array}$ \\
\hline 1 & 462 & -0.181 \\
2 & 497 & -0.245 \\
3 & 534 & -0.125 \\
4 & 557 & -0.432 \\
5 & 585 & -0.412 \\
6 & 616 & -0.151 \\
7 & 640 & -0.0819 \\
8 & 661 & -0.0962 \\
9 & 691 & -0.153 \\
10 & 744 & -0.0730 \\
Average & & -0.187 \\
\hline
\end{tabular}

${ }^{\mathrm{a}}$ The data pertains to $36-72 \mathrm{~h}$ after onset for the $63 \mathrm{high}-$ speed streamdriven storms with GOES magnetic field measurements.

[68] In Table 5 the linear correlation coefficients between the heating rate $\mathrm{dT} / \mathrm{dt}$ of the outer electron radiation belt and the amplitudes of various fluctuations in the solar wind are collected. The correlation coefficients are only for the time interval 36-72 h after the onset of the 93 high-speed streamdriven storms. Those fluctuation amplitudes are the variations in the vector magnetic field $\delta \mathrm{B}=\left(\delta \mathrm{B}_{\mathrm{x}}^{2}+\delta \mathrm{B}_{\mathrm{y}}^{2}+\delta \mathrm{B}_{\mathrm{z}}^{2}\right)^{1 / 2}$, the normalized variations in the vector magnetic field $\delta \mathrm{B} / \mathrm{B}$, the variations in the solar wind speed $\delta \mathrm{v}$, the north-south angular variations in the solar wind vector $\delta \varphi$, the variations in the solar wind number density $\delta \mathrm{n}$, the normalized variations in the solar wind number density $\delta \mathrm{n} / \mathrm{n}$, the variations in the solar wind ram pressure caused by density variations $\delta \mathrm{nv}^{2}$, the variations in the solar wind ram pressure caused by the speed variations $2 \mathrm{nv} \delta \mathrm{v}$, and the sum of the two solar wind ram pressure variations $\delta \mathrm{nv}^{2}+2 \mathrm{nv} \delta \mathrm{v}$. For the correlation calculations the heating rate $\mathrm{dT} / \mathrm{dt}$ is measured by the $24 \mathrm{~h}$ change $\Delta \mathrm{T}_{24}$ in the temperature $\mathrm{T}$ of the outer electron radiation belt at geosynchronous orbit. For the amplitudes of variation of the solar wind, in each case the amplitude of the fluctuations is taken to be the standard deviations of the solar wind measurements going into an hourly average in the OMNI2 data set. To compare with the $24 \mathrm{~h}$ difference $\Delta \mathrm{T}_{24}$, in each case the amplitudes of the variations are averaged over the same $24 \mathrm{~h}$ as the difference. For example, in the second row of Table 5 the linear correlation coefficient between $\Delta \mathrm{T}_{24}$ and $\langle\delta \mathrm{B}\rangle_{24}$ is -0.159 . In the last four rows of Table 5 the linear correlation coefficients between $\Delta \mathrm{T}_{24}$ and the $24 \mathrm{~h}$ averages of the solar wind magnetic field strength $\mathrm{B}$, the solar wind velocity $\mathrm{v}$, the solar wind number

Figure 16. For the 93 high-speed stream-driven storms, the superposed averages of variances in the upstream solar wind are plotted: (a) the $\mathrm{Kp}$ index is plotted with indications of the storm eras, (b) the hourly standard deviation of the solar wind speed, (c) the hourly standard deviation of the directions (azimuth and elevation) of the solar wind velocity vector, (d) the hourly standard deviation of the solar wind number density, (e) the hourly standard deviation of the solar wind magnetic field strength, and (f) the hourly standard deviation of the solar wind magnetic field vector divided by the hourly averaged magnetic field strength. All quantities are from the OMNI2 data set. density $\mathrm{n}$, and the solar wind ram pressure $n v^{2}$ are collected, with the correlations calculated only in the $36-72 \mathrm{~h}$ intervals after storm onset. The fourth column of Table 5 is the number of point pairs going into each correlation. For the solar wind parameters, the number of pairs $\mathrm{N}_{\text {meas }}$ ranges from 8588 to 8792 , so if $\mathrm{N}_{\text {ind }}=\mathrm{N}_{\text {meas }}$ the 2 sigma level of correlation $2 / \mathrm{N}_{\text {ind }}^{1 / 2}$ ranges from 0.0213 to 0.0216 . The last two columns of

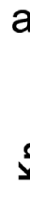

a
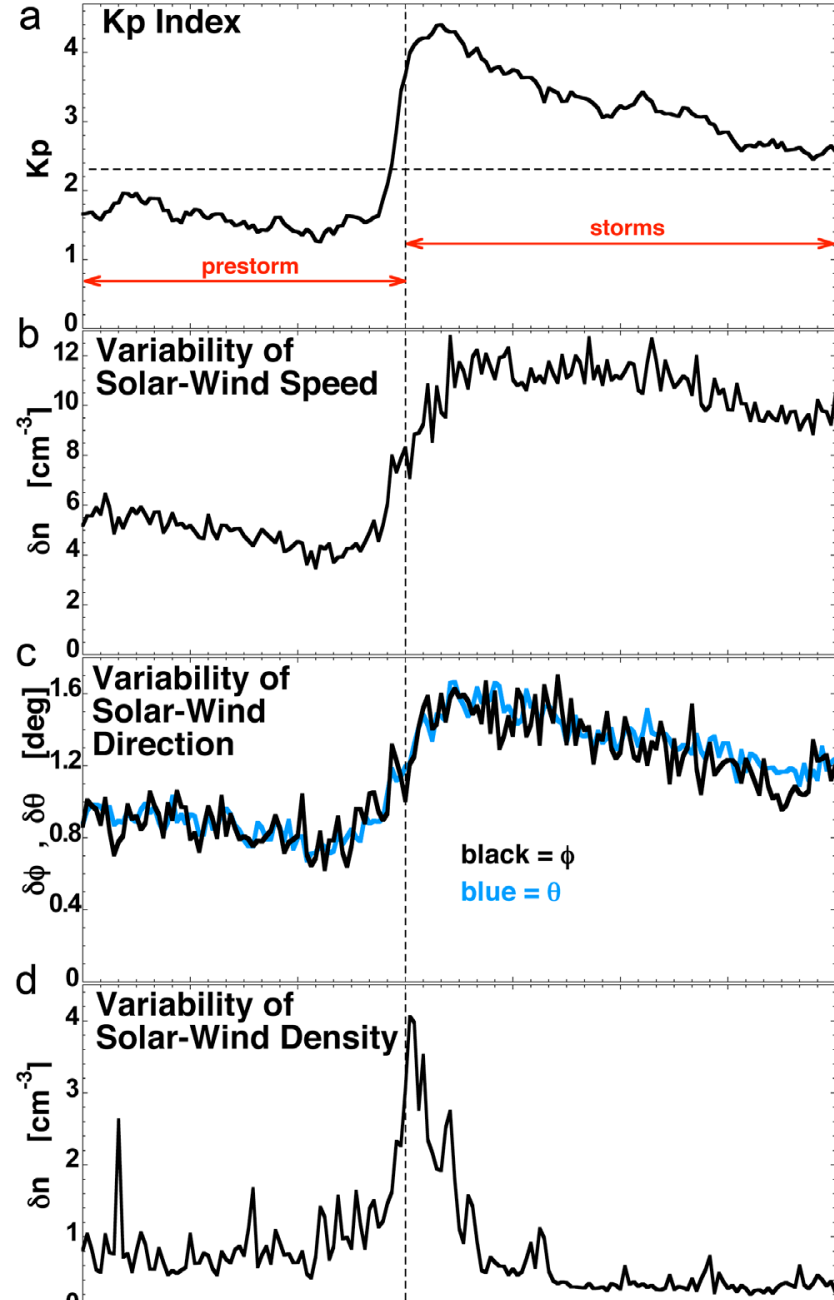

e

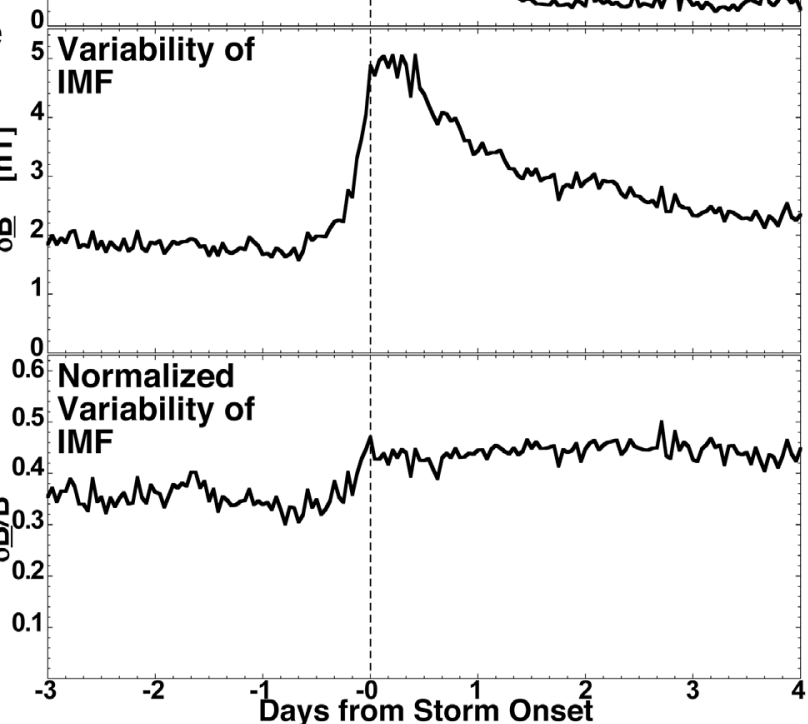




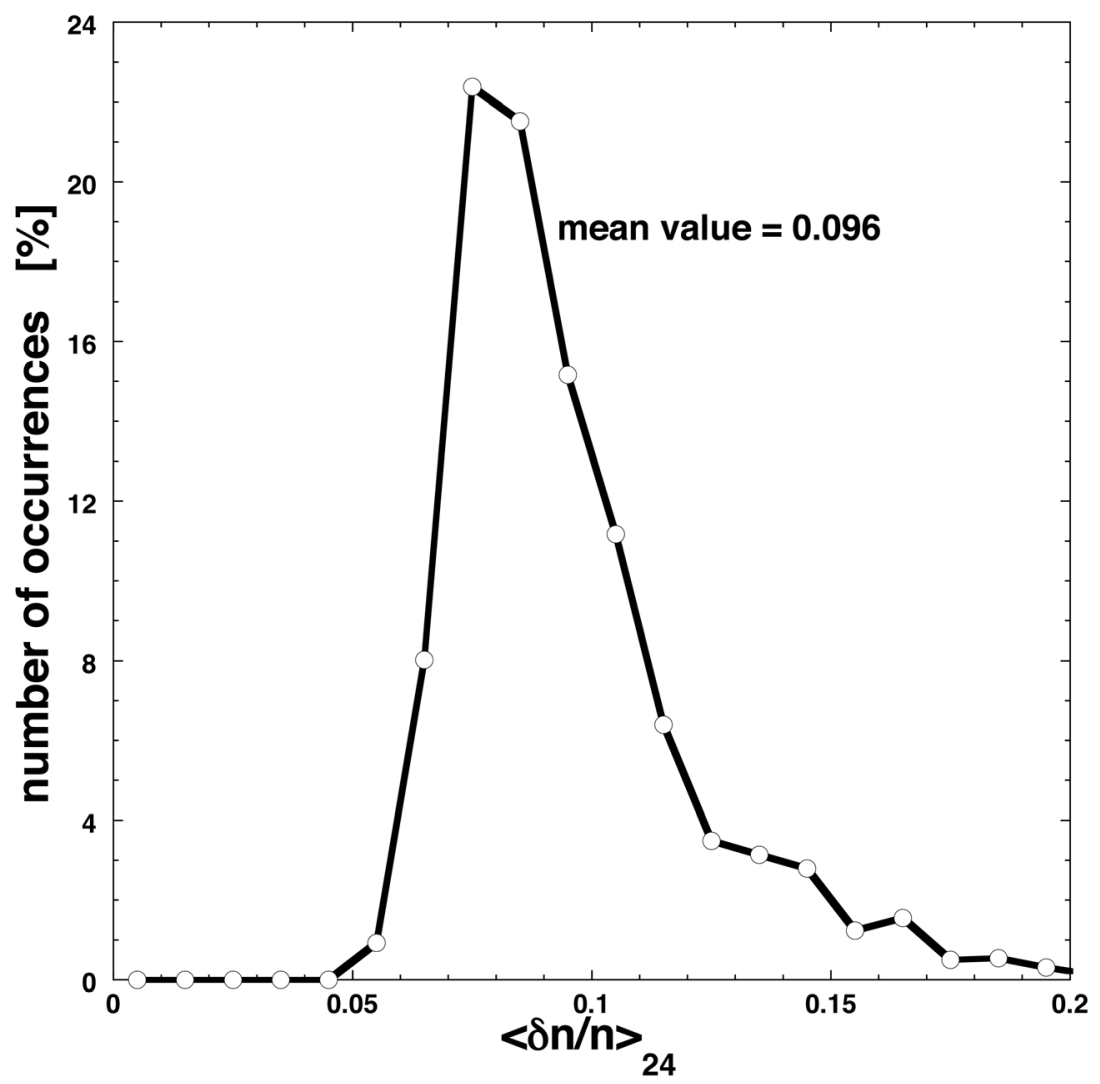

Figure 17. The occurrence distribution of $\langle\delta n / n\rangle_{24}$ of the solar wind in the time intervals $36-72 \mathrm{~h}$ after storm onset for the 93 storms.

Table 5 contain the linear correlation coefficients between the $24 \mathrm{~h}$ averages of the fluctuation amplitudes and the $24 \mathrm{~h}$ averages of the solar wind velocity $\mathrm{v}_{\mathrm{sw}}$ and density $\mathrm{n}_{\mathrm{sw}}$ for the 36-72 $\mathrm{h}$ interval.

[69] Note first in Table 5 the correlation coefficients between the heating rate and the basic solar wind parameters (last four rows). The radiation belt heating rate $\Delta T_{24}$ during the 36-72 h interval after storm onset is almost independent $\left(\mathrm{R}_{\text {corr }}=-0.038\right)$ of the magnetic field strength $\mathrm{B}$ of the solar wind, it is positively correlated $\left(R_{\text {corr }}=+0.285\right)$ with the solar wind speed $\mathrm{v}$, it is negatively correlated $\left(\mathrm{R}_{\text {corr }}=\right.$ -0.284 ) with the solar wind density $\mathrm{n}$, and it is negatively correlated $\left(\mathrm{R}_{\text {corr }}=-0.183\right)$ with the solar wind ram pressure $n v^{2}$. During this $36-72 \mathrm{~h}$ interval after storm onset the velocity $\mathrm{v}_{\mathrm{sw}}$ and density $\mathrm{n}_{\mathrm{sw}}$ of the high-speed solar wind are strongly anticorrelated $\left(\mathrm{R}_{\text {corr }}=-0.567\right)$, so it is no surprise that the radiation belt heating rate is correlated with velocity $\mathrm{v}_{\mathrm{sw}}$ and anticorrelated with density $\mathrm{n}_{\mathrm{sw}}$ in Table 5. And during this 36-72 $\mathrm{h}$ interval after storm onset the ram pressure $\mathrm{n}_{\mathrm{sw}} \mathrm{v}_{\mathrm{sw}}^{2}$ and velocity $\mathrm{v}_{\mathrm{sw}}$ are nearly independent $\left(\mathrm{R}_{\text {corr }}=+0.033\right)$ whereas the ram pressure $\mathrm{n}_{\mathrm{sw}} \mathrm{v}_{\mathrm{sw}}^{2}$ and density $\mathrm{n}_{\mathrm{sw}}$ are strongly positively correlated $\left(\mathrm{R}_{\mathrm{corr}}=+0.759\right)$, so it is no surprise that the radiation belt heating rate is anticorrelated with ram pressure $\mathrm{n}_{\mathrm{sw}} \mathrm{v}_{\mathrm{sw}}^{2}$ in Table 5, as it is anticorrelated with the number density $\mathrm{n}$.

[70] Note in Table 5 that the correlation coefficients between $\Delta \mathrm{T}_{24}$ and the $24 \mathrm{~h}$ averages of the fluctuating solar wind quantities are all weaker in magnitude than the correlation coefficients between $\Delta \mathrm{T}_{24}$ and $\left\langle\mathrm{v}_{\mathrm{sw}}\right\rangle_{24}$ and $\left\langle\mathrm{n}_{\mathrm{sw}}\right\rangle_{24}$. Note also that any (except $\delta \mathrm{n} / \mathrm{n}$ ) of the solar wind fluctuation amplitudes that has a correlation coefficient with $\Delta \mathrm{T}_{24}$ that is significantly larger than random $\left(0.0216\right.$ for $\mathrm{N}_{\text {ind }}=\mathrm{N}_{\text {meas }}$ or 0.072 for $\mathrm{N}_{\text {ind }}=\mathrm{N}_{\text {meas }} / 11$ ) also has a strong correlation with either $\left\langle n_{\mathrm{sw}}\right\rangle_{24}$ or $\left\langle\mathrm{v}_{\mathrm{sw}}\right\rangle_{24}$. These two facts lead to the interpretation that any such correlation between $\Delta T_{24}$ and a solar wind fluctuation amplitude could be owed to the fluctuation amplitude acting as a proxy for either $\mathrm{v}_{\mathrm{sw}}$ or $\mathrm{n}_{\mathrm{sw}}$. In particular, fluctuations in the solar wind density and in the solar wind ram pressure could be acting proxies for the solar wind density $\mathrm{n}_{\mathrm{sw}}$, and fluctuations in the solar wind speed and direction could be acting as proxies for the solar wind speed $\mathrm{v}_{\mathrm{sw}}$.

[71] The one exception to the above discussion is $\delta \mathrm{n} / \mathrm{n}$, where it is seen in Table 5 that $\langle\delta n / n\rangle_{24}$ has a correlation coefficient of +0.176 with $\Delta \mathrm{T}_{24}$, but is almost uncorrelated with $\left\langle\mathrm{v}_{\mathrm{sw}}\right\rangle_{24}$ and $\left\langle\mathrm{n}_{\mathrm{sw}}\right\rangle_{24}$. The correlation $\mathrm{R}_{\mathrm{corr}}=+0.176$ is at the 5 sigma level of significance for $\mathrm{N}_{\text {ind }}=\mathrm{N}_{\text {meas }} / 11=$ $8588 / 11$ independent measurements. The quantity $\delta \mathrm{n} / \mathrm{n}$ could be thought of as the fractional variance of the solar wind ram pressure owed to density fluctuations: $\delta \mathrm{nv}^{2} / \mathrm{nv}^{2}$. This could be a measure of the movement magnetopause owing to density fluctuations in the solar wind. In Figure 17 the occurrence distribution of $\langle\delta n / n\rangle_{24}$ is plotted for the time interval 36-72 $\mathrm{h}$ after storm onset for the $93 \mathrm{high}$-speed stream-driven storms. The mean value of $\langle\delta \mathrm{n} / \mathrm{n}\rangle_{24}$ in that $36-72 \mathrm{~h}$ time interval is 0.096 . The standoff distance $r$ of the magnetopause at the nose of the magnetosphere can be estimated by the expression $\mathrm{r}=11.8 \mathrm{P}_{\mathrm{ram}}^{-1 / 6}$ [e.g., Kivelson and Russell, 1995, 
equation (6.21)], where $r$ is in Earth radii $R_{E}$ and the ram pressure of the solar wind $\mathrm{P}_{\text {ram }}$ is in $\mathrm{nPa}$. This expression gives $\partial \mathrm{r} / \partial$ Pram $=-(11.8 / 6) \mathrm{P}_{\mathrm{ram}}^{-7 / 6}$. This derivative can be written $\Delta \mathrm{r}=-(11.8 / 6) \mathrm{P}_{\text {ram }}^{-7 / 6} \Delta \mathrm{P}_{\text {ram }}=-1.93 \Delta \mathrm{P}_{\text {ram }} / \mathrm{P}_{\text {ram. }}$. If $\delta \mathrm{n} / \mathrm{n}=\Delta \mathrm{P}_{\text {ram }} / \mathrm{P}_{\text {ram }}$, then the variation in the magnetopause standoff distance (in $\mathrm{R}_{\mathrm{E}}$ ) is given by $\Delta \mathrm{r}=-1.93 \delta \mathrm{n} / \mathrm{n}$. For $\delta \mathrm{n} / \mathrm{n}=0.096$, this yields a standard deviation variation of the magnetopause location by $\Delta \mathrm{r}=0.19 \mathrm{R}_{\mathrm{E}}=1180 \mathrm{~km}$, which is a motion of $\pm 1180 \mathrm{~km}$ about its equilibrium position. This magnetopause motion could be a measure of compressive fluctuations in the magnetosphere, which could affect radiation belt evolution (perhaps by magnetic pumping [e.g., Liu et al., 1999] or by the creation of electron anisotropies that drive higher-frequency plasma waves).

\section{Discussion}

[72] Section 10.1 contains a discussion about the heating rates of the outer electron radiation belt during high-speed stream-driven storms, section 10.2 contains a brief comparison with CME-driven storms, section 10.3 contains a discussion of the possible heating mechanisms operating during high-speed stream-driven storms, and section 10.4 discusses some needed future work.

\subsection{Heating Rates of the Outer Electron Radiation Belt During High-Speed Stream-Driven Storms}

[73] For the purpose of this discussion, the heating rate of the outer electron radiation belt at geosynchronous orbit during high-speed stream-driven storms will be taken to be $\Delta \mathrm{T}_{24}=32 \mathrm{keV} \mathrm{d}^{-1}$, which is the all local time average obtained from the individual measurements of $\Delta \mathrm{T}_{24}$ in the 36-72 $\mathrm{h}$ interval after storm onset (third row of Table 1).

[74] The fractional heating value $\Delta \mathrm{T}_{24} / \mathrm{T}$ for the outer electron radiation belt at geosynchronous orbit, which has a temperature of 120-180 keV during high-speed streamdriven storms, is $\Delta \mathrm{T}_{24} / \mathrm{T} \sim\left(32 \mathrm{keV} \mathrm{d}^{-1}\right) /(150 \mathrm{keV}) \sim 20 \%$ per day.

[75] The daily rate of change of the kinetic energy density $\mathcal{E}=\mathrm{nk}_{\mathrm{B}} \mathrm{T}$ of the outer electron radiation belt at geosynchronous orbit owing to the heating is given by $\Delta \varepsilon=n k_{B} \Delta T_{24}$. From Figure $3 \mathrm{c}$, the number density of the outer electron radiation belt during high-speed stream-driven storms is taken to be $\mathrm{n}=7 \times 10^{-4} \mathrm{~cm}^{-3}$ (see Figure 4); with $\Delta \mathrm{T}_{24}=$ $32 \mathrm{keV} \mathrm{d}^{-1}$ this yields $\Delta \varepsilon=3.6 \times 10^{-11} \mathrm{erg} \mathrm{cm}^{-3} \mathrm{~d}^{-1}$. (Note that this temperature change results in a change in electron kinetic pressure $\mathrm{P}=\mathrm{nk}_{\mathrm{B}} \mathrm{T}$ of $3.6 \times 10^{-3} \mathrm{nPa} \mathrm{d}^{-1}$.) These values are entered into Table 1, along with values for local noon and local midnight.

[76] The daily change in the total kinetic energy of the outer electron radiation belt at geosynchronous orbit is estimated as follows. The volume of a geosynchronous orbit dipole flux tube is $7.6 \times 10^{9} \mathrm{~cm}^{3}$ per $\mathrm{cm}^{2}$ of area at the equator. The area $A$ in the equator of a band $1 \mathrm{R}_{\mathrm{E}}$ in radius at geosynchronous orbit is $A=\left(1 R_{E}\right)\left(2 \pi 6.6 R_{E}\right)=1.7 \times 10^{19} \mathrm{~cm}^{2}$. Thus, the total volume of the flux tubes in the magnetosphere that cross the equator within $0.5 \mathrm{RE}$ of geosynchronous orbit is $\mathrm{V}=\left(7.6 \times 10^{9}\right)\left(7 \times 10^{19}\right) \mathrm{cm}^{3}=1.27 \times 10^{29} \mathrm{~cm}^{3}$. The daily change in the total kinetic energy is $\Delta \varepsilon=\mathrm{V} \Delta \mathcal{E}=4.6 \times$ $10^{18} \mathrm{erg} \mathrm{d}^{-1}$. This corresponds to a heating rate of $5.3 \times$ $10^{13} \mathrm{erg} \mathrm{s}^{-1}=5.3 \times 10^{6}$ Watt for the heating of a $1 \mathrm{R}_{\mathrm{E}}$ thick shell of the outer electron radiation belt at geosynchronous orbit during high-speed stream-driven storms.

[77] The specific entropy $\mathrm{S}$ of the outer electron radiation belt population is given by $\mathrm{S}=\mathrm{T} / \mathrm{n}^{2 / 3}$. The rate of change in the specific entropy $\partial \mathrm{S} / \partial \mathrm{t}$ owed to the heating is therefore $\partial \mathrm{S} / \partial \mathrm{t}=\Delta \mathrm{T}_{24} / \mathrm{n}^{2 / 3}$. For $\Delta \mathrm{T}_{24}=32 \mathrm{keV} \mathrm{d}^{-1}$ and for $\mathrm{n}=7 \times$ $10^{-4} \mathrm{~cm}^{-3}$, this yields $\partial \mathrm{S} / \partial \mathrm{t}=4.1 \times 10^{6} \mathrm{eV} \mathrm{cm}^{2}$ day $^{-1}$ at geosynchronous orbit owing to the heating of the outer electron radiation belt during high-speed stream-driven storms. This value is entered into Table 1 along with values for noon and midnight.

\subsection{Comparison With CME-Driven Storms}

[78] Some information about the heating rates during CME driven storms can be found in the work of Denton et al. [2010]. The heating of the outer electron radiation belt occurs predominantly during the Dst recovery phase. CMEdriven storms (which are brief and nonrecurrent) occasionally produce high fluxes of relativistic electrons [cf. Borovsky and Denton, 2006, Figure 13; Wrenn, 2009, Figure 3], but not nearly as often as do the long-duration, recurrent, high-speed stream-driven storms. On average, the number density of the outer electron radiation belt at geosynchronous orbit during CME-driven storms is about the same as it is for high-speed stream-driven storms, but the temperatures and resulting relativistic fluxes are lower [Denton et al., 2010]. As yet, the reasons for the differences in behavior of the outer electron radiation belt during the two types of storms are not understood.

\subsection{Energization Mechanisms}

[79] Energization mechanisms considered in the literature for the outer electron radiation belt fall into two categories [cf. Green and Kivelson, 2004; Iles et al., 2006; Shprits et al., 2008a, 2008b]: (1) local acceleration mechanisms that heat the electrons in place or (2) radial transport. During the heating phase of high-speed stream-driven storms, the fact that the electron radiation belt at geosynchronous orbit is heated at constant density (e.g., Figure 3) [see also Borovsky et al., 1998a; Borovsky and Steinberg, 2006; Denton et al., 2010] indicates that the energization mechanism operating is a local mechanism, and further indicates that the mechanism operates without an active electron source population. Local energization mechanisms for the outer electron radiation belt include cyclotron-resonant energization by whistler waves [Summers and Ma, 2000; Albert, 2004; Horne et al., 2005] or by magnetosonic waves [Horne et al., 2007; Tao et al., 2009], drift-resonant energization by ULF waves [Hudson et al., 2000; Elkington et al., 2003], and magnetic pumping by compressive ULF pulsations [Borovsky, 1986; Liu et al., 1999]. Until heating rates are calculated for the various mechanisms, one cannot say whether the measured heating rates support one specific mechanism versus the others.

\subsection{Future Work}

[80] To advance the understanding of the physics of the electron radiation belt, a study is needed in which heating rates calculated for the various energization mechanisms of section 10.2 are compared with the measured heating rates of the present study. A drawback to obtaining accurate calculations is the lack of full information about energies, 
frequency spectra, and wave vector spectra of plasma waves in the magnetosphere as functions of local time and latitude during high-speed stream-driven storms.

[81] For high-speed stream-driven storms, a systematic examination of the density-temperature evolution of the entire outer electron radiation belt would be very useful. The density-temperature description is much more compact than is a multienergy flux description; for the evolution of the electron belt versus time and $\mathrm{L}$ shell this compact $\mathrm{n}-\mathrm{T}$ description will be enlightening and intuitive. Relativistic Maxwellian density and temperature fits for the bulk of the outer electron radiation belt $(\mathrm{L}>4)$ as determined by instrumentation on the GPS spacecraft [Cayton et al., 1998; Friedel et al., 2005] exist. Systematic analysis of the data could produce global heating rates and energy budgets for the electron belt. Relativistic Maxwellian fits to the AE- 8 radiation belt model by Pierrard and Lemaire [1996] indicate that the electron radiation belt inward of geosynchronous orbit shows a greater temperature change from solar min to solar max than does the belt at geosynchronous orbit.

[82] The authors plan to examine the temperature and the heating rates of the outer electron radiation belt at geosynchronous orbit as a function of pitch angle using relativistic Maxwellian fits to pitch angle resolved count rates. This will provide information about the adiabaticity of the radiation belt electrons, about the usefulness of double-adiabatic representations [cf. Birn et al., 1995], and about pitch angle scattering rates.

\section{Summary}

[83] In this study 93 high-speed stream-driven storms were utilized for superposed epoch analysis: superposed averaging and extraction of epoch data. Multisatellite measurements of the temperature of the outer electron radiation belt at geosynchronous orbit were analyzed during the time intervals of the storms when electron fluxes grow to dangerous levels. The findings of the study are the following.

[84] 1 . The heating rate $\mathrm{dT} / \mathrm{dt}$ of the outer electron radiation belt at geosynchronous orbit was measured for the time interval 36-72 $\mathrm{h}$ after storm onset. Directly values $\left(32 \mathrm{keV} \mathrm{d}^{-1}\right)$ are somewhat higher than values $\left(24 \mathrm{keV} \mathrm{d}^{-1}\right)$ obtained from fits to superposed averages.

[85] 2. The outer electron radiation belt at local noon geosynchronous orbit is hotter than the outer electron radiation belt at local midnight at geosynchronous orbit (owing to particle orbit effects): likewise observed heating rates are slightly higher at noon than at midnight.

[86] 3. During high-speed stream-driven storms, the heating rate of the outer electron radiation belt at geosynchronous orbit is increased when the $\mathrm{Kp}$ index is increased: the value $\partial(\mathrm{dT} / \mathrm{dt}) / \partial \mathrm{Kp}=7.8 \mathrm{keV} \mathrm{d}^{-1} \mathrm{Kp}^{-1}$ is found.

[87] 4. During high-speed stream-driven storms, the heating rate of the outer electron radiation belt at geosynchronous orbit is increased when the solar wind speed $v_{\mathrm{sw}}$ is increased: the value $\partial(\mathrm{dT} / \mathrm{dt}) / \partial \mathrm{v}_{\mathrm{sw}}=0.11 \mathrm{keV} \mathrm{d}^{-1}\left(\mathrm{~km} \mathrm{~s}^{-1}\right)^{-1}$ is found.

[88] 5. During high-speed stream-driven storms, the heating rate of the outer electron radiation belt at geosynchronous orbit is increased when the solar wind number density $\mathrm{n}_{\mathrm{sw}}$ is decreased: the value $\partial(\mathrm{dT} / \mathrm{dt}) / \partial \mathrm{n}_{\mathrm{sw}}=-4.4 \mathrm{keV} \mathrm{d}^{-1} \mathrm{~cm}^{-3}$ is found.
[89] 6. Analyzing the thee-way correlations between $\mathrm{dT} / \mathrm{dt}, \mathrm{Kp}$, and $\mathrm{v}_{\mathrm{sw}}$ by separately holding $\mathrm{v}_{\mathrm{sw}}$ fixed or $\mathrm{Kp}$ fixed, it is concluded that the correlation between $\mathrm{dT} / \mathrm{dt}$ and $\mathrm{v}_{\mathrm{sw}}$ is fundamental and that the correlation between $\mathrm{dT} / \mathrm{dt}$ and $\mathrm{Kp}$ is caused by $\mathrm{Kp}$ acting as a proxy for $\mathrm{v}_{\mathrm{sw}}$.

[90] 7. Analyzing the thee-way correlations between $\mathrm{dT} / \mathrm{dt}, \mathrm{n}_{\mathrm{sw}}$, and $\mathrm{v}_{\mathrm{sw}}$ by separately holding $\mathrm{v}_{\mathrm{sw}}$ fixed or $\mathrm{n}_{\mathrm{sw}}$ fixed, it is concluded that the anticorrelation between $\mathrm{dT} / \mathrm{dt}$ and $\mathrm{n}_{\mathrm{sw}}$ is as fundamental as is the positive correlation between $\mathrm{dT} / \mathrm{dt}$ and $\mathrm{v}_{\mathrm{sw}}$.

[91] 8. During high-speed stream-driven storms, the heating rate of the outer electron radiation belt at geosynchronous orbit is uncorrelated with the level of magnetic field fluctuations $\delta \mathrm{B} / \mathrm{B}$ at geosynchronous orbit. (Here the measured amplitudes of $\delta \mathrm{B} / \mathrm{B}$ do not discern compressive from shear fluctuations.) This is because there is a tendency for the heating rate to be negatively correlated with the level of fluctuations $\delta \mathrm{B} / \mathrm{B}$ and positively correlated with the solar wind speed $\mathrm{v}_{\mathrm{sw}}$, with $\mathrm{v}_{\mathrm{sw}}$ and $\delta \mathrm{B} / \mathrm{B}$ simultaneously varying with a strong positive correlation between each other.

[92] 9. During high-speed stream-driven storms, the heating rate of the outer electron radiation belt at geosynchronous orbit is weakly correlated with the amplitudes of magnetic field, density, velocity, and ram pressure fluctuations in the upstream solar wind. Most of these weak correlations appear to be caused by the various solar wind fluctuation amplitudes acting as proxies for either the solar wind velocity $\mathrm{v}_{\mathrm{sw}}$ or the solar wind number density $\mathrm{n}_{\mathrm{sw}}$.

[93] 10. One solar wind quantity that is correlated with $\mathrm{dT} / \mathrm{dt}$ and that is not acting as a proxy is $\delta \mathrm{n} / \mathrm{n}$. The amplitude of $\delta \mathrm{n} / \mathrm{n}$ can be related to the amplitude of magnetopause motions, which could be a measure of the driving of compressive fluctuations in the magnetosphere.

\section{Appendix A: Correlations}

[94] In correlating the measured values of the heating rate $\Delta \mathrm{T}_{24}$ with time-averaged quantities such as $\left\langle\mathrm{v}_{\mathrm{sw}}\right\rangle_{24}$, the number of independent measurements is of concern to discern the significance of the correlation coefficient. One could take $\mathrm{N}_{\text {ind }}=\mathrm{N}_{\text {meas }}$ in the expression $2 / \mathrm{N}_{\text {ind }}^{1 / 2}$ to be the 2 sigma level of correlation [Hald, 1952], where $\mathrm{N}_{\text {meas }}$ is the total number of measurements. But two effects may lower the effective value of $\mathrm{N}_{\text {ind }}$ in the $2 / \mathrm{N}_{\text {ind }}^{1 / 2}$ expression: (1) the $\left\langle\mathrm{v}_{\mathrm{sw}}\right\rangle_{24}$ measurements have been created by time averaging $v_{\text {sw }}$ and so the $\left\langle v_{\text {sw }}\right\rangle_{24}$ values are not independent of each other even if the $v_{s w}$ values are, and (2) there is temporal persistence in the $\Delta T_{24}$ values and in the $\mathrm{v}_{\mathrm{sw}}$ and $\left\langle\mathrm{v}_{\mathrm{sw}}\right\rangle_{24}$ values. These two effects are explored in sections $\mathrm{A} 1$ and $\mathrm{A} 2$. In section $\mathrm{A} 3$ the options to estimate of the effective value of $\mathrm{N}_{\text {ind }}$ are discussed.

\section{A1. Numerical Experiments With Differencing and Averaging}

[95] When cross correlating $\Delta \mathrm{T}_{24}$ values with values of $\langle\mathrm{Kp}\rangle_{24},\left\langle\mathrm{v}_{\mathrm{sw}}\right\rangle_{24},\left\langle\mathrm{n}_{\mathrm{sw}}\right\rangle_{24}$, or $24 \mathrm{~h}$ averages of fluctuations, one set of points is a $24 \mathrm{~h}$ difference of hourly $\mathrm{T}$ values and the other set of points is a $24 \mathrm{~h}$ average of hourly values. Certainly the $24 \mathrm{~h}$ averaging yields points that are no longer independent of each other. The question is, with $\mathrm{N}_{\text {meas }}$ such point pairs, is $2 / \mathrm{N}_{\text {meas }}^{1 / 2}$ a valid measure of the size of random 


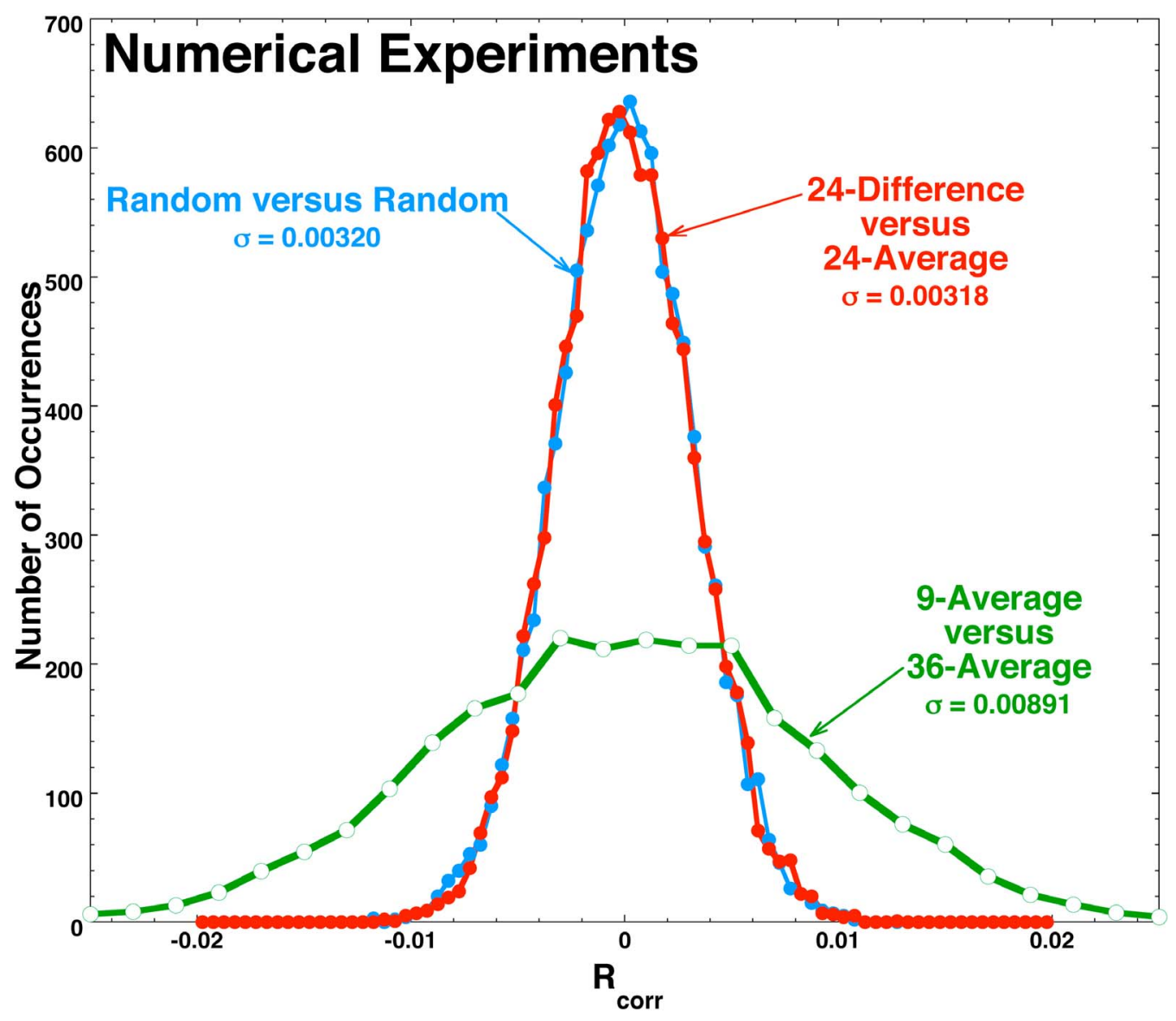

Figure A1. Thee distributions of 10,000 values of $\mathrm{R}_{\text {corr }}$. The $\mathrm{R}_{\text {corr }}$ values in the blue distribution are from 10,000 sets each with 100,000 points $(\mathrm{x}, \mathrm{y})$ where $\mathrm{x}$ and $\mathrm{y}$ are random numbers. The $\mathrm{R}_{\text {corr }}$ values in the red distribution are from 10,000 sets each with 100,000 points $\left(\Delta \mathrm{x}_{24},\langle\mathrm{y}\rangle_{24}\right)$ where $\Delta \mathrm{x}_{24}$ is the 24-point difference of $\mathrm{x}$ values and $\langle\mathrm{y}\rangle_{24}$ is the 24-point average of $\mathrm{y}$ values. The $\mathrm{R}_{\text {corr }}$ values in the green distribution are from 10,000 sets each with 100,000 points $\left(\langle y\rangle_{9},\langle y\rangle_{36}\right)$ where $\langle\mathrm{x}\rangle_{9}$ is the 9-point average of $\mathrm{x}$ values and $\langle\mathrm{y}\rangle_{36}$ is the 36-point average of $\mathrm{y}$ values.

correlations. To test the validity of the $2 / \mathrm{N}_{\text {meas }}^{1 / 2}$ rule of thumb, numerical experiments were performed.

[96] First, an ensemble of 10,000 sets of 100,000 pairs of random numbers $(\mathrm{x}, \mathrm{y})$ was created. The random numbers were boxcar distributed. For each of the 10,000 sets of point pairs, the linear correlation coefficient $\mathrm{R}_{\text {corr }}$ between $\mathrm{x}$ and $\mathrm{y}$ was calculated. The occurrence distribution of those 10,000 values of $R_{\text {corr }}$ are binned as the blue curve in Figure A1. The distribution is approximately Gaussian and has a standard deviation of 0.00320 . This standard deviation is very close to $1 / \mathrm{N}_{\text {meas }}^{1 / 2}=0.00316$ for $\mathrm{N}_{\text {meas }}=100,000$. (For a discussion of the validity of the $2 / \mathrm{N}^{1 / 2}$ rule of thumb for correlations when the data values are not Gaussian distributed, see Appendix B of Borovsky and Funsten [2003].)

[97] Next, the experiment was repeated with the 10,000 sets of 100,000 pairs $(\mathrm{x}, \mathrm{y})$ by taking the 24-point differences of the $100,000 \mathrm{x}$ values to make 100,000 values of $\Delta \mathrm{x}_{24}$ and taking the 24-point average of the 100,000 y values to make 100,000 values of $\langle y\rangle_{24}$. The for each of the 10,000 sets of $\left(\Delta x_{24},\langle y\rangle_{24}\right)$ values, the linear correlation coefficient $\mathrm{R}_{\text {corr }}$ is calculated. The occurrence distribution of these $R_{\text {corr }}$ values is plotted as the red curve in Figure A1. The distribution is approximately Gaussian and has a standard deviation of 0.00318 , which is again very close to the $1 / \mathrm{N}_{\text {meas }}^{1 / 2}$ value of 0.00316 for $\mathrm{N}_{\text {meas }}=100,000$ points.

[98] Hence, the $24 \mathrm{~h}$ averaging does not alter the appropriateness of the $2 / \mathrm{N}_{\text {meas }}^{1 / 2}$ benchmark for the correlation coefficients between the $24 \mathrm{~h}$ differences $\Delta \mathrm{T}_{24}$ and the $24 \mathrm{~h}$ averages of $\mathrm{Kp}, \mathrm{v}_{\mathrm{sw}}, \mathrm{n}_{\mathrm{sw}}$, etc.

\section{A2. Temporal Persistence in the Measurements}

[99] Temporal persistence in a time series of measurements adds redundant information into the measurement points reducing the statistical independence of the measurements. This will act to lower the effective value of $\mathrm{N}_{\text {ind }}$ in the $2 / \mathrm{N}_{\text {ind }}^{1 / 2}$ rule of thumb for correlation coefficients. To study the magnitude of this reduction in the effective value of $\mathrm{N}_{\text {ind }}$ in one set of correlations $\left(\Delta \mathrm{T}_{24},\left\langle\mathrm{v}_{\mathrm{sw}}\right\rangle_{24}\right)$, the autocorrelation functions of $\Delta \mathrm{T}_{24}$ and $\left\langle\mathrm{v}_{\mathrm{sw}}\right\rangle_{24}$ are examined for the measurements in the 26-72 $\mathrm{h}$ timeframe after storm onset, and the persistence in the correlation coefficient between $\Delta \mathrm{T}_{24}$ and $\left\langle\mathrm{v}_{\mathrm{sw}}\right\rangle_{24}$ is examined.

[100] The autocorrelation function is a measure of the persistence in a time series. In Figure A2 the autocorrelation 


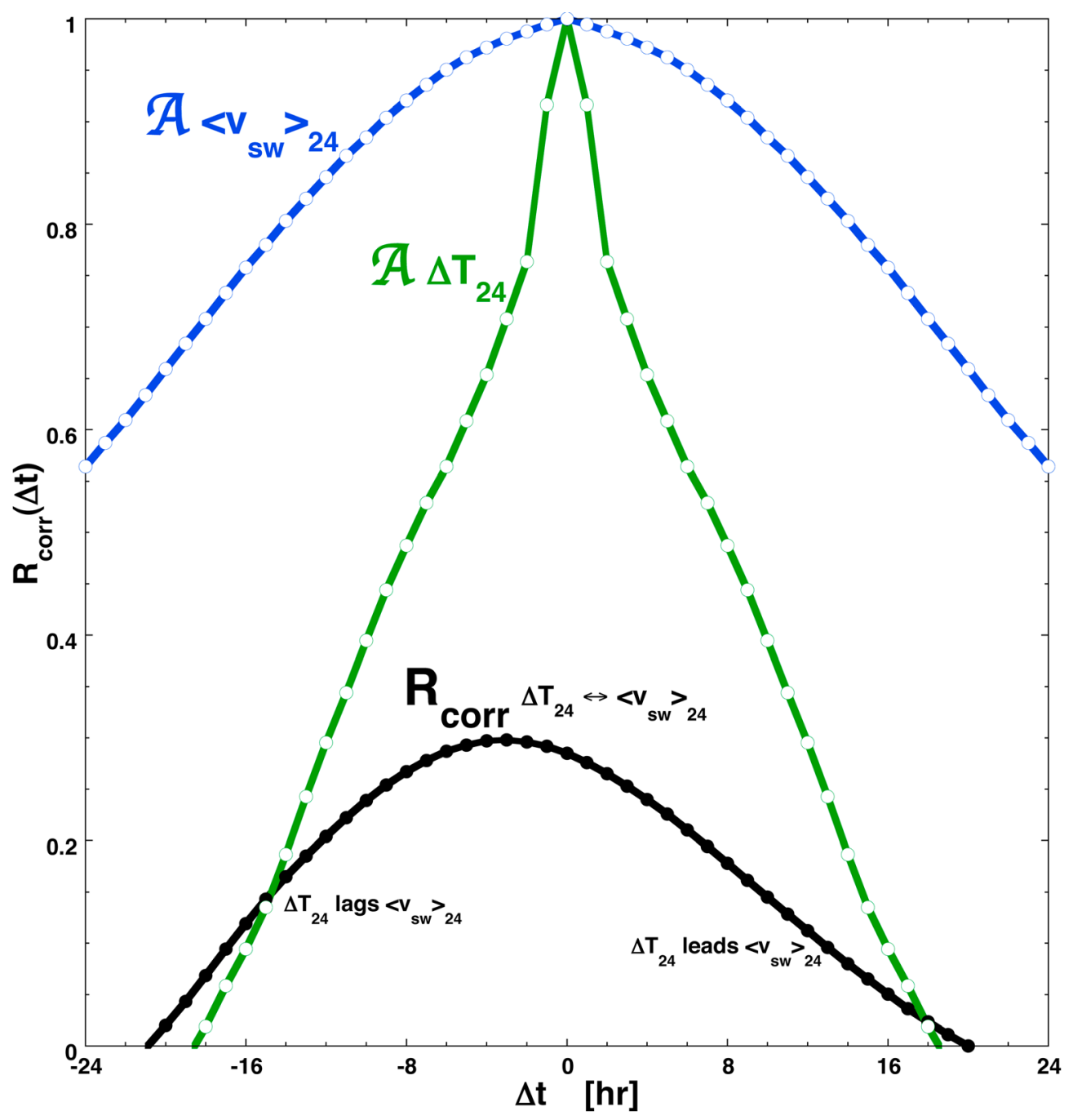

Figure A2. For measurements in the 36-72 $\mathrm{h}$ time window after storm onset for the 93 storms, the autocorrelation functions of $\Delta \mathrm{T}_{24}$ (green) and $\left\langle\mathrm{v}_{\mathrm{sw}}\right\rangle_{24}$ (blue) are plotted, and the linear correlation coefficient $\mathrm{R}_{\text {corr }}(\Delta \mathrm{t})$ between $\Delta \mathrm{T}_{24}$ and $\left\langle\mathrm{v}_{\mathrm{sw}}\right\rangle_{24}$ is plotted in black as a function of the time shift $\Delta \mathrm{t}$ between the $\Delta \mathrm{T}_{24}$ and $\left\langle\mathrm{v}_{\mathrm{sw}}\right\rangle_{24}$ measurements.

functions of $\Delta \mathrm{T}_{24}$ and $\left\langle\mathrm{v}_{\mathrm{sw}}\right\rangle_{24}$ are plotted as the green and blue curves, respectively. Only measurements in the 36-72 $\mathrm{h}$ intervals after storm onset for the 93 high-speed stream-driven storms is used in the autocorrelation functions. The autocorrelation function $\mathrm{A}(\Delta \mathrm{t})$ is constructed from a function $\mathrm{f}(\mathrm{t})$ by first subtracting the average value of the function $\langle\mathrm{f}(\mathrm{t})\rangle$ to produce a new function $\mathrm{F}(\mathrm{t})=\mathrm{f}(\mathrm{t})-\langle\mathrm{f}(\mathrm{t})\rangle$; the autocorrelation function $\Delta(\Delta t)$ of $f(t)$ is then

$$
\mathcal{A}(\Delta \mathrm{t})=\int \mathrm{F}(\mathrm{t}) \mathrm{F}(\mathrm{t}-\Delta \mathrm{t}) \mathrm{dt} / \int \mathrm{F}(\mathrm{t}) \mathrm{F}(\mathrm{t}) \mathrm{dt} .
$$

[101] For a time shift $\Delta t=0$, the autocorrelation function $\mathrm{A}$ $(0)=1$ and the autocorrelation function is symmetric for positive or negative values of $\Delta \mathrm{t}$. The time scale for decline of the autocorrelation function from unity is a measure of the persistence of the function $\mathrm{f}(\mathrm{t})$. Typically, the time shift $\Delta \mathrm{t}$ at which $A(\Delta t)=1 / \mathrm{e}=0.368$ is taken as the "autocorrelation time" of the function $\mathrm{f}(\mathrm{t})$. As can be seen in Figure A2, the autocorrelation time of $\left\langle\mathrm{v}_{\mathrm{sw}}\right\rangle_{24}$ is greater than $24 \mathrm{~h}$. Extrap- olating the plotted autocorrelation function to the $1 / \mathrm{e}$ level yields a correlation time of about $33 \mathrm{~h}$. This is because (1) the solar wind velocity $\mathrm{v}_{\mathrm{sw}}$ has a long autocorrelation time during the high-speed stream-driven storms and (2) there has been $24 \mathrm{~h}$ average if $\mathrm{v}_{\mathrm{sw}}$ to produce $\left\langle\mathrm{v}_{\mathrm{sw}}\right\rangle_{24}$. The autocorrelation time for $\Delta \mathrm{T}_{24}$ is about $11 \mathrm{~h}$, which means information about $\mathrm{dT} / \mathrm{dt}$ is spread across about 11 hourly measurements owing to persistence of $\mathrm{dT} / \mathrm{dt}$.

[102] A check on this persistence is obtained by calculating the correlation coefficient $R_{\text {corr }}(\Delta t)$ between $\Delta T_{24}$ and $\left\langle\mathrm{v}_{\mathrm{sw}}\right\rangle_{24}$ with time shifts $\Delta \mathrm{t}$ between $\Delta \mathrm{T}_{24}$ and $\left\langle\mathrm{v}_{\mathrm{sw}}\right\rangle_{24}$. The resulting $R_{\text {corr }}(\Delta t)$ values are plotted as the black curve in Figure A2. Values of $\Delta \mathrm{t}>0$ have $\Delta \mathrm{T}_{24}$ leading $\left\langle\mathrm{v}_{\mathrm{sw}}\right\rangle_{24}$ in time and values of $\Delta t<0$ have $\Delta T_{24}$ lagging in time behind $\left\langle v_{s w}\right\rangle_{24}$. As can be seen, the black curve falls to $1 / \mathrm{e}$ of its peak values in about $14 \mathrm{~h}$. This $14 \mathrm{~h}$ is close to the $\Delta \mathrm{T}_{24}$ autocorrelation time of $11 \mathrm{~h}$. Note that the peak of the $\mathrm{R}_{\text {corr }}$ values occurs for a time shift $\Delta \mathrm{t} \sim-3 \mathrm{~h}$.

[103] With these autocorrelation values (about $11 \mathrm{~h}$ for $\Delta \mathrm{T}_{24}$ and about $33 \mathrm{~h}$ for $\left.\left\langle\mathrm{v}_{\mathrm{sw}}\right\rangle_{24}\right)$ numerical experiments are 
performed to discern the effective $\mathrm{N}_{\text {ind }}$ value to take in the $2 / \mathrm{N}_{\text {ind }}^{1 / 2}$ expression. The numerical experiment of section $\mathrm{A} 1$ is repeated by 9 -point averaging the $\mathrm{x}$ values and 36 -point averaging the $\mathrm{y}$ values, producing 10,000 sets each with 100,000 points $\left(\langle\mathrm{x}\rangle_{9},\langle\mathrm{y}\rangle_{36}\right)$. The 10,000 linear correlation coefficients $\mathrm{R}_{\text {corr }}$ are calculated and the distribution of the $\mathrm{R}_{\text {corr }}$ values is plotted as the green curve in Figure A1. The standard deviation of the $R_{\text {corr }}$ values is 0.00891 , which is approximately 3 times the 0.00316 value of $1 / \mathrm{N}_{\text {meas }}^{1 / 2}$ for 100,000 points. This value 0.00819 is on the order of the value $1 /\left(\mathrm{N}_{\text {meas }} / 9\right)^{1 / 2}=0.00949$, where the 9 was the smaller of the two averagings 9 and 36. Having autocorrelation values of about $11 \mathrm{~h}$ for $\Delta \mathrm{T}_{24}$ and about $33 \mathrm{~h}$ for $\left\langle\mathrm{v}_{\mathrm{sw}}\right\rangle_{24}$, this numerical experiment guides us to use the smaller of the two values and thus take $\mathrm{N}_{\text {ind }}=\mathrm{N}_{\text {meas }} / 11$ as an effective value in the $2 / \mathrm{N}_{\text {ind }}^{1 / 2}$ expression.

\section{A3. Effective Number of Measurements}

[104] In the rule of thumb $2 / \mathrm{N}_{\text {ind }}^{1 / 2}$ for discerning whether correlation coefficients are significant (relative to random correlations), thee choices are discussed for the value of $\mathrm{N}_{\text {ind }}$, the number of independent measurements. First, one could take $\mathrm{N}_{\text {ind }}$ to be the actual number of measurements $\mathrm{N}_{\text {meas }}$, but owing to the persistence in the measurements that would be on overestimate of the number of independent measurements $\mathrm{N}_{\text {ind }}$. Second, based on the measurements of persistence in the data sets, one could take $\mathrm{N}_{\text {ind }}=\mathrm{N}_{\text {meas }} / 11$ for the present study using $1 \mathrm{~h}$ data points with $11 \mathrm{~h}$ persistence. This is probably the most accurate estimate of $\mathrm{N}_{\text {ind }}$. Third, to be conservative about estimating the significance of correlation coefficients, one could take for the present study $\mathrm{N}_{\text {ind }}=\mathrm{N}_{\text {meas }} / 36$. The 36 comes from the fact that in each time interval 36-72 $\mathrm{h}$ after storm onset there are $361 \mathrm{~h}$ measurements. Hence $\mathrm{N}_{\text {meas }} / 36$ takes there to be 1 independent measurement per satellite per storm. (Actually, owing to data dropouts, etc. there are on average less then 36 measurements taken per storm.)

[105] Acknowledgments. The authors wish to thank Tom Cayton for providing the density-temperature fits for the SOPA energetic particle data set, Howard Singer for help with the GOES magnetic field data, and Steve Morley for helpful conversations. J.E.B. wishes to thank the Department of Communication Systems at Lancaster University for their hospitality, and M.H.D. wishes to thank the Space Science and Applications Group and LANL for their hospitality. Work at Los Alamos was supported by the NASA Living with a Star TR\&T Program and by the Los Alamos National Laboratory LDRD Program and work at Lancaster was partially supported by STFC grant ST/G002401/1.

[106] Masaki Fujimoto thanks Gordon Wrenn and another reviewer for their assistance in evaluating this paper.

\section{References}

Albert, J. M. (2004), Using quasi-linear diffusion to model acceleration and loss from wave-particle interactions, Space Weather, 2, S09S03, doi:10.1029/2004SW000069.

Baker, D. N., R. L. McPherron, T. E. Cayton, and R. W. Klebesadel (1990), Linear prediction filter analysis of relativistic electron properties at 6.6 $\mathrm{R}_{\mathrm{E}}$, J. Geophys. Res., 95, 15,133, doi:10.1029/JA095iA09p15133.

Bartels, J., and J. Veldkamp (1949), International data on magnetic disturbances, First Quarter, 1949, J. Geophys. Res., 54, 295, doi:10.1029/ JZ054i003p00295.

Bartels, J., N. H. Heck, and H. F. Johnston (1939), The thee-hour-range index measuring geomagnetic activity, Terr. Magn. Atmos. Electr., 44, 411, doi:10.1029/TE044i004p00411.

Belcher, J. W., and L. Davis (1971), Large-amplitude Alfven waves in the interplanetary medium, 2, J. Geophys. Res., 76, 3534, doi:10.1029/ JA076i016p03534.
Belian, R. D. (1999), Personnel involved with the Synchonous Orbit Particle Analyzer (SOPA) and description of the Charged Particle Analyzer (CPA) detectors, Rep. LA-UR-99-2832, Los Alamos Natl. Lab., Los Alamos, N. M. Belian, R. D., G. R. Gisler, T. Cayton, and R. Chistensen (1992), High-Z energetic particles at geosynchronous orbit during the great solar proton event series of October 1989, J. Geophys. Res., 97, 16,897, doi:10.1029/ 92JA01139.

Belian, R. D., T. E. Cayton, R. A. Chistensen, J. C. Ingraham, M. M. Meier, G. D. Reeves, and A. J. Lazarus (1996), Relativistic electrons in the outerzone: Amn 11 year cycle; Their relation to the solar wind, AIP Conf. Proc., $383,13$.

Bevington, P. R., and D. K. Robinson (1992), Data Reduction and Error Analysis for the Physical Sciences, 2nd ed., McGraw-Hill, New York.

Birn, J., S. P. Gary, and M. Hesse (1995), Microscale anisotropy reduction and macroscale dynamics of the magnetotail, J. Geophys. Res., 100, 19,211, doi:10.1029/95JA01401.

Birn, J., M. F. Thomsen, J. E. Borovsky, G. D. Reeves, D. J. McComas, R. D. Belian, and M. Hesse (1998), Substorm electron injections: Geosynchonous observations and test particle simulations, J. Geophys. Res., 103, 9235, doi:10.1029/97JA02635.

Birn, J., M. Hesse, K. Schindler, and S. Zaharia (2009), Role of entropy in magnetotail dynamics, J. Geophys. Res., 114, A00D03, doi:10.1029/ 2008JA014015.

Blake, J. B., R. S. Selesnick, D. N. Baker, and S. Danekal (2001), Studies of relativistic electron injection events in 1997 and 1998, J. Geophys. Res., 106, 19,157, doi:10.1029/2000JA003039.

Borovsky, J. E. (1986), Magnetic pumping by magnetosonic waves in the presence of noncompressive electromagnetic fluctuations, Phys. Fluids, 29, 3245, doi:10.1063/1.865842.

Borovsky, J. E. (2008), The flux tube texture of the solar wind: Strands of the magnetic carpet at $1 \mathrm{AU}, J$. Geophys. Res., 113, A08110, doi:10.1029/2007JA012684.

Borovsky, J. E. (2010), On the variations of the solar-wind magnetic field about the Parker-spiral direction, J. Geophys. Res., 115, A09101, doi:10.1029/2009JA015040.

Borovsky, J. E., and M. H. Denton (2006), The differences between CMEdriven storms and CIR-driven storms, J. Geophys. Res., 111, A07S08, doi:10.1029/2005JA011447.

Borovsky, J. E., and M. H. Denton (2008), A statistical look at plasmaspheric drainage plumes, J. Geophys. Res., 113, A09221, doi:10.1029/ 2007JA012994.

Borovsky, J. E., and M. H. Denton (2009a), Electron loss rates from the outer electron radiation belt caused by the filling of the outer plasmasphere: The calm before the storm, J. Geophys. Res., 114, A11203, doi:10.1029/2009JA014063.

Borovsky, J. E., and M. H. Denton (2009b), Relativistic-electron dropouts and recovery: A superposed epoch study of the magnetosphere and the solar wind, J. Geophys. Res., 114, A02201, doi:10.1029/2008JA013128.

Borovsky, J. E., and M. H. Denton (2010a), The magnetic field at geosynchronous orbit during high-speed stream-driven storms: Connections to the solar wind, the plasma sheet, and the outer electron radiation belt, J. Geophys. Res., 115, A08217, doi:10.1029/2009JA015116.

Borovsky, J. E., and M. H. Denton (2010b), Solar-wind turbulence and shear: A superposed-epoch analysis of corotating interaction regions at 1 AU, J. Geophys. Res., 115, A10101, doi:10.1029/2009JA014966.

Borovsky, J. E., and H. O. Funsten (2003), Role of solar wind turbulence in the coupling of the solar wind to the Earth's magnetosphere, J. Geophys. Res., 108(A6), 1246, doi:10.1029/2002JA009601.

Borovsky, J. E., and J. T. Steinberg (2006), The "calm before the storm" in $\mathrm{CIR} /$ magnetosphere interactions: Occurrence statistics, solar-wind statistics, and magnetospheric preconditioning, J. Geophys. Res., 111, A07S10, doi:10.1029/2005JA011397.

Borovsky, J. E., C. K. Goertz, and G. Joyce (1981), Magnetic pumping of particles in the outer Jovian magnetosphere, J. Geophys. Res., 86, 3481, doi:10.1029/JA086iA05p03481.

Borovsky, J. E., M. F. Thomsen, D. J. McComas, T. E. Cayton, and D. J. Knipp (1998a), Magnetospheric dynamics and mass flow during the November 1993 storm, J. Geophys. Res., 103, 26,373, doi:10.1029/97JA03051.

Borovsky, J. E., M. F. Thomsen, and R. C. Elphic (1998b), The driving of the plasma sheet by the solar wind, J. Geophys. Res., 103, 17,617, doi:10.1029/97JA02986.

Borovsky, J. E., M. F. Thomsen, R. C. Elphic, T. E. Cayton, and D. J. McComas (1998c), The transport of plasma sheet material from the distant tail to geosynchronous orbit, J. Geophys. Res., 103, 20,297, doi:10.1029/97JA03144.

Burin des Rozier, E., X. Li, D. N. Baker, T. A. Fritz, R. Friedel, T. G. Onsager, and I. Dandouras (2009), Energetic plasma sheet electrons and their relationship with the solar wind: A Cluster and Geotail study, J. Geophys. Res., 114, A02220, doi:10.1029/2008JA013696. 
Burlaga, L. F., W. H. Mish, and Y. C. Whang (1990), Coalescence of recurrent streams of different sizes and amplitudes, J. Geophys. Res., 95, 4247, doi:10.1029/JA095iA04p04247.

Burton, M. E., M. Neugebauer, N. U. Crooker, R. von Steiger, and E. J. Smith (1999), Identification of trailing edge solar wind stream interfaces: A comparison of Ulysses plasma and compositional measurements, J. Geophys. Res., 104, 9925.

Cayton, T. E., and R. D. Belian (2007), Numerical modeling of the synchonous orbit particle analyzer, Rep. LA-14335, Los Alamos Natl. Lab. Los Alamos, N. M.

Cayton, T. E., R. D. Belian, S. P. Gary, T. A. Fritz, and D. N. Baker (1989), Energetic electron components at geosynchronous orbit, Geophys. Res. Lett., 16, 147, doi:10.1029/GL016i002p00147.

Cayton, T. E., D. M. Drake, K. M. Spencer, M. Herrin, T. J. Wehner, and R. C. Reedy (1998), Description of the BDD-IIR: Electron and proton sensors on GPS, Rep. LA-UR-98-1162, Los Alamos Natl. Lab., Los Alamos, N. M.

Crooker, N. U., J. Feynman, and J. T. Gosling (1977), On the high correlation between long-term averages of solar wind speed and geomagnetic activity, J. Geophys. Res., 82, 1933.

Crooker, N. U., M. E. Burton, G. L. Siscoe, S. W. Kahler, J. T. Gosling, and E. J. Smith (1996), Solar wind streamer belt structure, J. Geophys. Res., 101, 24,331, doi:10.1029/96JA02412.

Degeling, A. W., and R. Rankin (2008), Resonant drift echoes in electron phase space density produced by dayside Pc5 waves following a geomagnetic storm, J. Geophys. Res., 113, A10220, doi:10.1029/2008JA013254.

Denton, M. H., and J. E. Borovsky (2008), Superposed epoch analysis of high-speed-stream effects at geosynchronous orbit: Hot plasma, cold plasma, and the solar wind, J. Geophys. Res., 113, A07216, doi:10.1029/2007JA012998.

Denton, M. H., and J. E. Borovsky (2009), The superdense plasma sheet in the magnetosphere during high-speed stream-driven storms: Plasma transport timescales, J. Atmos. Sol. Terr. Phys., 71, 1045, doi:10.1016/ j.jastp.2008.04.023

Denton, M. H., J. E. Borovsky, R. M. Skoug, M. F. Thomsen, B. Lavraud, M. G. Henderson, R. L. McPherron, J. C. Zhang, and M. W. Liemohn (2006), Geomagnetic storms driven by ICME- and CIR-dominated solar wind, J. Geophys. Res., 111, A07S07, doi:10.1029/2005JA011436.

Denton, M. H., J. E. Borovsky, R. B. Horne, R. L. McPherron, S. K. Morley, and B. T. Tsurutani (2008), High-speed solar wind streams: A call for key research, Eos Trans. $A G U, 89(7), 62$, doi:10.1029/2008EO070002.

Denton, M. H., J. E. Borovsky, and T. E. Cayton (2010), A temperature and density description of relativistic electrons in the outer radiation belt during geomagnetic storms, J. Geophys. Res., 115, A01208, doi:10.1029/ 2009JA014183.

Desorgher, L., P. Buhler, A. Zehnder, E. Daly, and L. Adams (1998), Outer radiation belt variations during 1995, Adv. Space Res., 22, 83 doi:10.1016/S0273-1177(97)01105-8

Dunham, W. D., S. A. Macintyre, and C. R. Upton (1996), Design and performance of the GOES-8 high resolution magnetometer, Proc. SPIE, 2812,365

Elkington, S. R., M. K. Hudson, and A. A. Chan (1999), Acceleration of relativistic electrons via drift-resonant interaction with toroidal-mode PC-5 ULF oscillations, Geophys. Res. Lett., 26, 3273, doi:10.1029/ 1999GL003659.

Elkington, S. R., M. K. Hudson, and A. A. Chan (2003), Resonant acceleration and diffusion of outer zone electrons in an asymmetric geomagnetic field, J. Geophys. Res., 108(A3), 1116, doi:10.1029/2001JA009202.

Elphic, R. C., M. F. Thomsen, J. E. Borovsky, and D. J. McComas (1999), Inner edge of the electron plasma sheet: Empiracal models of boundary location, J. Geophys. Res., 104, 22,679, doi:10.1029/1999JA900213.

Engebretson, M. J., K. Takahashi, and M. Scholer (Eds.) (1994), Solar Wind Sources of Magnetospheric Ultra-Low-Frequency Waves, AGU, Washington, D. C.

Falthammar, C.-G. (1965), Effects of time-dependent electric fields on geomagnetically trapped radiation, J. Geophys. Res., 70, 2503, doi:10.1029/ JZ070i011p02503

Freeman, J. W. (1964), The morphology of the electron distribution in the outer radiation zone and near the magnetospheric boundary as observed by Explorer 12, J. Geophys. Res., 69, 1691, doi:10.1029/JZ069i009p01691.

Friedel, R. H. W., G. D. Reeves, and T. Obara (2002), Relativistic electron dynamics in the inner magnetosphere-A review, J. Atmos. Sol. Terr. Phys. 64, 265, doi:10.1016/S1364-6826(01)00088-8.

Friedel, R. H. W., S. Bourdarie, and T. E. Cayton (2005), Intercalibration of magnetospheric energetic electron data, Space Weather, 3, S09B04 doi:10.1029/2005SW000153

Fung, S. F., and L. C. Tan (1998), Time correlation of low-altitude relativistic trapped electron fluxes with solar wind speeds, Geophys. Res. Lett., 25, 2361, doi:10.1029/98GL01717.
Goertz, C. K. (1978), Energization of charged particles in Jupiter's outer magnetosphere, J. Geophys. Res., 83, 3145, doi:10.1029/ JA083iA07p03145.

Gosling, J. T., and V. J. Pizzo (1999), Formation and evolution of corotating interaction regions and their thee dimensional structure, Space Sci. Rev., 89, 21, doi:10.1023/A:1005291711900.

Graham, R. (1994), Killer electrons on rise, Albuquerque Journal, p. B8, 15 Aug.

Green, J. C., and M. G. Kivelson (2004), Relativistic electrons in the outer radiation belt: Differentiating between acceleration mechanisms, J. Geophys. Res., 109, A03213, doi:10.1029/2003JA010153.

Green, J. C., T. G. Onsager, T. P. O’Brien, and D. N. Baker (2004), Testing loss mechanisms capable of rapidly depleting relativistic electron flux in the Earth's outer radiation belt, J. Geophys. Res., 109, A12211, doi:10.1029/2004JA010579.

Gussenhoven, M. S., D. A. Hardy, and N. Heinemann (1983), Systematics of the equatorward diffuse auroral boundary, J. Geophys. Res., 88, 5692 , doi:10.1029/JA088iA07p05692.

Hald, A. (1952), Statistical Theory With Engineering Applications, chap. 19.12, John Wiley, New York.

Hones, E. W. (1963), Motions of charged particles trapped in the Earth's magnetosphere, J. Geophys. Res., 68, 1209, doi:10.1029/JZ068i005p01209.

Horne, R. B., R. M. Thorne, S. A. Glauert, J. M. Albert, N. P. Meredith and R. R. Anderson (2005), Timescale for radiation belt electron acceleration by whistler mode chorus waves, J. Geophys. Res., 110, A03225, doi:10.1029/2004JA010811.

Horne, R. B., R. M. Thorne, S. A. Glauert, N. P. Meredith, D. Pokhotelov, and O. Santolik (2007), Electron acceleration in the Van Allen radiation belts by fast magnetosonic waves, Geophys. Res. Lett., 34, L17107, doi:10.1029/2007GL030267.

Hudson, M. K., S. R. Elkington, J. G. Lyon, and C. C. Goodrich (2000), Increase in relativistic electron flux in the inner magnetosphere: ULF wave mode structure, Adv. Space Res., 25, 2327, doi:10.1016/S02731177(99)00518-9.

Hudson, M. K., B. T. Kress, H. R. Mueller, J. A. Zastrow, and J. B. Blake (2008), Relationship of the Van Allen radiation belts to solar wind drivers, J. Atmos. Sol. Terr. Phys., 70, 708, doi:10.1016/j.jastp. 2007.11.003.

Hundhausen, A. J., S. J. Bame, J. R. Asbridge, and S. J. Sydoriak (1970), Solar wind proton properties: Vela 3 observations from July 1965 to June 1967, J. Geophys. Res., 75, 4643, doi:10.1029/JA075i025p04643.

Iles, R. H. A., N. P. Meredith, A. N. Fazakerley, and R. B. Horne (2006), Phase space density analysis of the outer radiation belt energetic electron dynamics, J. Geophys. Res., 111, A03204, doi:10.1029/2005JA011206. Ilie, R., M. W. Liemohn, M. F. Thomsen, J. E. Borovsky, and J. Zhang (2008), Influence of epoch time selection on the results of superposed epoch analysis using ACE and MPA data, J. Geophys. Res., 113, A00A14, doi:10.1029/2008JA013241.

Jeans, J. H. (1954), The Dynamical Theory of Gases, 4th ed., Sects. 242-243, Dover, New York.

Kaye, S. M., C. S. Lin, G. K. Parks, and J. R. Winckler (1978), Adiabatic modulation of equatorial pitch angle anisotropy, J. Geophys. Res., 83, 2675, doi:10.1029/JA083iA06p02675.

Kelley, M. C., B. T. Tsurutani, and F. S. Mozer (1975), Properties of ELF electromagnetic waves in and above the Earth's ionosphere deduced from plasma wave experiments on the OVI-17 and Ogo 6 satellites, J. Geophys. Res., 80, 4603, doi:10.1029/JA080i034p04603.

King, J. H., and N. E. Papitashvili (2005), Solar wind spatial scales in and comparisons of hourly wind and ACE plasma and magnetic field data, J. Geophys. Res., 110, A02104, doi:10.1029/2004JA010649.

Kivelson, M. G., and C. T. Russell (1995), Introduction to Space Physics, Cambridge Univ. Press, Cambridge, U. K

Lam, H.-L. (2004), On the prediction of relativistic electron fluence based on its relationship with geomagnetic activity over a solar cycle, J. Atmos. Sol. Terr. Phys., 66, 1703, doi:10.1016/j.jastp.2004.08.002.

Lazarus, A., J. Dasper, A. Szabo, and K. Ogilvie (2003), Solar wind streams and their interactions, AIP Conf. Proc., 679, 187.

Lezniak, T. W., R. L. Arnoldy, G. K. Parks, and J. R. Winkler (1968), Measurements and intensity of energetic electrons at the equator at $6.6 \mathrm{R}_{\mathrm{E}}$, Radio Sci., 3, 710 .

Liu, W. W., G. Rostoker, and D. N. Baker (1999), Internal acceleration of relativistic electrons by large-amplitude ULF pulsations, J. Geophys. Res., 104, 17,391, doi:10.1029/1999JA900168.

Longden, N., M. H. Denton, and F. Honary (2008), Particle precipitation during ICME-driven and CIR-driven geomagnetic storms, J. Geophys. Res., 113, A06205, doi:10.1029/2007JA012752.

Love, D. L., D. S. Toomb, D. C. Wilkinson, and J. B. Parkinson (2000), Penetrating electron fluctuations associated with GEO spacecraft anomalies, IEEE Trans. Plasma Sci., 28, 2075, doi:10.1109/27.902234. 
Lyatsky, W., and G. V. Khazanov (2008), Effect of solar wind density on relativistic electrons at geosynchronous orbit, Geophys. Res. Lett., 35, L03109, doi:10.1029/2007GL032524.

Maezawa, K., and T. Murayama (1986), Solar wind velocity effects on the auroral zone magnetic disturbances, in Solar Wind-Magnetosphere Coupling, edited by Y. Kamide and J. A. Slavin, p. 59, Terra Sci., Tokyo.

Mann, I. R., T. P. O’Brien, and D. K. Milling (2004), Correlations between ULF wave power, solar wind speed, and relativistic electron flux in the magnetosphere: Solar cycle dependence, J. Atmos. Sol. Terr. Phys., 66 , 187, doi:10.1016/j.jastp.2003.10.002.

Mathie, R. A., and I. R. Mann (2000), A correlation between extended intervals of ULF wave power and storm-time geosynchronous relativistic electron flux enhancements, Geophys. Res. Lett., 27, 3261, doi:10.1029/ 2000GL003822.

McPherron, R. L., and J. Weygand (2006), The solar wind and geomagnetic activity as a function of time relative to corotating interaction regions, in Recurrent Magnetic Storms: Corotating Solar Wind Streams, Geophys. Monogr. Ser., vol. 167, edited by B. Tsurutani et al., p. 125, AGU, Washington, D. C.

McPherron, R. L., C. T. Russell, and P. J. Coleman (1972), Fluctuating magnetic fields in the magnetosphere, Space Sci. Rev., 13, 411, doi:10.1007/BF00219165.

Miyoshi, Y., and R. Kataoka (2005), Ring current ions and radiation belt electrons during geomagnetic storms driven by coronal mass ejections and corotating interaction regions, Geophys. Res. Lett., 32, L21105, doi:10.1029/2005GL024590.

Nagai, T. (1988), "Space weather forecast": Prediction of relativistic electron intensity at synchonous orbit, Geophys. Res. Lett., 15, 425, doi:10.1029/GL015i005p00425.

Neugebauer, M., and C. W. Snyder (1966), Mariner 2 observations of the solar wind: 1. Average properties, J. Geophys. Res., 71, 4469.

Neugebauer, M., P. C. Liewer, B. E. Goldstein, X. Zhou, and J. T. Steinberg (2004), Solar wind stream interaction regions without sector boundaries, J. Geophys. Res., 109, A10102, doi:10.1029/2004JA010456.

Onsager, T. G., G. Rostoker, H.-J. Kim, G. D. Reeves, T. Obara, H. J. Singer, and C. Smithtro (2002), Radiation belt electron flux dropouts: Local time, radial, and particle-energy dependence, J. Geophys. Res. 107(A11), 1382, doi:10.1029/2001JA000187.

Onsager, T. G., J. C. Green, G. D. Reeves, and H. J. Singer (2007), Solar wind and magnetospheric conditions leading to the abrupt loss of outer radiation belt electrons, J. Geophys. Res., 112, A01202, doi:10.1029/ 2006JA011708

Orr, D. (1973), Magnetic pulsations within the magnetosphere: A review, J. Atmos. Terr. Phys., 35, 1, doi:10.1016/0021-9169(73)90214-6.

Osherovich, V. A., J. Fainberg, R. G. Stone, A. Vinas, R. Fitzenreiter, and C. J. Farrugia (1999), MHD of gas with polytropic index below unity and classification of magnetic clouds, AIP Conf. Proc., 471, 717.

Pagel, A. C., N. U. Crooker, T. H. Zurbuchen, and J. T. Gosling (2004), Correlation of solar wind entropy and oxygen ion charge state ratio, J. Geophys. Res., 109, A01113, doi:10.1029/2003JA010010.

Paulikas, G. A., and J. B. Blake (1976), Modulation of trapped energetic electrons at 6.6 Re by the interplanetary magnetic field, Geophys. Res. Lett., 3, 277, doi:10.1029/GL003i005p00277.

Paulikas, G. A., and J. B. Blake (1979), Effects of the solar wind on magnetospheric dynamics: Energetic electrons at the synchonous orbit, in Quantitative Modeling of Magnetospheric Processes, Geophys. Monogr. Ser., vol. 21, edited by W. P. Olson, 180 pp., AGU, Washington, D. C.

Perry, K. L., M. K. Hudson, and S. R. Elkington (2005), Incorporating spectral characteristics of Pc5 waves into thee-dimensional radiation belt modeling and the diffusion of relativistic electrons, J. Geophys. Res., 110, A03215, doi:10.1029/2004JA010760

Pierrard, V., and J. Lemaire (1996), Fitting the AE-8 energy spectra with two Maxwellian functions, Radiat. Meas., 26, 333-337, doi:10.1016/ 1350-4487(96)00057-1.

Richardson, I. G. (2006), The formation of CIRs at stream-stream interfaces and resultant geomagnetic activity, in Recurrent Magnetic Storms: Corotating Solar Wind Streams, Geophys. Monogr. Ser., vol. 167, edited by B. Tsurutani et al., p. 45, AGU, Washington, D. C.

Richardson, J. D., J. W. Belcher, A. J. Lazarus, K. I. Paularina, and P. R. Gazis (1996), Statistical properties of the solar wind, AIP Conf. Proc., $382,483$.

Roederer, J. G. (1970), Dynamics of Geomagnetically Trapped Radiation, Springer, Berlin.

Romanova, N. V., V. A. Plipenko, N. V. Yagova, and A. V. Belov (2005), Statistical correlation of the rate of failures on geosynchronous satellites with fluxes of energetic electrons and protons, Cosmic Res., Engl. Transl., 43, 179, doi:10.1007/s10604-005-0032-6.

Rostoker, G. (1972), Geomagnetic indices, Rev. Geophys., 10, 935, doi:10.1029/RG010i004p00935.
Rostoker, G., S. Skone, and D. N. Baker (1998), On the origin of relativistic electrons in the magnetosphere associate with some geomagnetic storms, Geophys. Res. Lett., 25, 3701, doi:10.1029/98GL02801.

Russell, C. T., and R. L. McPherron (1973), Semiannual variation of geomagnetic activity, J. Geophys. Res., 78, 92, doi:10.1029/JA078i001p00092.

Saito, T. (1969), Geomagnetic pulsations, Space Sci. Rev., 10, 319, doi:10.1007/BF00203620.

Selesnick, R. S., and J. B. Blake (2002), Relativistic electron drift shell splitting, J. Geophys. Res., 107(A9), 1265, doi:10.1029/2001JA009179.

Shprits, Y. Y., and R. M. Thorne (2004), Time dependent radial diffusion modeling of relativistic electrons with realistic loss rates, Geophys. Res. Lett., 31, L08805, doi:10.1029/2004GL019591.

Shprits, Y. Y., S. R. Elkington, N. P. Meredith, and D. A. Subbotin (2008a), Review of modeling of losses and sources of relativistic electrons in the outer radiation belt I: Radial transport, J. Atmos. Sol. Terr. Phys., 70, 1679, doi:10.1016/j.jastp.2008.06.008.

Shprits, Y. Y., D. A. Subbotin, N. P. Meredith, and S. R. Elkington (2008b), Review of modeling of losses and sources of relativistic electrons in the outer radiation belt II: Local acceleration and losses, J. Atmos. Sol. Terr. Phys., 70, 1694

Sibeck, D. G., et al. (1989), The magnetospheric response to 8-min-period strong-amplitude upstream pressure variations, J. Geophys. Res., 94, 2505, doi:10.1029/JA094iA03p02505.

Singer, H. J., L. Matheson, R. Grubb, A. Newman, and S. D. Bouwer (1996), Monitoring space weather with the GOES magnetometers, Proc. SPIE, 2812, 299.

Smith, E. J., A. M. A. Frandsen, B. T. Tsurutani, R. M. Thorne, and K. W. Chan (1974), Plasmaspheric hiss intensity variations during magnetic storms, J. Geophys. Res., 79, 2507, doi:10.1029/JA079i016p02507.

Snyder, C., M. Neugebauer, and U. R. Rao (1963), The solar wind velocity and its correlation with cosmic-ray variations and with solar and geomagnetic activity, J. Geophys. Res., 68, 6361.

Summers, D., and C. Y. Ma (2000), A model for generating relativistic electrons in the Earth's inner magnetosphere based on gyroresonan wave-particle interactions, J. Geophys. Res., 105, 2625, doi:10.1029/ 1999JA900444.

Summers, D., C. Ma, and T. Mukai (2004), Competition between acceleration and loss mechanisms of relativistic electrons during geomagnetic storms, J. Geophys. Res., 109, A04221, doi:10.1029/ 2004JA010437.

Tao, X., J. M. Albert, and A. A. Chan (2009), Numerical modeling of multidimensional diffusion in the radiation belts using layer methods, J. Geophys. Res., 114, A02215, doi:10.1029/2008JA013826.

Thomsen, M. F. (2004), Why Kp is such a good measure of magnetospheric convection, Space Weather, 2, S11004, doi:10.1029/2004SW000089.

Tsurutani, B. T., W. D. Gonzalez, Y. Kamide, C. M. Ho, G. S. Lakhina, J. K. Arballo, R. M. Thorne, J. S. Pickett, and R. A. Howard (1999), The interplanetary causes of magnetic storms, HILDCAAs and viscous interaction, Phys. Chem. Earth, Part C, 24, 93.

Tsurutani, B. T., et al. (2006a), Corotating solar wind streams and recurrent geomagnetic activity: A review, J. Geophys. Res., 111, A07S01, doi:10.1029/2005JA011273.

Tsurutani, B., R. McPherron, W. Gonzalez, G. Lu, J. H. A. Sobral, and N. Gopalswamy (Eds.) (2006b), Recurrent Magnetic Storms: Corotating Solar Wind Streams, Geophys. Monogr. Ser., vol. 167, AGU, Washington, D. C.

Tsyganenko, N. A. (1989), A magnetospheric magnetic field model with a warped tail current sheet, Planet. Space Sci., 37, 5, doi:10.1016/00320633(89)90066-4

Tsyganenko, N. A., H. J. Singer, and J. C. Kasper (2003), Storm-time distortion of the inner magnetosphere: How severe can it get?, J. Geophys. Res., 108(A5), 1209, doi:10.1029/2002JA009808.

Varotsou, A., R. H. Friedel, G. D. Reeves, B. Lavraud, R. M. Skoug, T. E. Cayton, and S. Boiurdarie (2008), Characterization of relativistic electron flux rise times during the recovery phase of geomagnetic storms as measured by the NA41 GPS satellite, J. Atmos. Sol. Terr. Phys., 70, 1745, doi:10.1016/j.jastp.2008.01.020.

Vassiliadis, D., A. J. Klimas, S. G. Kanekal, D. N. Baker, and R. S. Weigel (2002), Long-term-average, solar cycle, and seasonal response of magnetospheric energetic electrons to the solar wind speed, J. Geophys. Res., 107(A11), 1383, doi:10.1029/2001JA000506.

West, H. I., R. M. Buck, and J. R. Walton (1973), Electron pitch angle distributions thoughout the magntosphere as observed on Ogo 5, J. Geophys. Res., 78, 1064, doi:10.1029/JA078i007p01064.

Wrenn, G. L. (2009), Chonology of "killer" electron: Solar cycles 22 and 23, J. Atmos. Sol. Terr. Phys., 71, 1210, doi:10.1016/j.jastp.2008.08.002. Wrenn, G. L., D. J. Rodgers, and K. A. Ryden (2002), A solar cycle of spacecraft anomalies due to internal charging, Ann. Geophys., 20, 953, doi:10.5194/angeo-20-953-2002. 
Yermolaev, Y. I., M. Y. Yermolaev, I. G. Lodkina, and N. S. Nikolaeva (2007), Statistical investigation of heliospheric conditions resulting in magnetic storms, Cosmic Res., Engl. Transl., 45, 1, doi:10.1134/ S0010952507010017.

Zhang, J. C., M. W. Liemohn, J. U. Kozyra, M. F. Thomsen, H. A. Elliott, and J. M. Weygand (2006), A statistical comparison of solar wind sources of moderate and intense geomagnetic storms at solar minimum and maximum, J. Geophys. Res., 111, A01104, doi:10.1029/ 2005JA011065.

J. E. Borovsky, Space Science and Applications, Los Alamos National Laboratory, Mail Stop D466, Los Alamos, NM 87545, USA.

M. H. Denton, Physics Department, Lancaster University, Bailrigg, Lancaster, LA1 4YW, UK 